University of Redlands

\title{
Modeling Sea Level Rise and Assessment of Coastal Wetland Loss
}

A Major Individual Project submitted in partial satisfaction of the requirements for the degree of Master of Science in Geographic Information Systems

by

AiLam Truong

Mark Kumler, Ph.D., Committee Chair

Ruijin Ma, Ph.D.

August 2010 
Modeling Sea Level Rise and Assessment of Coastal Wetland Loss

Copyright $@ 2010$

by

AiLam Truong 
The report of AiLam Truong is approved.

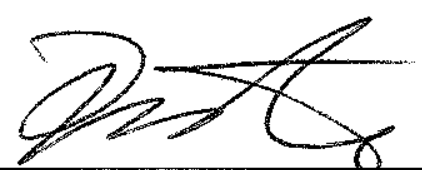

Ruijin Ma, Ph.D.

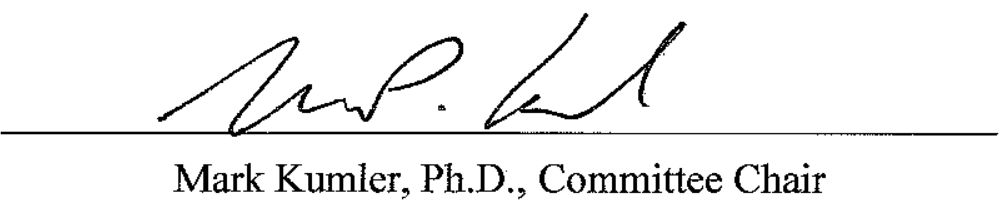

August 2010 



\section{Acknowledgements}

I am lucky to have so many people to support me throughout this year. Special thanks go to Joe, his family, my parents, and my son for their tremendous support.

Dr. Mark Kumler, thank you for your great attention to detail and guidance throughout this project. I would also like to thank Dr. Douglas Flewelling for taking the time out of his busy schedule to help push me through my challenges. Thanks Dr. Ruijin Ma for his interest in my project and his expertise in raster datasets.

I would like to thank my client, Tony McKinney for his patience and support. Special thanks to Delissa Padilla from the Virginia Fish and Wildlife Office. Without her support, I would not be able to complete my project.

I would like to thank Debra Riley, Program Coordinator, for being the godmother of the GIS program. She is always there for me when I needed a hug or words of encouragement. Thanks Ruben Ortiz for your excellent IT support.

Much appreciation goes to Jonathan Peer and Alexis Sites, my fellow cohort members for their mental support. Special thanks go to Jon for improving my writing. 



\author{
Abstract \\ Modeling Sea Level Rise and Assessment of Coastal Wetland Loss \\ by \\ AiLam Truong
}

Global sea level increases will impact the Southern California coastlines over the next one hundred years. The California Coastal Commission is concerned with potential threats to coastal wetlands, habitats, and marine species. The Carlsbad Fish and Wildlife Office (CFWO) of the U.S. Fish and Wildlife Service needed a GIS solution to be used with the Sea Level Affected Marshes Modeling (SLAMM) application to predict the potential effects of sea level rise. SLAMM is a simulation process that predicts wetland conversions and shoreline modification during long-term sea level rise. Three tools were developed using ArcGIS software to enable users to conduct risk analyses of coastlines by identifying vulnerable wetland areas, and to produce outputs that can be used for analysis. This tool will enable the CFWO to conduct accurate analyses to aid decision makers to put forward policies that preserve existing coastlines, habitats and species. 



\section{Table of Contents}

Chapter 1 - Introduction $\quad 1$

1.1 Client 1

1.2 Problem Statement 1

1.3 Proposed Solution 2

1.3.1 Goals and Objectives 2

1.3.2 Scope 2

1.3.3 Methods 2

1.4 Audience 3

1.5 Overview of the Rest of this Report 3

Chapter 2 - Background and Literature Review 5

2.1 Sea Level Rise $\quad 5$

2.2 GIS Technology and Coastal Zone Management 5

2.3 SLAMM and Modeling Sea Level Rise 7

2.3.1 Other Methods $\quad 7$

$\begin{array}{lll}2.4 & \text { Summary } & 8\end{array}$

Chapter 3 - $\quad$ Systems Analysis and Design 9

3.1 Problem Statement 9

3.2 Requirements Analysis 9

3.2.1 Functional Requirements 9

3.2.2 Non-Functional Requirements 10

$\begin{array}{lll}3.3 & \text { System Design } & 12\end{array}$

$\begin{array}{lll}3.4 & \text { Project Plan } & 13\end{array}$

Phase 1: Identify Problem and Requirement Analysis 14

Phase 2: Data Download and Data Exploration $\quad 14$

Phase 3: Development of Geodatabase $\quad 15$

Phase 4: Development of Model $\quad 15$

Phase 5: Project Implementation and Documentation 16

$\begin{array}{lll}3.5 & \text { Summary } & 16\end{array}$

Chapter 4 - Geodatabase $\quad 19$

4.1 Conceptual Data Model 19

4.2 Logical Data Model $\quad 22$

4.3 Data Sources $\quad 23$

4.4 Data Acquisition $\quad 24$

4.4.1 LiDAR to Bare-Earth DEM 24

4.4.2 NED 25

4.4.3 Extent of the Study Area 25

4.4.4 NWI 26

4.4.5 SLAMM Code $\quad 27$

$\begin{array}{lll}4.5 & \text { Summary } & 29\end{array}$

Chapter 5 - Implementation $\quad 31$

5.1 DEM and Slope Model 31

$\begin{array}{lll}5.1 .1 & \text { DEM } & 31\end{array}$

5.1.2 Slope 32

$\begin{array}{lll}5.2 & \text { NWI Model } & 32\end{array}$ 
5.2.1 Part One of NWI Model 33

$\begin{array}{ll}5.2 .2 & \text { Classify Polygon } \\ 5.2 .3 & 34\end{array}$

5.2.3 Dike ASCII 36

5.2.4 Further SLAMM Code Classification 37

5.2.5 SLAMM Application 43

5.2.6 File Setup 43

5.2.7 Parameter Setup $\quad 44$

5.2.8 Execution Setup $\quad 47$

5.3 SLAMM Exchange Format to Feature Class Model 50

5.4 Summary 50

Chapter 6 - $\quad$ Results and Analysis $\quad 51$

$\begin{array}{lll}\text { 6.1 GIS Tools } & 51\end{array}$

6.2 Los Peñasquitos Lagoon $\quad 54$

6.3 Tijuana Estuary

$\begin{array}{lll}6.4 & \text { Discussion } & 60\end{array}$

6.5 Challenges $\quad 61$

$\begin{array}{lll}6.6 & \text { Summary } & 62\end{array}$

$\begin{array}{lll}\text { Chapter } 7 \text { - Conclusions and Future Work } & 63\end{array}$

$\begin{array}{ll}\text { Works Cited } & 65\end{array}$

$\begin{array}{lll}\text { Appendix A. } & \text { SLAMM Results for Los Peñasquitos } & 67\end{array}$

$\begin{array}{lll}\text { Appendix B. SLAMM Results for Tijuana Estuary } & 77\end{array}$

$\begin{array}{lll}\text { Appendix C. } & \text { User Guide } & 87\end{array}$ 


\section{Table of Figures}

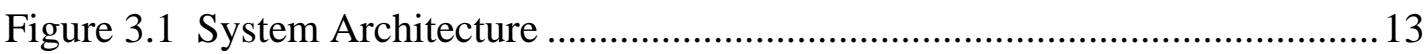

Figure 3.2 Original Project Plan ............................................................................14

Figure 3.3 Original Plan: Modeling Sea Level System .............................................16

Figure 4.1 Sea Coastline Habitat Model ...............................................................19

Figure 4.2 Coastline and Land Type Model ..........................................................22

Figure 4.3 Coastline and Habitat Model ...............................................................21

Figure 4.4 System Model..............................................................................22

Figure 4.5 Logical Model ..................................................................................2

Figure 4.6 Bare-Earth Extraction Tool ................................................................2

Figure 4.7 Using NED to Fill In Gaps ...............................................................25

Figure 4.8 Extent of the Study Area ………………………...............................2.

Figure 4.9 NWI Quadrants............................................................................2

Figure 4.10 NWI Dataset Classification System ……………………………........2

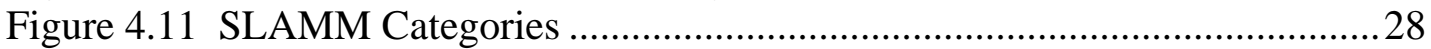

Figure 4.12 Example of NWI Classified to SLAMM Code ....................................28

Figure 5.1 DEM and Slope Model.......................................................................31

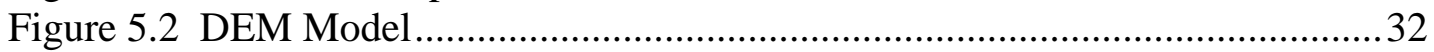

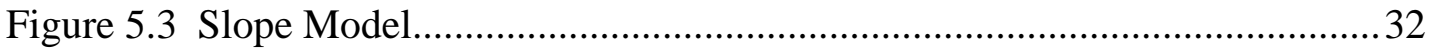

Figure 5.4 NWI Model........................................................................................

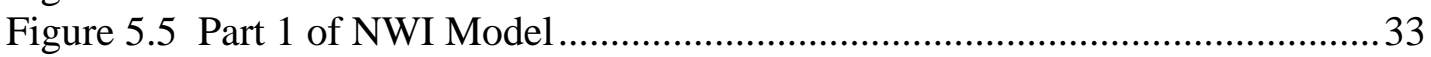

Figure 5.6 Merging NWI Quadrants............................................................................ 34

Figure 5.7 Joining NWI Attribute Table to SLAMM Code Table ..............................34

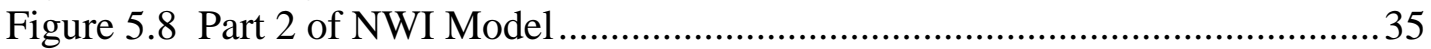

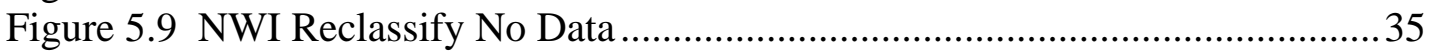

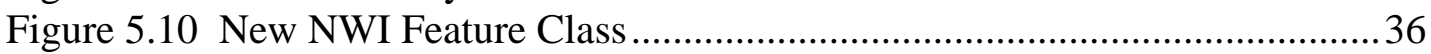

Figure 5.11 Reclassified Polygon to SLAMM Code 1 (Developed Dry Land).........37

Figure 5.12 Further SLAMM Code Classification …………………………..............37

Figure 5.13 SLAMM Code Misclassification......................................................38

Figure 5.14 Corrected Classification …………………….......................................39

Figure 5.15 Misclassification of Developed Dry Land................................................40

Figure 5.16 One Polygon Reclassified as Ocean Beach .............................................4 41

Figure 5.17 Two Polygons Reclassified as Regularly Flooded Marsh.......................42

Figure 5.18 Set Extent in Environment Settings.........................................................43

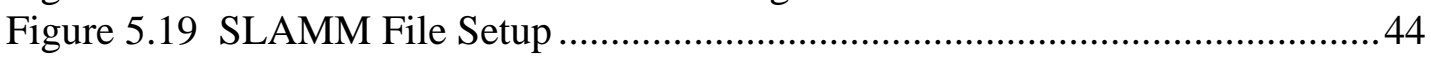

Figure 5.20 SLAMM Parameter Setup for Sites and Subsites.....................................45

Figure 5.21 NOAA Tidal and Currents Report for La Jolla, CA Station ...................46

Figure 5.22 NOAA Tidal and Currents Report for Imperial Beach, CA Station.......47

Figure 5.23 SLAMM Execution Setup …………………………………………....4 48

Figure 5.24 SLAMM Exchange Format to ArcMap Raster ........................................50

Figure 6.1 Inaccurate vs. Accurate NWI Classifications ...............................................53

Figure 6.2 2-Meter Rise Accuracy Comparison ......................................................53

Figure 6.3 Los Peñasquitos Regularly Flooded Marsh for all SLR scenarios ...........55

Figure 6.4 Los Peñasquitos Tidal Flat for all SLR scenarios .....................................55 
Figure 6.5 Los Peñasquitos Initial Condition................................................... 56

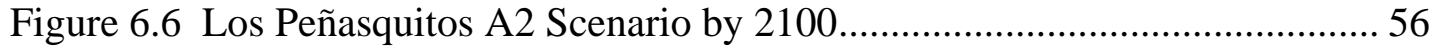

Figure 6.7 Los Peñasquitos 2-Meter Rise Scenario by 2100 ................................. 57

Figure 6.8 Tijuana Estuary Initial Condition........................................................ 58

Figure 6.9 Tijuana Estuary A2 Scenario by 2100 ................................................ 59

Figure 6.10 Tijuana Estuary 2-Meter Rise Scenario by 2100 ............................... 60 


\section{List of Tables}

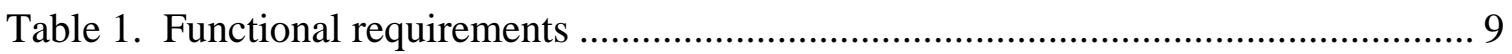

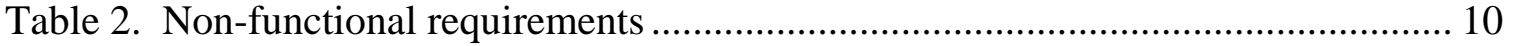

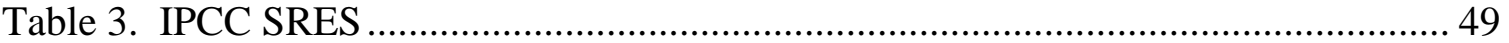

Table 4. SLAMM CSV Output Viewed in Excel ........................................................ 52

Table 5. Los Peñasquitos Lagoon Predictions of Acreage Loss/Gain by 2100 ............... 54

Table 6. Tijuana Estuary Predictions of Acreage Loss/Gain by 2100 ........................... 57

Table 7. SLAMM Inputs Based on IPCC, 2001 (Eustatic Sea Level Rise in meters)..... 61 



\section{Chapter 1 - Introduction}

The California coastline changes constantly for many reasons. Today, global sea level rise due to climate change is one of the main factors affecting California's coastline. Some of the factors contributing to sea level change include tectonic land movements, thermal expansion, and melting of the Greenland and Antarctic ice sheets (Church, 2007).

According to the Intergovernmental Panel on Climate Change (IPCC), the global sea level has risen at an average rate of $1.8 \mathrm{~mm}$ each year from 1961 to 2003 (Watson, 2002). By 2100, sea level rise will reach $90 \mathrm{~mm}$ to $880 \mathrm{~mm}$ (Watson, 2002). At this pace, many coastal wetlands are at risk for permanent loss (Watson, 2002 and Pugh, 2004). When looking at sea level rise at a regional level, the California coastlines have risen nearly eight inches in the past century, and the rise is expected to reach 1.4 meters by 2100 (Heberger, 2009). At this rate, sea level rise will alter the California coastlines by accelerating erosion and causing beaches and emergent wetlands to move inland. A method to predict the effects of sea level rise on coastal wetlands is necessary because it will help decision makers put forward policies that preserve existing coastlines, habitats, and species.

The purpose of this project was to use GIS to design a model that would process data that can be used with the Sea Level Affected Marshes Model version 6 (SLAMM6). SLAMM is an application used to model sea level rise. The goal is to produce data from the SLAMM6 model to create maps for risk analyses. There are two main objectives for this analysis: to identify low-lying areas with highest risk, and to identify potential loss of coastal wetlands. This project was intended to help the Carlsbad Fish and Wildlife Office (CFWO) of the U.S. Fish and Wildlife Service identify vulnerable coastal areas so coastal managers can better prepare for changes in coastal ecosystems caused by sea level rise.

\subsection{Client}

The client for this project was Tony McKinney, Branch Chief and GIS Coordinator of the CFWO, and he was the point of contact for the project. The CFWO needed a GIS solution that could be used to predict potential movement of wetlands and the impact on habitats and species for the south San Diego coastline. The client wished to use SLAMM6 to assess the effects of sea level rise for two main study areas in San Diego County: Los Peñasquitos Lagoon and Tijuana Estuary. For this project, the client provided LiDAR data, aerial photo imagery, and a National Wetland Index (NWI) dataset. In addition, the client provided technical support for the SLAMM6 application.

\subsection{Problem Statement}

As global sea level increases due to global climate change, the Southern California coastal wetlands are vulnerable to inundation. The CFWO was concerned with the potential threat to coastal wetlands - an area that provides important habitats for many upland and marine species. Since the impact is not fully understood, it is important to help decision makers put forward policies to preserve and protect existing coastlines, 
habitats, and species. A GIS tool is needed to efficiently prepare data for input to the SLAMM application, and to analyze the SLAMM output.

\subsection{Proposed Solution}

The proposed solution was to develop a geoprocessing model using ESRI ArcGIS ModelBuilder to automate the data conversion process that produces ASCII files to use in the SLAMM6 application. The model needed to convert DEM, NWI, and Slope data to ASCII format. Simplifying the data conversion process would eliminate errors and allow the SLAMM6 model to execute successfully. This model would also help GIS users produce accurate data and maps.

\subsubsection{Goals and Objectives}

The goal of this project was to help the CFWO conduct risk analyses of coastlines caused by sea level rise. The project objective for the solution was to reduce the time spent on data conversion, allowing the CFWO to focus on using the SLAMM6 application to model sea level rise. The specific objectives were:

- Identify low-lying areas with highest risk

- Examine potential loss of coastal wetlands

By meeting the project goal and objectives, the CFWO would be able to conduct accurate analyses to help decision makers protect or preserve coastal wetlands.

\subsubsection{Scope}

The purpose of this project was to conduct risk analyses for the San Diego coastal wetlands. The project focused on three study sites in this area: Los Peñasquitos Lagoon, San Dieguito Lagoon, and Tijuana Estuary. The specific scope of this project included developing a GIS model to use for data conversion, modeling sea level rise in SLAMM6, providing maps, presenting at the CFWO, and providing complete documentation.

\subsubsection{Methods}

Significant time was invested in learning the SLAMM6 application to understand the data needed to run the model, how to obtain those data, and the steps and techniques to prepare the data. Data used in this project included: the 2009 NWI dataset, 2010 SLAMM6 code, 2005 LiDAR data, and the 3-meter 1999 National Elevation Dataset (NED). All data were re-projected to North American Datum 1983 (NAD83) Universal Transverse Mercator Zone 11 North (UTM Zone 11). All raster data were re-sampled to 5-meter resolution.

Hardware and software used in this project included: ESRI ArcMap 9.3.1, ArcGIS Desktop 9.3.1, the LiDAR Analyst extension for ArcGIS 4.2.0.11, ModelBuilder 9.2, and SLAMM6. GIS was used throughout the project to build the geoprocessing model, manipulate data, and create maps. SLAMM6 was used to model sea level rise and produce data for final maps.

A geoprocessing model was built using ESRI ArcGIS ModelBuilder to convert DEM (derived from LiDAR), NWI, and slope data to ASCII formatted files. The model 
begins by clipping the DEM to the extent of the study area (including a buffer zone of one-half mile). Next, the bare-earth DEM is merged with the NED dataset data to fill in gaps where LiDAR data were not available, and then re-sampled to 5-meter resolution. The model then creates a slope raster from the DEM, and converts both DEM and slope rasters to ASCII format. Finally, the model processes NWI data by joining the attribute table to SLAMM code, clips the data to the extent, reclassifies developed and undeveloped dry land, converts the feature class to raster, and converts the NWI raster to ASCII format.

The three ASCII files produced from the geoprocessing model were used in SLAMM6 to model sea level rise. Four different IPCC Special Reports on Emissions Scenarios (SRES) and one-fixed scenario were used to simulate sea level rise: A1B, A1FI, A2, B1, and 2-meter rise. The four IPCC scenarios were simulated at the estimated mean and max eustatic sea level rise. Data produced from the SLAMM6 model were used to create maps for impact analysis.

\subsection{Audience}

The paper discusses how GIS was used with SLAMM6 for ecological and sea level modeling. It was intended for professionals interested in using GIS and SLAMM6 to manage coastlines. The audience may include GIS users, non-GIS users, and professionals in coastal and wildlife management. This report can also be useful to coastal zone managers interested in analyzing potential threats to coastlines and wildlife habitats caused by sea level rise.

\subsection{Overview of the Rest of this Report}

This report is divided into three main categories, including project background, overall approach of the project, and the outcome of the project. The first category consists of Chapters 1 and 2. Chapter 1 introduces the project by identifying the problem, proposed solution, goal and objectives, scope of the project, the techniques used to implement this project, the target audience, and a brief outline of the report. Chapter 2 discusses work that was conducted by other researchers or professionals highlighting GIS technology, coastal zone management, and utilizing SLAMM6 to model sea level rise.

The second category consists of Chapters 3,4 , and 5 , which contain the overall approach to the project. Chapter 3 identifies the problem statement, describes the requirements analysis, system design, project plan, and provides a summary of the overall system analysis and design of the project. Chapter 4 provides the structure of the database design that includes a conceptual and logical data model, and sources of the data and methods for obtaining the data. Chapter 5 explains specific processes and steps used for implementing this project.

The final category consists of Chapters 6 and 7. Chapter 6 discusses the results and findings of the analysis of the project. Chapter 7 summarizes the overall project by describing the project accomplishments, the results of the analyses, and potential future work. 


\section{Chapter 2 - Background and Literature Review}

Sea level rise is a global issue that will have different levels of impact on coastal wetlands depending on the elevation and habitats of each region. In order to assess the issue on San Diego coastal wetlands, it is important to understand the causes of sea level rise, previous work in GIS and coastal zone management, and how SLAMM was applied to simulate wetland conversions and shoreline modifications.

\subsection{Sea Level Rise}

According to the Intergovernmental Panel on Climate Change (IPCC), the global sea level has risen at an average rate of $1.8 \mathrm{~mm}$ each year from 1961 to 2003 (Watson, 2002). By year 2100, sea level rise will reach $90 \mathrm{~mm}$ to $880 \mathrm{~mm}$ (Watson, 2002). Some of the factors contributing to sea level change include tectonic land movements, thermal expansion, and melting of the Greenland and Antarctic ice sheets (Church et al., 2007). There are two types of tectonic land movement: rapid and slow. Earthquakes are rapid movements, whereas mantle convection and sediment transport are slow movements. Thermal expansion is the effect of ocean water reaching warmer temperatures. Much depends on the rate at which heat moves from the ocean surface layers into the ocean interior. If heat is taken up more readily, climate change will cause sea levels to increase more rapidly (Church et al., 2007). Climate change is also another driving force behind the melting ice sheets. Four studies have shown that the Greenland ice sheet is the most vulnerable to climatic warming. As a result, the melting may contribute about 3 meters of sea level rise (Church et al., 2007).

When looking at sea level rise at a regional level, California coastlines have risen nearly 0.2 meter in the past century and the rise is expected to reach 1.4 meters by 2100 (Herberger, Cooley, Herrera, Gleick, \& Moore, 2009). At this rate, sea level rise will alter the California coastlines by accelerating erosion and causing beaches and emergent wetlands to push back inland. A coastal wetland is an area that provides important habitats for many upland and marine species. The consequences of sea level rise affect coastal wetlands by causing significant reductions in the area and distribution of salt, brackish, and tidal freshwater marshes (Craft et al., 2009). Although wetlands have the ability to adapt to sea level rise through an accretion process, at the predicted rate of sea level rise the soil may not have enough time to adapt. In addition, more than $90 \%$ of California's original wetlands have already been lost to economic development (U.S. FWS, 1999). As a result, wetlands surrounded by developments are likely to be damaged or lost because there is not enough room for movement.

\subsection{GIS Technology and Coastal Zone Management}

Geographic information system (GIS) is a technology that captures, manages, analyzes, and displays data in ways that reveal information that can answer questions and solve problems involving spatial content. In the past decade, GIS has become a powerful assessment tool for efforts in coastal zone management because of improved computing 
speed and large storage capacity. The improvements in technologies have a significant impact on the way spatial data are acquired, stored, managed, and displayed.

Coastal Zone Management is a broad discipline that is responsible for a wide range of issues including:

- Coastal development

- Water quality

- Shoreline erosion

- Public access

- Natural resource protection

- Energy facility siting

- Coastal hazards such as hurricanes and flooding (NOAA, 2010a)

In order to manage these coastal issues effectively, planners need to understand the correlation between the natural environment and human activities to form a system. This system must be able to store biological, physical, socio-economic, and legal data (Nwilo, 2001). According to Pan (2001, p.37), some of the benefits of using GIS technology for coastal zone management include:

- Providing a stable platform for the integration of disparate data from different sources

- Allowing a large quantity of data to be stored and processed

- Providing a seamless geographic database overcoming the restrictions of traditional map and chart boundaries

- Providing facilities for sophisticated analysis and cross-examination of the data

- Providing advanced facilities for the display and visualization of data to a wider audience

Many studies have used GIS technology to enhance decision-making in coastal zone management. For example, Green and King et al. used GIS for estuary management (2001). According to NOAA, an "estuary is a semi-enclosed body of water which has a free connection to the open sea and within which seawater is measurably diluted by fresh water derived from land drainage” (2010b, p. 1). This coastal feature is a fragile environment that can be easily affected by human activities such as development, industry, or tourism. To manage this complex environment, Green and King developed an environmental database, comprising a number of raster and vector datasets and the selection of suitable environmental datasets according to certain criteria (2001). They used GIS buffer analysis to identify the location of artificial reefs. They also used GIS overlay analysis to create a composite in which only those areas that fulfill all the siting criteria would be displayed. Their purpose was to use GIS to collect, store, analyze, and display spatial data and information to aid in estuary management (Green \& King, 2001.

Recently, the use of Light Detection and Ranging (LiDAR) data has become more popular in the GIS environment, especially in coastal zone management. LiDAR is a modern airborne remote sensing technique for surveying topography (Pan, Paul S.Y., 2001). Most coastlines are diverse and consist of bays, inlets, estuaries, beaches, rockyshores, high cliffs, sand dunes, near-shore sand banks, and mud flats. Capturing data can be challenging and expensive. Since the late 1990s, LiDAR has provided a high-value and cost-effective solution (Pan, Paul S.Y., 2001). This technology has the ability to 
capture detailed topographical data, especially for coastal zones. LiDAR data provides accurate horizontal resolution, which "may also improve feature recognition for roads or dikes that can have considerable influence over catchment delineation and the spread of flooding” (Poulter \& Halpin, 2007, p. 168).

\subsection{SLAMM and Modeling Sea Level Rise}

The Sea Level Affected Marshes Model (SLAMM) "simulates the dominant processes involved in wetland conversions and shoreline modification during long-term SLR" (Clough, 2010, p. 2). SLAMM is widely used to process the effect of wetlands under different scenarios of sea level rise including inundation, erosion, overwash, saturation, accretion, and salinity (Clough, 2010). For example, Galbraith et al. used SLAMM to predict the percentage of intertidal habitat loss (2005). They also used SLAMM to alter the habitat environment to fit inundated conditions. The variables used for their study included: elevation, habitat type, slope, sedimentation and accretion, and erosion rates. Their results, indicate that more than $50 \%$ of the current tidal flats in the study area will be lost by 2100 (Galbraith et al., 2005). In addition, up to 70\% of its intertidal feeding habitat will disappear at the current rate of sea level rise, which coincides with their prediction (Galbraith et al., 2005).

Craft et al. (2009) used SLAMM and GIS to explore the Georgia coastline for potential effects of accelerated sea level rise on tidal marsh areas and ecosystem services. SLAMM version 5 was used to model saltwater intrusion in river-dominated estuaries of the study area. Model simulations were based on the IPCC Special Reports on Emissions Scenarios (SRES) A1B mean $(39 \mathrm{~cm})$ and maximum $(69 \mathrm{~cm})$ increase in sea level rise over the next 100 years with an increment of 25 years (Craft, 2009). The SRES A1 scenario assumes rapid economic growth, low population growth, and rapid introduction of new and more efficient technology (Topfer, 2000). The A1B scenario is balanced across all sources. The simulation model predicts that the tidal marsh area and delivery of ecosystem services along the Georgia coast will experience a minimum increase of $52 \mathrm{~cm}$ and a maximum of $82 \mathrm{~cm}$ of sea level rise by 2100 (Craft et al., 2009). The results show sea level rise will cause tidal flat erosion and result in habitat loss.

Craft et al. (2009) also suggest that SLAMM has certain limitations with sea level rise simulations, especially with the data inputs used in the SLAMM5 sea level rise simulations. For example, the resolutions of the NED elevation data that can be downloaded are typically moderate. To model sea level rise, higher resolution elevation data is needed for more accurate results. Additionally, Craft et al. (2009) found that SLAMM does not have a feedback mechanism, which plays an important role as sea level rise accelerates. Despite the limitations, Craft et al. (2009) found this method very useful when predicting the movement of tidal marshes.

\subsubsection{Other Methods}

There are several methods used for modeling inundation. For example, Poulter \& Halpin (2007) used a digital elevation model (DEM) derived from LiDAR data to predict sea level rise. For inundation modeling, a raster-based flood modeling approach was used with 6-meter and 15-meter resolution LiDAR DEMs. The surface flow connections are based on several calculated factors, including LiDAR elevation at location $\mathrm{x}$ and $\mathrm{y}$, the 
projected sea level, and codes of (1) for flooded or (0) for not flooded. This study showed that the high-resolution DEMs derived from LiDAR provided benefits by allowing for the evaluation of multiple sea level scenarios. Poulter \& Halpin (2007) found that rasterbased flood modeling approach help minimize errors resulting from absent fine-scale features. Furthermore, the raster-based algorithm approach is more appropriate when using data that contains roads, dikes, and ditches. This study was more focused on the assessment of higher resolution DEMs and the different approaches that can be used in modeling sea level rise.

\subsection{Summary}

The impact of sea level rise is a global issue that requires immediate attention. The predicted worldwide sea level rise of .88 meter by 2100 will significantly affect global coastlines. This will accelerate erosion, causing beaches and emergent wetlands to push further inland. Sea level rise will affect the southern California coastal wetlands significantly because more than $90 \%$ of the original wetlands have already been lost to economic development. At the predicted regional sea level rise of 1.4 meter by 2100 , most of the southern California coastal wetlands will be damaged or lost.

In order to address this issue, a GIS tool is required to process data. In the past decade, GIS has become a powerful assessment tool for coastal zone management. It has the ability to store, manage, and display complex spatial data. GIS is also capable of handling raster data. Many studies have shown that GIS is very effective in modeling hydraulic features. Additionally, recent LiDAR technologies have allowed coastal managers to make accurate assessments because of the high-resolution elevation data that can be derived from LiDAR data, especially when measuring the impact on sea level rise.

To model sea level rise, many studies have used the SLAMM application, GIS, and other algorithms to predict the potential effects on coastal wetlands. With the required data, the model can simulate all six processes including inundation, erosion, overwash, saturation, accretion, and salinity. All of these components are important to modeling sea level rise. 


\section{Chapter 3 - Systems Analysis and Design}

A successful GIS project involves understanding the needs of the client, the user, and the scope of the project to develop an effective plan for GIS implementation. This chapter first revisits the problem that this project is trying to address. Next, it discusses three major components, including the requirements analysis, system overview, and the development of the project plan. The requirements analysis describes the functional and non-functional requirements for the proposed GIS solution. The overview of the system design discusses the hardware and software required for this project. Finally, the project plan captures the process to manage the tasks for this project.

\subsection{Problem Statement}

As global sea level increases due to global climate change, the Southern California coastal wetlands are vulnerable to inundation. The Carlsbad Fish and Wildlife Office (CFWO) was concerned with the potential threat to coastal wetlands - an area that provides important habitats for many upland and marine species. Since the impact is not fully understood, it is important to predict and assess the potential impacts of sea level rise to help decision makers put forward policies to preserve and protect existing coastlines, habitats, and species. GIS tools are needed to efficiently prepare data for input to the SLAMM application, and to analyze the SLAMM output.

\subsection{Requirements Analysis}

To ensure the project meets the user's needs, a requirements analysis was conducted to determine the functional and non-functional requirements of the GIS tools.

\subsubsection{Functional Requirements}

Functional requirements outline the intended behavior of the system. It takes user needs into consideration from a system perspective. This section defines the access method, system interface, and the data exchange capabilities needed for the GIS model built for this project. The functional requirements for the GIS model are listed in Table 1. Functional requirements.

Table 1. Functional requirements

\begin{tabular}{|l|l|}
\hline Requirement & Description \\
\hline Operate from a desktop computer or laptop & $\begin{array}{l}\text { Enables user to operate the model from a } \\
\text { desktop or laptop computer }\end{array}$ \\
\hline Convert DEM, Slope, and NWI datasets & $\begin{array}{l}\text { Enables user to input DEM and NWI } \\
\text { datasets for the area of interest to process } \\
\text { into ASCII format }\end{array}$ \\
\hline
\end{tabular}




\begin{tabular}{|l|l|}
\hline Requirement & Description \\
\hline Retrieve SLAMM output & $\begin{array}{l}\text { Enables user to retrieve SLAMM output } \\
\text { into ArcMap }\end{array}$ \\
\hline $\begin{array}{l}\text { Save raster dataset, feature classes, and text } \\
\text { format in a user-selected output destination }\end{array}$ & $\begin{array}{l}\text { Enables user to select a preexisting file } \\
\text { geodatabase or file folder to save output } \\
\text { features from the GIS model }\end{array}$ \\
\hline
\end{tabular}

The user will be operating the GIS model from a desktop or laptop computer. The GIS model can be installed on multiple systems and operated independently. It is not necessary to implement an enterprise system because the risk assessment on coastal wetlands is conducted once every decade.

The user needs a model that can process DEM and the NWI datasets, create a Slope dataset from a DEM, and convert all three datasets into ASCII format. These ASCII files are used as inputs for the SLAMM application. After the SLAMM application simulates wetland conversions and predicts shoreline modification, it produces outputs in the ASCII format. The user needs to be able to retrieve the ASCII output from SLAMM and utilize them to create a feature class in ArcMap. The user should have the option to select a preexisting file geodatabase or file folder to save outputs from the model.

\subsubsection{Non-Functional Requirements}

Non-functional requirements focus on the properties a system must have. This section defines the technical, operational, and transitional requirements of the model. Listed in Table 2 are the non-functional requirements for this project.

Table 2. Non-functional requirements

\begin{tabular}{|c|c|}
\hline Requirement & Description \\
\hline \multicolumn{2}{|c|}{ Technical } \\
\hline $\begin{array}{l}\text { Hardware specifications for ArcGIS } \\
\text { ArcInfo Desktop 9.3.1 }\end{array}$ & $\begin{array}{l}\text { CPU: } 1.6 \mathrm{GHz} \text { or higher } \\
\text { Processor: Intel Core Duo, Pentium } 4 \text { or } \\
\text { Xeon } \\
\text { Memory RAM: } 1 \mathrm{~GB} \text { minimum, } 2 \text { GB or } \\
\text { higher recommended }\end{array}$ \\
\hline $\begin{array}{l}\text { ArcGIS 9.3.1 with Spatial Analyst } \\
\text { extension and SLAMM }\end{array}$ & $\begin{array}{l}\text { User must have ArcGIS ArcInfo Desktop } \\
\text { 9.3.1 with the Spatial Analyst extension, } \\
\text { and SLAMM Beta Version 6.0.1 installed } \\
\text { on their desktop or laptop }\end{array}$ \\
\hline
\end{tabular}




\begin{tabular}{|l|l|}
\hline \multicolumn{1}{|c|}{ Requirement } & \multicolumn{1}{c|}{ Description } \\
\hline Data knowledge & $\begin{array}{l}\text { Users must be familiar with data used for } \\
\text { the model }\end{array}$ \\
\hline GIS experience & $\begin{array}{l}\text { Users must have GIS experience to } \\
\text { navigate through ArcMap tools }\end{array}$ \\
\hline \multicolumn{1}{|c|}{ Operational } \\
\hline Update SLAMM software & $\begin{array}{l}\text { Download updated version of SLAMM as } \\
\text { necessary }\end{array}$ \\
\hline Batch processing & $\begin{array}{l}\text { User must be able to process data in } \\
\text { batches }\end{array}$ \\
\hline Store data & A file geodatabase is needed to store data \\
\hline Transitional & Requirements \\
\hline Instruction Manual & A step-by-step handbook is needed \\
\hline Test model & Model needs to be tested prior to delivery \\
\hline User training & Conduct training at CFWO for one user \\
\hline Project briefing & Deliver project presentation at CFWO \\
\hline
\end{tabular}

\subsubsection{Technical Requirements}

The hardware needed for this system includes a computer equipped with a CPU with 1.6 GHz or higher, Intel Core Duo, Pentium 4, or Xeon Processor, and 1 GB minimum, 2 GB recommended or higher Memory/Ram. The CFWO already has sufficient hardware to support the system.

From a system perspective, the user will need software, hardware, data, and procedures to support the model. Software used to support the system includes ArcGIS ArcInfo 9.3.1 with the Spatial Analyst extension, and SLAMM Beta Version 6.0.1.

This model will be operated as needed. Users can install and operate this model independently on their personal computers provided they have the required GIS software and hardware.

The user must have knowledge of the data used for the analyses. Some of the data processing methods will be automated using ModelBuilder tools. The user must have GIS experience to navigate through the system. In addition, when conducting spatial analyses, the user will have to depend on their own experience and discretion. Since the data used 
for this model is complex, error handling can be challenging. Therefore, it is critical to have experienced GIS users.

\subsubsection{Operational Requirements}

One of the major components of this system is the SLAMM application. SLAMM software is under development and is frequently updated; as a result, the required data for this model may also change. If this is the case, ModelBuilder tools may need to be updated to produce data that meet the new SLAMM requirements. Batch processing is needed due to the large amount of data conversion required. Data archiving after batch processing will be needed. A geodatabase will be created to store the data, but the geodatabase must comply with U.S. FWS standards and guidelines.

\subsubsection{Transitional Requirements}

It is important that the user knows how to process data using the model designed for this project. An instruction manual will be provided to the CFWO. Prior to product delivery, the model will be tested to ensure that it is functioning properly and producing the required outputs. One training session will be provided onsite to a single user. The model will be delivered to the client on a DVD. The project will be presented to the CFWO staff at the same time the DVD and training are provided.

\subsection{System Design}

The system was designed based on the functional and non-functional requirements gathered in section 3.2.1 and 3.2.2. Figure 3.3.1 displays an overview of the system architecture. The system was built for a desktop or laptop platform, with ArcInfo 9.3.1 and SLAMM 6.0.1 installed. The user can process raw data by using the GIS model built for this project. Input and output data will be stored in a file geodatabase for easy access. The user can use data output from the SLAMM and the GIS model to create maps. 


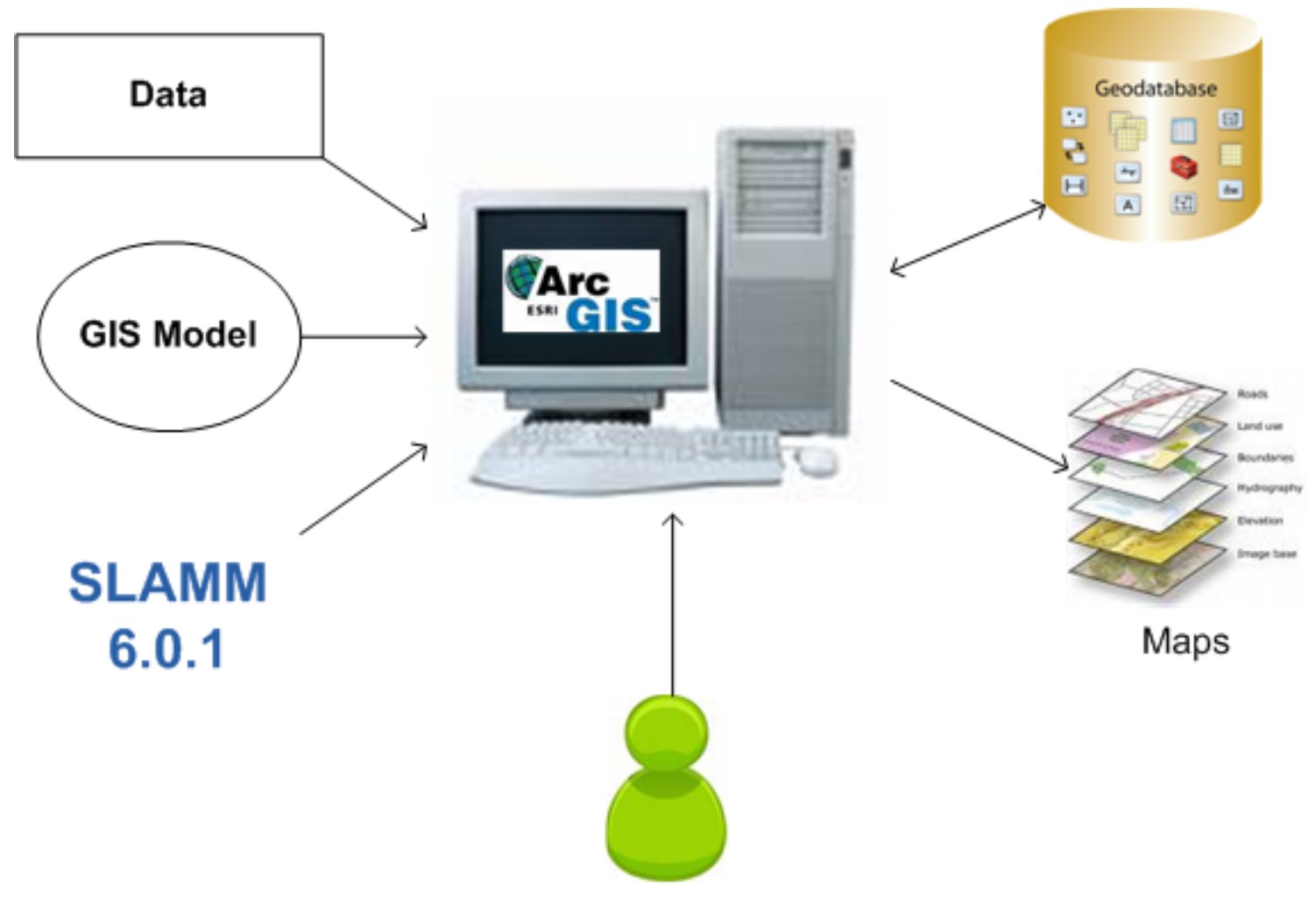

Figure 3.1 System Architecture

\subsection{Project Plan}

A project plan was developed to manage key tasks. The original plan was developed early in the project, consisting of three major phases, as shown in Figure 3.4.1.

- Phase 1: Data Exploration and Requirements Analysis

- Phase 2: Conceptual Design

- Phase 3: Develop Geodatabase/Prototype 


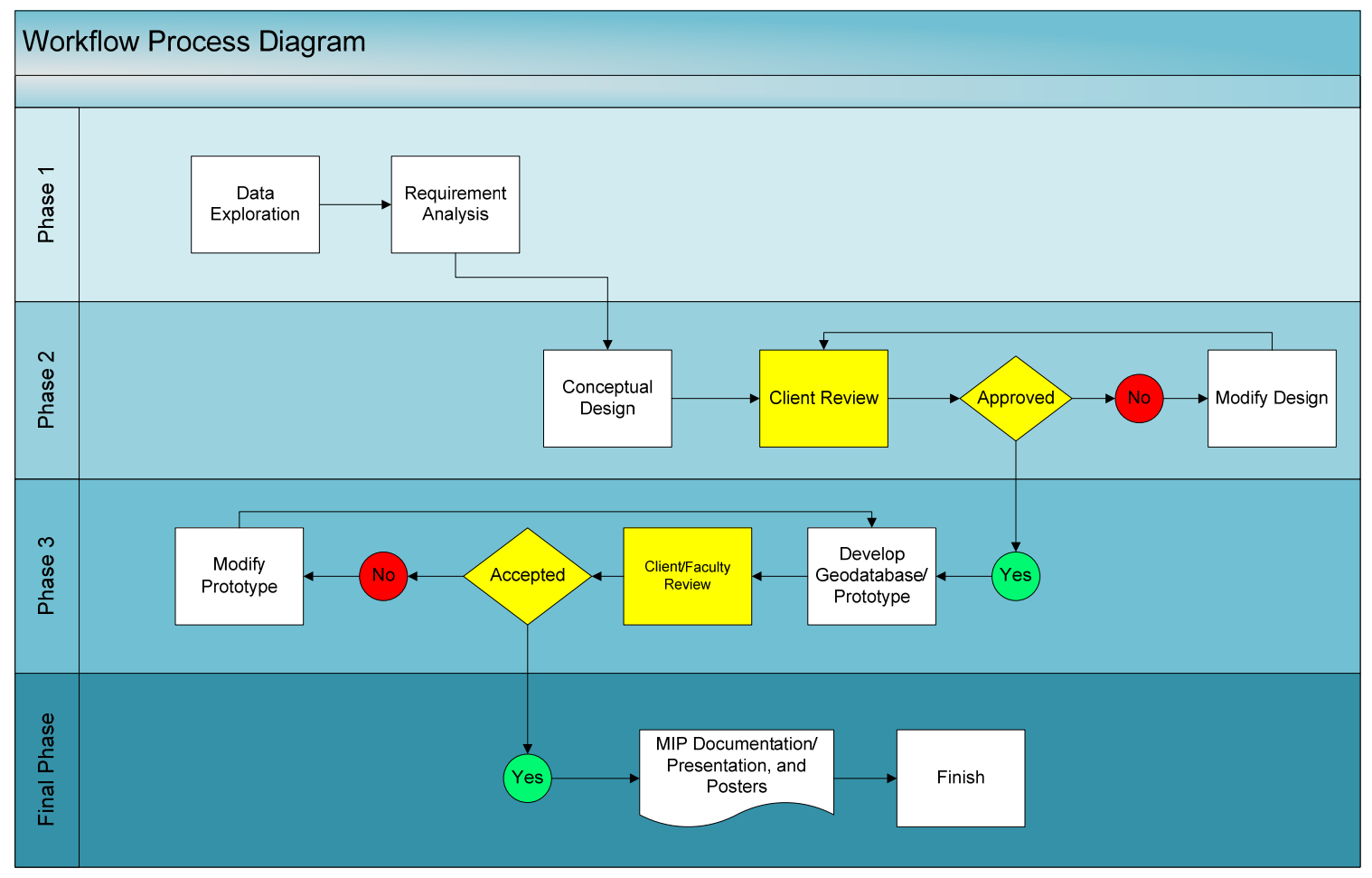

\section{Figure 3.2 Original Project Plan}

However, after several meetings with the client, the plan was modified as follows:

- Phase 1: Identify Problem and Requirements Analysis

- Phase 2: Data Download and Exploration

- Phase 3: Development of Geodatabase

- Phase 4: Development of Model and Testing

- Phase 5: Project Implementation and Documentation

\section{Phase 1: Identify Problem and Requirement Analysis}

In Phase 1, meetings were conducted with the client to identify the problem the client was trying to address, determine the functional and non-functional requirements of the project, and create a project plan.

\section{Phase 2: Data Download and Data Exploration}

Phase 2 identified data required for the SLAMM application, explored the data provided by the client, and compiled data (LiDAR, NED, NWI, polygon feature class for study sites, and SLAMM code table) from various sources. The most challenging task in this phase was to discover the data processing methods for the SLAMM input data. Since the SLAMM application is designed for experienced users, the documentation does not specify how each of the datasets should be prepared. 
During the data exploration task, it was discovered that the provided LiDAR data did not cover the entire San Dieguito Lagoon study area. As a result, the study site was removed from the project because the data could not be acquired in time for this project.

\section{Phase 3: Development of Geodatabase}

In Phase 3, the conceptual data design model and the physical geodatabase design model were created. Feature classes were created to store the SLAMM input data. These feature classes were stored in feature datasets based on the individual study areas.

\section{Phase 4: Development of Model}

In Phase 4, ArcGIS ModelBuilder tools were developed and tested to retrieve and process data. The original plan was to design a Modeling Sea Level System with a simple user interface shown in Figure 3.3. This system would include several GIS models behind the scenes to process the data to input into the SLAMM application. The user has the option to select either the LiDAR, Slope, or NWI button to execute the model designed specifically for that function. For example, when the user selects the LiDAR button, the system launches the Extract to bare-earth DEM tool from within LiDAR Analyst. It prompts the user to select the single file or batch file process depending on their needs. Once LiDAR data was converted to bare-earth DEM, the model would automatically launch the DEM model to define the projection, re-project the raster to specified projection, and convert the DEM raster dataset to ASCII format. For convenience, the system includes a button to launch the SLAMM application from ArcMap. The system also provides five different map options to choose from to create maps that meet U.S. Fish and Wildlife Service map standards. 


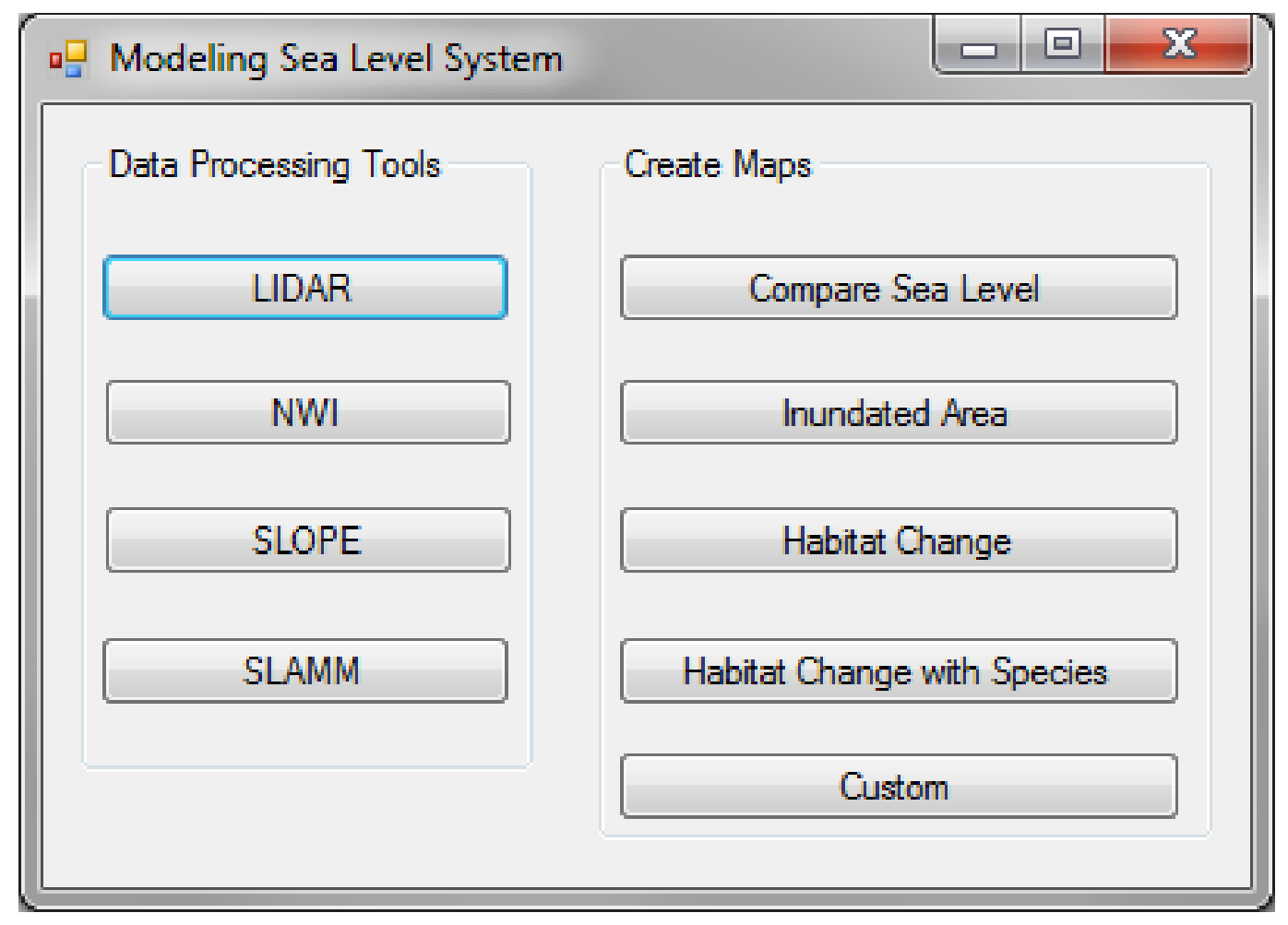

Figure 3.3 Original Plan: Modeling Sea Level System

However, after further discussions with the client, it was clear that building the Modeling Sea level System was not necessary because the client has no intention of using this application for future assessment. As an alternative, the scope of the project was reduced to developing three ArcGIS Modelbuilder tools that can accurately process data without the user interface shown in Figure 3.3. The first model converts DEM and Slope data to ASCII format. The second model converts NWI to ASCII format. The third model inputs SLAMM ASCII data into ArcMap, calculates raster files, and generates feature class outputs.

\section{Phase 5: Project Implementation and Documentation}

In Phase 5, the GIS models, file geodatabase, and user documentation were compiled on a DVD. The project was presented at the ESRI International User's Conference on July 13, 2010. A poster of the project and a DVD with the complete MIP report was delivered to the CFWO. User training and presentation was delivered onsite at the CFWO during their monthly meeting.

\subsection{Summary}

The overall system design and project plan were discussed in this chapter. A requirements analysis was conducted to determine: the functional requirements capturing the intended behavior of the system by defining the system access method, system 
interface, and data exchange capabilities needed for the GIS model built for this project; the non-functional requirements, defining the technical, operational, and transitional requirements of the software system. The overview of the system design discussed the hardware and software required for this project. The discussion of the project plan described the changes made to the task management process as the project progressed. 



\section{Chapter 4 - Geodatabase}

One of the functional requirements for this project was to create a database to store, organize, and manage the required data. The database needed the ability to transfer easily to another computer system or media. This chapter describes the conceptual and logical data model, the data sources used, and data acquisition methods.

\subsection{Conceptual Data Model}

There are four Unified Model Language (UML) diagrams illustrating the relationship of use cases in a relational database that are relevant to this project.

Figure 4.1 illustrates the one-to-many relationship between the sea, coastline, and habitat. The sea could have one or more coastlines, but one coastline could not have more than one sea. The association between habitats and coastline is zero-to-many habitats. A coastline may or may not contain a habitat, although it is likely for specie to live in at least one habitat. Habitats that are not near the coastline will not be included in this model.

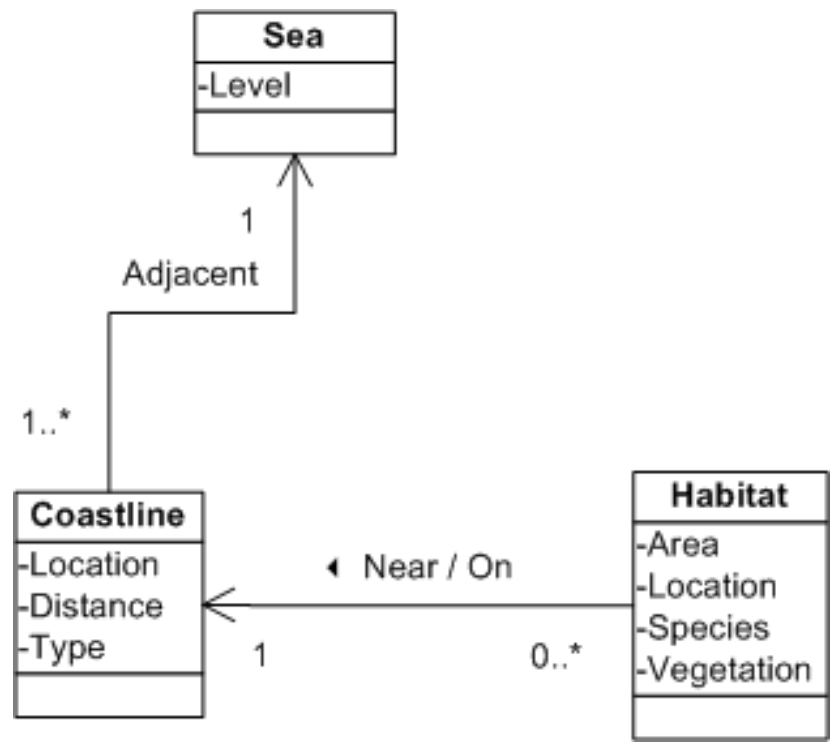

Figure 4.1 Sea Coastline Habitat Model

Figure 4.2 illustrates the relationship between the coastline and its physical features: beach, lagoon, estuary, and wetland. The association between the beach and coastline is zero-to-many. A coastline may or may not have beaches. The association between lagoons and coastline is zero-to-many. A coastline may or may not have a lagoon, but a lagoon must have at least one coastline. The association between estuary and coastline is zero-to-many. A coastline may or may not have an estuary, but an estuary must have one coastline. The association between wetland and coastline is zero-to-many. A coastline 
may or may not have a wetland, but a wetland must be adjacent to the coastline to be impacted by sea level.

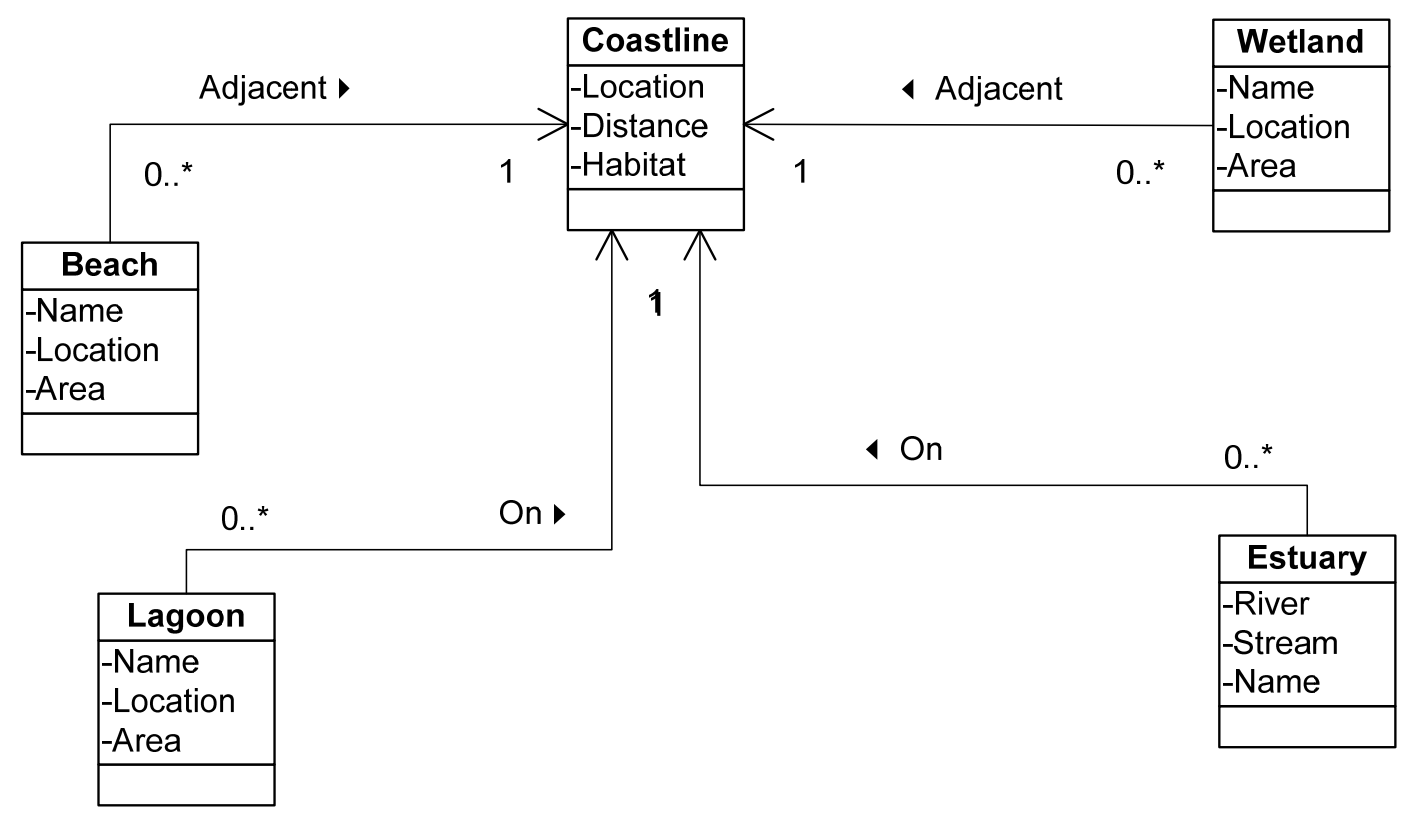

\section{Figure 4.2 Coastline and Land Type Model}

Figure 4.3 illustrates the relationship between the coastline and habitat. The association between the habitat and coastline is zero-to-many. A coastline may or may not contain any habitats. However, for the purpose of this project a habitat must be near or on the coastline in order to be relevant. The association between species and habitat is zero-to-many species living in one habitat. The coastline may have a habitat that may or may not have species living in them, but each species must have at least one habitat. The association between refuge and habitat is one-to-many habitats in a refuge. Conversely, there could be zero-to-one refuge for each habitat. On a coastline, a habitat does not have to be in a refuge, but a refuge must have at least one or more habitats in order for it to be a refuge. 


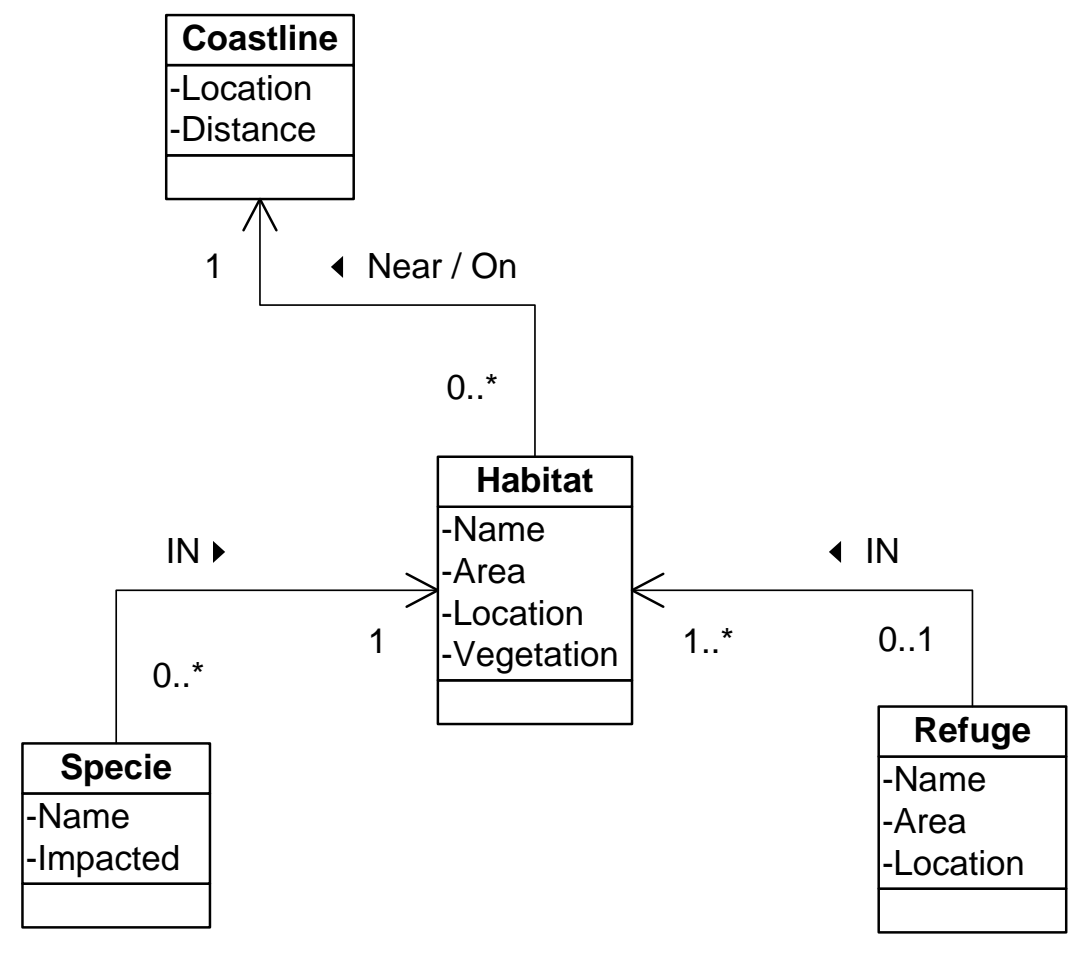

Figure 4.3 Coastline and Habitat Model

Figure 4.4 illustrates the relationships of the entire system model. Changes in sea level will affect the physical features of the coastline and its habitats. Changes to habitats will affect the associated species and refuges. 


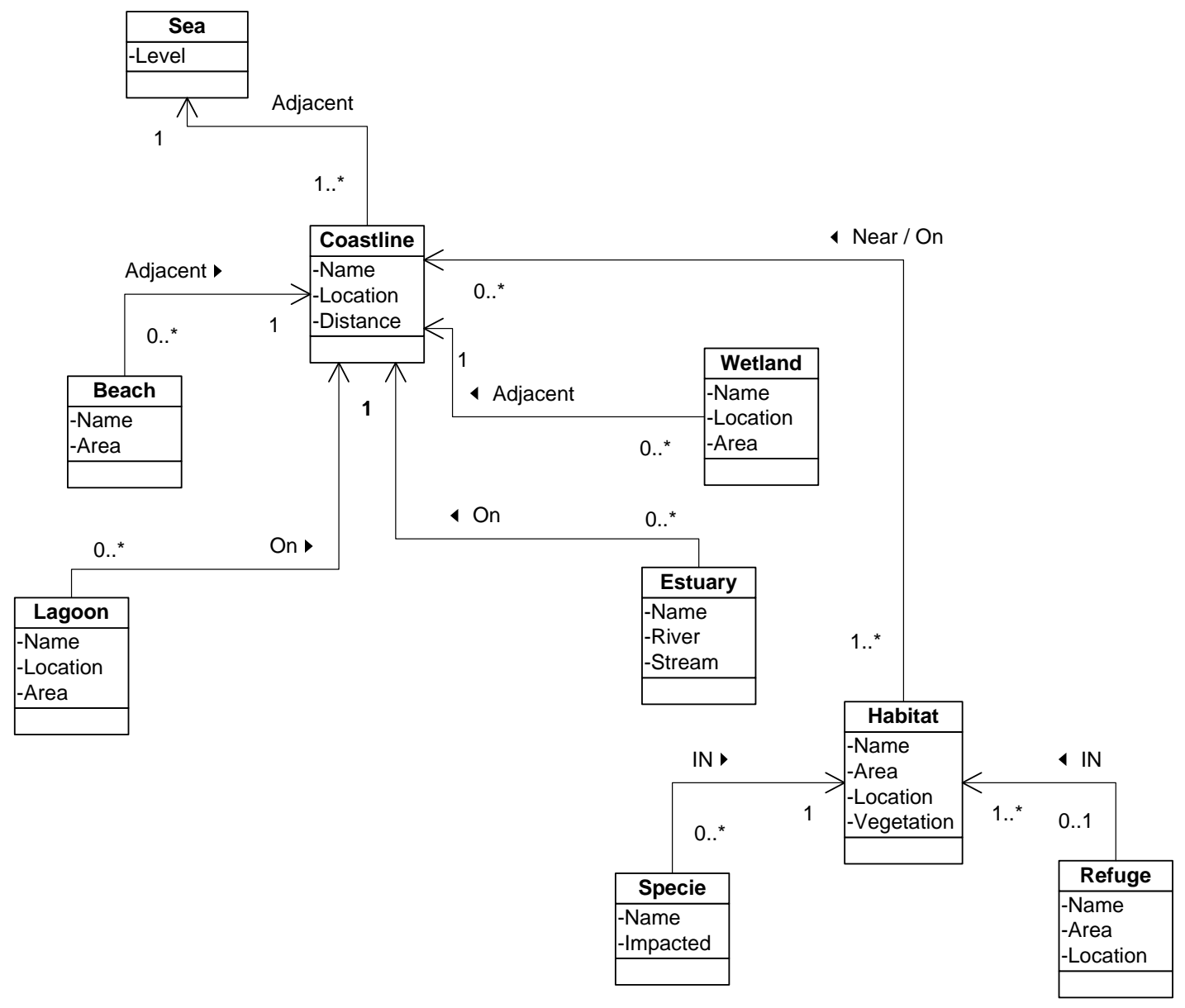

Figure 4.4 System Model

\subsection{Logical Data Model}

The logical data model takes the conceptual model and transfers it into a physical geodatabase design. A file geodatabase was chosen for this project because it has the capacity to store a large amount of data, multiple feature classes, raster datasets, and tables. In comparison, a personal geodatabase is limited to 2 GB storage capacity, and after $500 \mathrm{MB}$ the performance begins to degrade. The large capacity of the file geodatabase provides the client the ability to add more datasets for future study sites.

The logical model shown in Figure 4.5 is the data structure of the project's geodatabase. The geodatabase contains a feature dataset for each study site. Each dataset stores the extent of the study site, polygon of the lagoon or estuary, and the relevant NWI datasets. The geodatabase also stores the various elevation datasets and the SLAMMCODE table. 

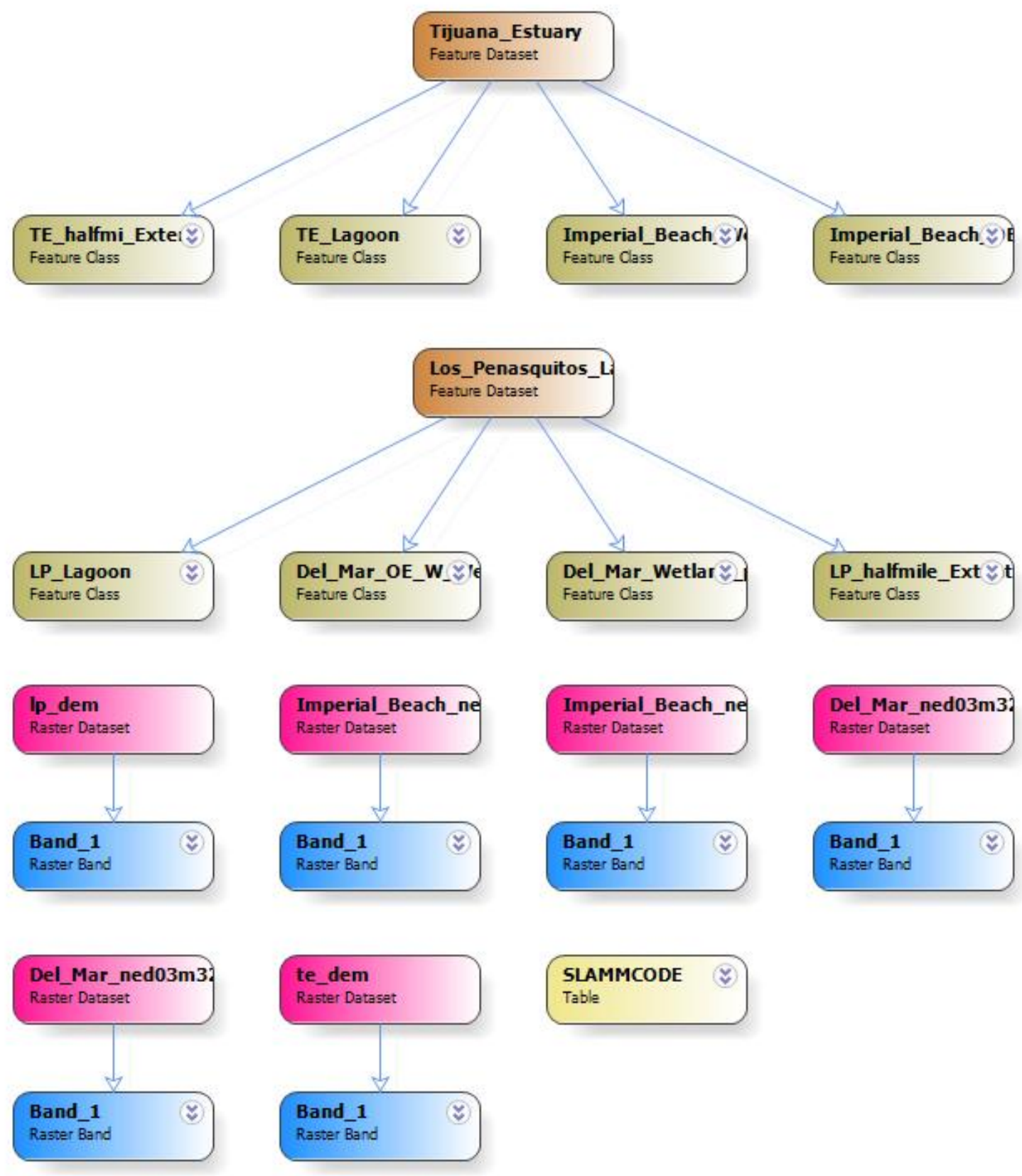

Figure 4.5 Logical Model

\subsection{Data Sources}

The data used in this project were primarily obtained from the client and official government websites. The client provided the LiDAR data, while the NED and NWI datasets were downloaded from the U.S. Geological Survey and the U.S. Fish and Wildlife Service websites (see Sections 4.4.2 and 4.4.4). The SLAMM code table was downloaded from the Warren Pinnacle website 
(http://warrenpinnacle.com/prof/SLAMM/index.html), which is the environmental consulting company that developed the SLAMM application.

\subsection{Data Acquisition}

This section describes the methods used for compiling the data specified in the SLAMM Technical Documentation, including LiDAR to bare-earth DEM, NED, the extent of the study area, the NWI dataset, and SLAMM code table.

\subsubsection{LiDAR to Bare-Earth DEM}

ArcGIS LiDAR Analyst Version 4.2.9.11 was used to process the client-provided LiDAR data to a bare-earth DEM. To identify the geographic coordinate system, the header information of the LiDAR LAS file was carefully examined using the Bare-Earth Extraction tool in LiDAR Analyst. The geographic coordinate system was identified and defined as North American Datum 1983 (NAD83) with the elevations based on the North American Vertical Datum 1988 (NAVD88). The horizontal and vertical map units were defined and the output destination was selected from the Bare-Earth Extraction tool, as shown in Figure 4.6. The Bare-Earth Extraction tool was designed to process both single LiDAR LAS files and batch files. In order to perform batch processing, a single LAS file was processed to obtain the Automated Feature Extraction (AFE) file. Batch processing was then used since there were multiple LiDAR LAS files covering each study site. Next, the DEM raster datasets were mosaicked and the resolution was set to 5 meters. This resolution was chosen because the smallest cell size supported by SLAMM is 5 meters. The projection of the raster dataset was defined as NAD83 California_VI_FIPS_0406_Feet, and then re-projected to NAD83 UTM_Zone_11_Meters. Finally, the resultant DEM was stored in the geodatabase.

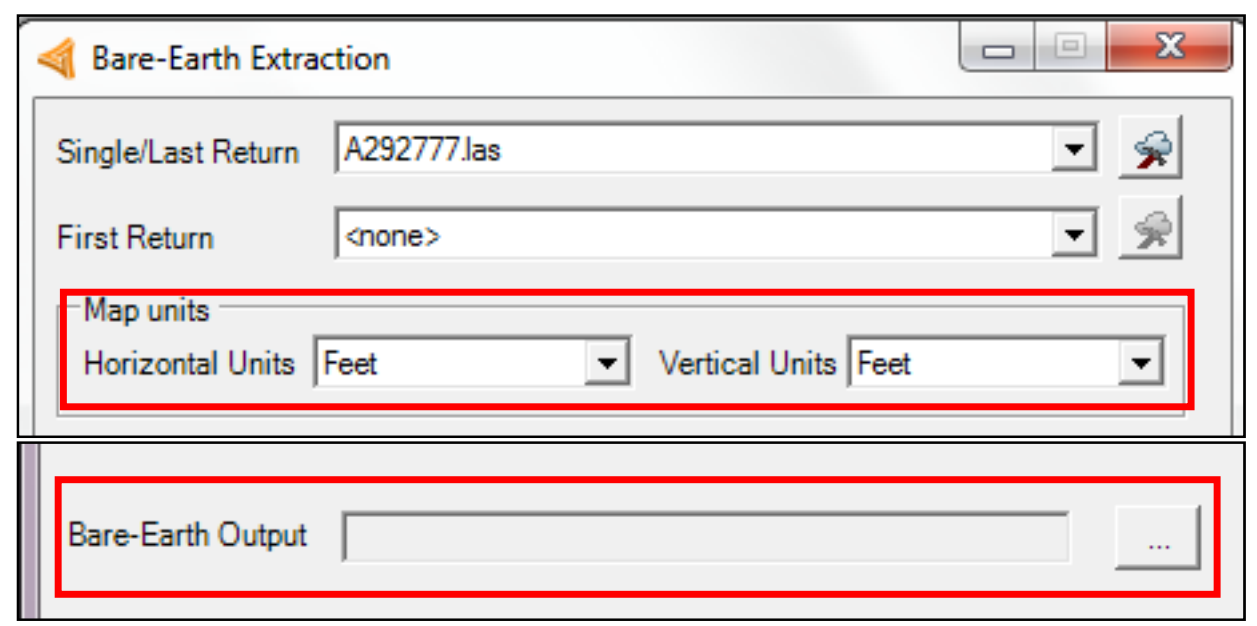

Figure 4.6 Bare-Earth Extraction Tool 


\subsubsection{NED}

Elevation values from the USGS National Elevation Dataset (NED)

(http://seamless.usgs.gov/) were used to fill in gaps in the study area where LiDAR data were not provided (Figure 4.7). The NED data were available at a 3-meter resolution.

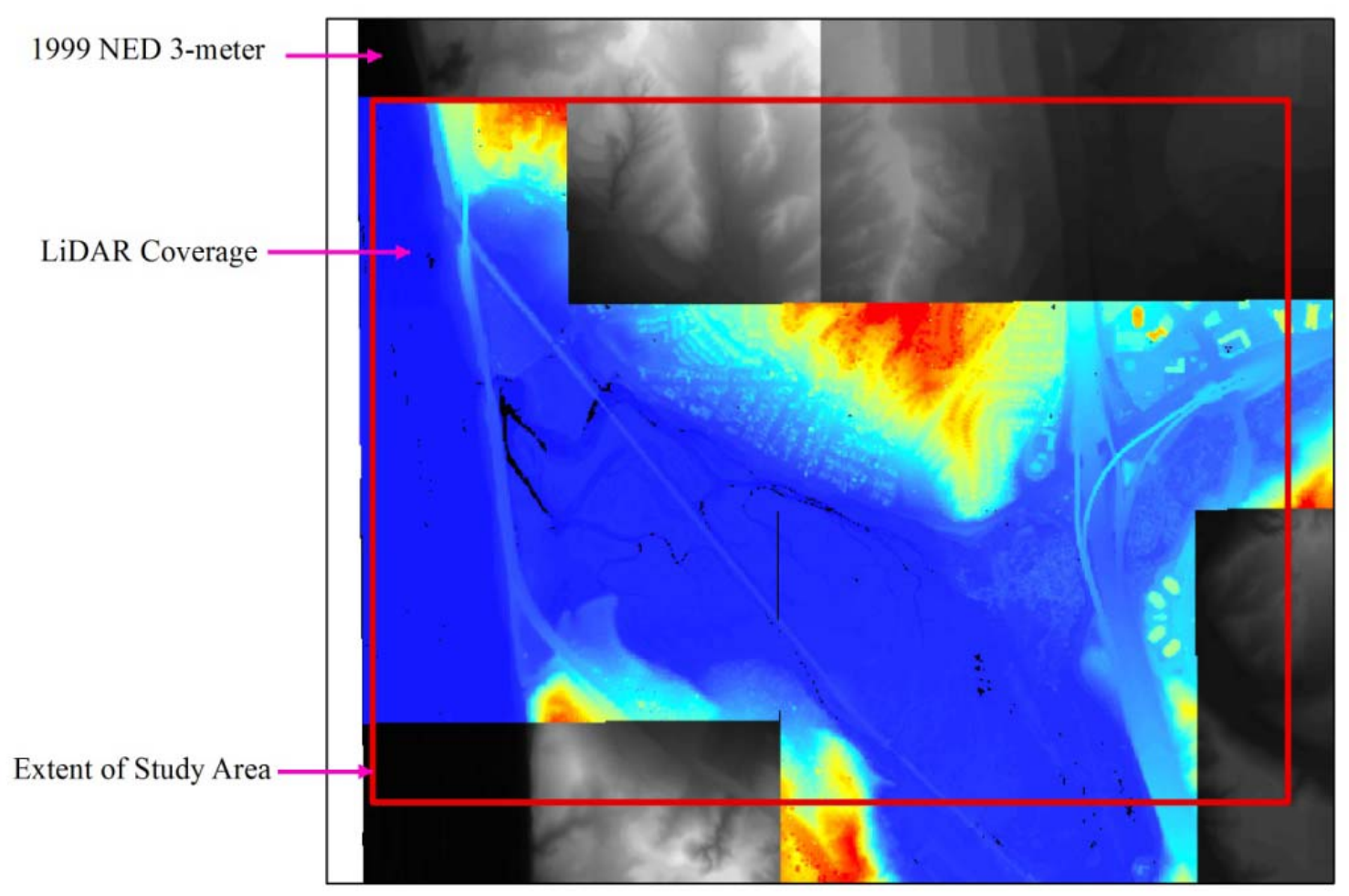

Figure 4.7 Using NED to Fill In Gaps

\subsubsection{Extent of the Study Area}

To ensure all datasets had the same extent, a polygon feature class was created. Using the polygon of the lagoon, a half-mile buffer zone was created, with dissolve type set as "all". The buffer radius should be selected based on the area of interest that best suits the area. Next, the Feature Polygon to Envelope tool was used to create a rectangular polygon around the buffer, as shown in Figure 4.8. This envelope feature class was then stored in the project geodatabase to use as a clip feature for all datasets. 


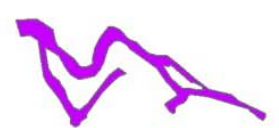

Lagoon Polygon

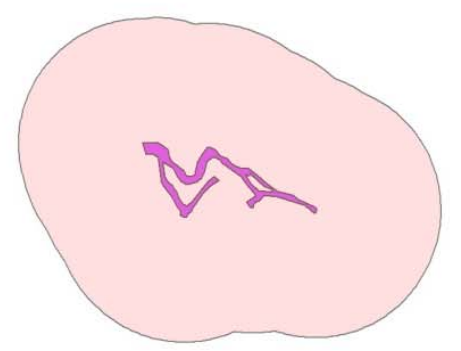

0.5 mile buffer

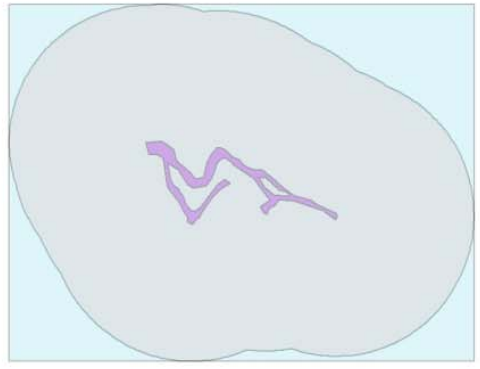

Envelope

\section{Figure 4.8 Extent of the Study Area}

\subsubsection{NWI}

To prepare the NWI data for the model, the NWI datasets were downloaded and stored in the project geodatabase. The first step was to identify the names of the quadrants for each study area using the Wetland Mapper website at http://www.fws.gov/wetlands/Data/Mapper.html. The Wetland Mapper tool allows the user to zoom into the desired location on the map to view the names of the quadrants. In this case, the quadrants covering Los Peñasquitos Lagoon are called Del_Mar and Del_Mar_OE_W (Figure 4.9). The names of the quadrants that cover Tijuana Estuary are called Imperial_Beach and Imperial_Beach_OE_W. After the names of the quadrants were identified, the NWI shapefiles were extracted with the Wetlands Data Extraction Tool located at http://wetlandswms.er.usgs.gov/imf/imf.jsp?site=extract_tool. To identify the NWI shapefiles, the following options were selected from the menu of the extraction tool:

- Select State: California

- Select Area Type: Lower 48 USGS 24K Quads (This dataset contains finer resolution).

- Select Quad: Select the quadrants located from the Wetland Mapper website in the previous step. For example: Del_Mar and Del_Mar_OE_W 


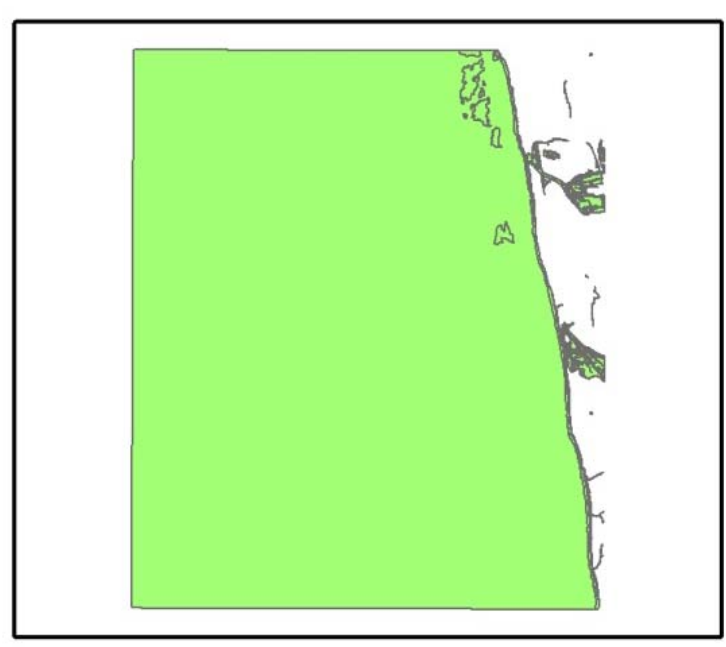

Del_Mar_OE_W

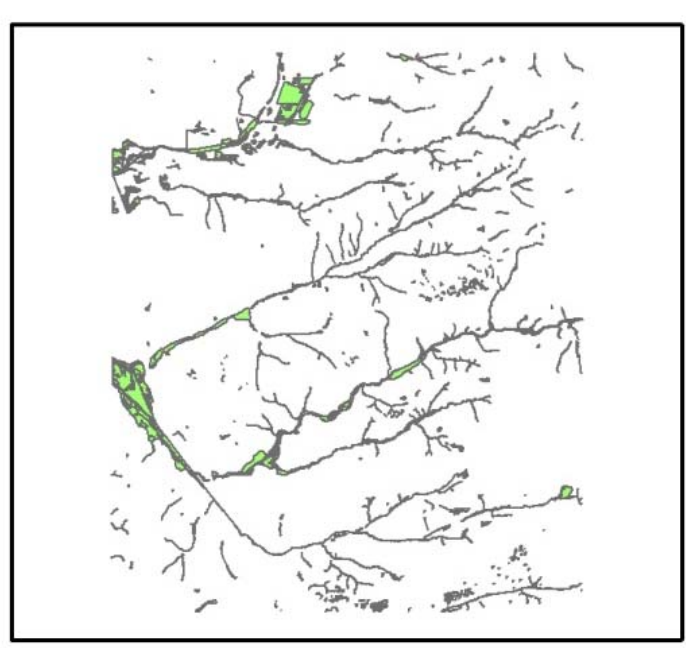

Del_Mar

\section{Figure 4.9 NWI Quadrants}

Finally, the NWI shapefiles were downloaded and stored in the project geodatabase.

\subsubsection{SLAMM Code}

The NWI datasets contain a series of letter and number codes that have been developed to adapt the national wetland classification system to map form. These alpha-numeric codes correspond to the classification nomenclature that best describes the habitat. Each code and character represents a system, subsystem, class, subclass, and common water regimes that are used in wetlands classifications, as shown in Figure 4.10. To simplify this classification system, SLAMM generalizes the NWI classifications into 26 categories, as shown in Figure 4.11. For example, the NWI codes PFO, PFO1, PFO3-5, and PSS were reclassified as SLAMM code 3, for Swamp (see Figure 4.12). 


\begin{tabular}{|c|c|c|}
\hline $\begin{array}{l}\text { SYSTEM } \\
\text { SUBSYSTEM } \\
\text { CLASS } \\
\text { SUBCLASS }\end{array}$ & Common Water Regimes & $\begin{array}{c}\text { Typical NWI } \\
\text { Symthols } \\
\text { (Cowardin Syste m) }\end{array}$ \\
\hline $\begin{array}{l}\text { PALUSTRINE (P) } \\
\text { Emergent (EM) } \\
\text { Persistent (1) } \\
\text { Forested (FO) } \\
\text { Broad-Leaf Deciduous (1) }\end{array}$ & $\begin{array}{l}\text { Temporarily Flooded }(\mathrm{A}) \\
\text { Intermittently Flooded }(\mathrm{J})\end{array}$ & $\begin{array}{l}\text { PEM1A } \\
\text { PEM1J } \\
\text { PFO1A } \\
\text { PFO1J }\end{array}$ \\
\hline $\begin{array}{l}\text { PALUSTRINE(P) } \\
\text { Emergent (EM) } \\
\text { Persistent (1) }\end{array}$ & Saturated(B) & PEM1B \\
\hline $\begin{array}{l}\text { PALUSTRINE(P) } \\
\text { Emergent (EM) } \\
\text { Persistent (1) }\end{array}$ & $\begin{array}{l}\text { Seasonally Flooded (C) } \\
\text { Semipermanently Flooded (F) }\end{array}$ & $\begin{array}{l}\text { FEM1C } \\
\text { FEM1F }\end{array}$ \\
\hline $\begin{array}{l}\text { PALUSTRINE (P) OR LACUSTRINE (L) } \\
\text { Littoral (2) } \\
\text { Emergent (EM) } \\
\text { Aquatic Bed (AB) } \\
\text { Unconsolidated Bottom (UB) }\end{array}$ & $\begin{array}{l}\text { Semipermanently Flooded (F) } \\
\text { Intermittently Exposed (G) } \\
\text { Fermanently Flooded (H) }\end{array}$ & $\begin{array}{ll}\text { PEMF } & \text { L2EM2F } \\
\text { PEMG } & \text { L2EM2G } \\
\text { PABF } & \text { L2EM2H } \\
\text { PABG } & \text { L2ABF } \\
\text { PUBF } & \text { L2ABG } \\
\text { PUBG } & \text { L2ABH }\end{array}$ \\
\hline
\end{tabular}

Figure 4.10 NWI Dataset Classification System

\begin{tabular}{|ll|}
\hline 1. Developed Dry Land & 14. Rocky Intertidal \\
2. Undeveloped Dry Land & 15. Inland Open Water \\
3. Swamp & 16. Riverine Tidal Open Water \\
4. Cypress Swamp & 17. Estuarine Open Water \\
5. Inland Fresh Marsh & 18. Tidal Creek \\
6. Tidal Fresh Marsh & 19. Open Ocean \\
7. Scrub Shrub & 20. Brackish Marsh \\
8. Salt marsh & 21. Tall Spartina \\
9. Mangrove & 22. Inland Shore \\
10. Estuarine Beach & 23. Tidal Swamp \\
11. Tidal Flat & 24. Blank \\
12. Ocean Beach & 25. Vegetation Tidal Flat \\
13. Ocean Flat & 26. Backshore \\
\hline
\end{tabular}

Figure 4.11 SLAMM Categories

\begin{tabular}{||c|c|c|c|}
\hline $\begin{array}{c}\text { NWI Code and } \\
\text { Character }\end{array}$ & $\begin{array}{c}\text { NWI } \\
\text { Description }\end{array}$ & $\begin{array}{c}\text { SLAMM } \\
\text { CODE }\end{array}$ & $\begin{array}{c}\text { SLAMM } \\
\text { Categories }\end{array}$ \\
\hline $\begin{array}{l}\text { PFO, PFO1, PFO3-5, } \\
\text { PSS }\end{array}$ & $\begin{array}{l}\text { Palustrine forested (living } \\
\text { or dead) and scrub shrub. }\end{array}$ & 3 & Swamp \\
\hline
\end{tabular}

Figure 4.12 Example of NWI Classified to SLAMM Code 
The SLAMM code was stored as an Excel database in the SLAMM6 Installer that can be downloaded from the Warren Pinnacle website http://warrenpinnacle.com/SLAMMFORUM/index.php?topic=55.0. The SLAMM installer needed to be extracted to a local hard drive to retrieve the SLAMM code table. To prepare the table for the model, all fields in the table were deleted except the NWI_ATTRIBUTE, SLAMMCODE, and DIKED fields. The table was saved as a dBase file (.dbf). This step was necessary because the table needed a unique identifier to join to another table in ArcMap. Using the Table to dBase tool in ArcMap, the system automatically generates the unique ID field. The SLAMM code table was then stored in the geodatabase.

\subsection{Summary}

This chapter discusses the database created to store, organize, and manage the data required for this project. It also describes the conceptual and logical data model, the data sources used, and data acquisition methods. 



\section{Chapter 5 - Implementation}

The goal of this project was to design three GIS models to prepare data for input to SLAMM, and transfer the output from SLAMM back into ArcMap. To develop the models for this project, it was important to explore the SLAMM application, SLAMM Technical Documentation, and SLAMM User Guide to identify the data required and to understand the methods involved in processing the data. This chapter discusses the various methods used to implement the GIS tools for this project. It contains four major sections including: DEM and Slope Model; NWI Model; SLAMM application; and SLAMM Exchange Format to Raster Model.

\subsection{DEM and Slope Model}

The DEM and Slope Model shown in Figure 5.1 was created using ArcGIS ModelBuilder. The model was designed as a toolbox stored in the project's geodatabase along with the other data for this project. This section discusses the steps and tools used in the DEM and Slope Model and provides the parameters used for these tools.

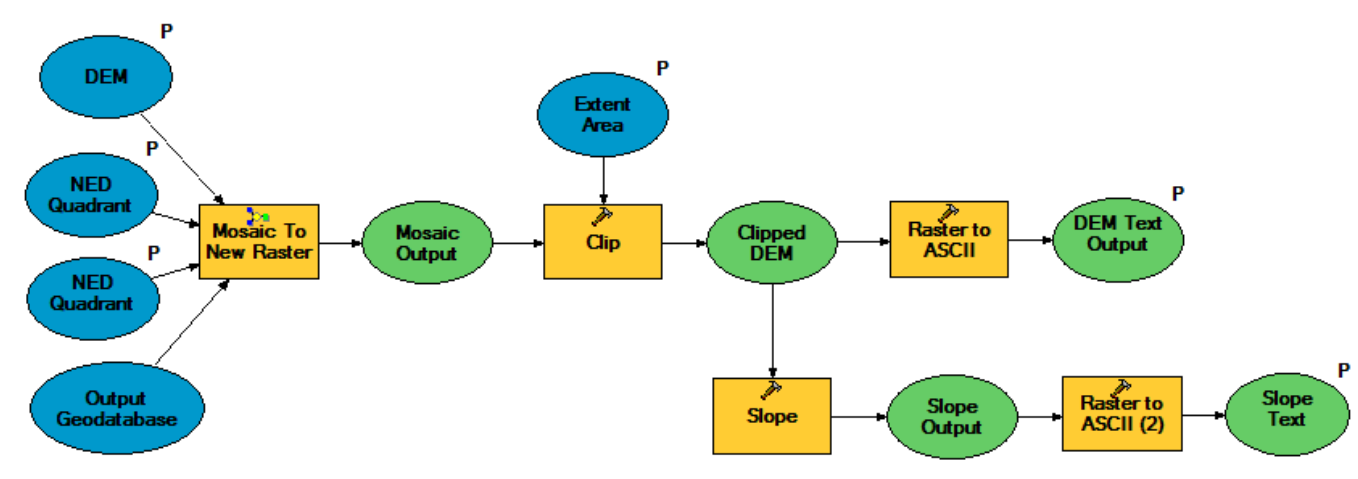

Figure 5.1 DEM and Slope Model

\subsubsection{DEM}

The first step of the DEM model shown in Figure 5.2, was to mosaic the DEM and NEDs stored in the project's geodatabase. Since the two elevation datasets had different resolutions, the cell size option in the Mosaic tool was set to a 5-meter resolution in the model. The DEM and NEDs input features in the model were set as parameters. This allows the user to input the datasets for the area of interest. Next, the Clip tool was used to clip the DEM raster dataset to the extent shapefile stored in the geodatabase. The input for the extent shapefile was also set as a parameter. Finally, the Raster to ASCII tool was used to convert the raster dataset to an ASCII format. The DEM text output was set as a parameter to allow a user to select the desired output destination, because a text file cannot be stored in the file geodatabase. 


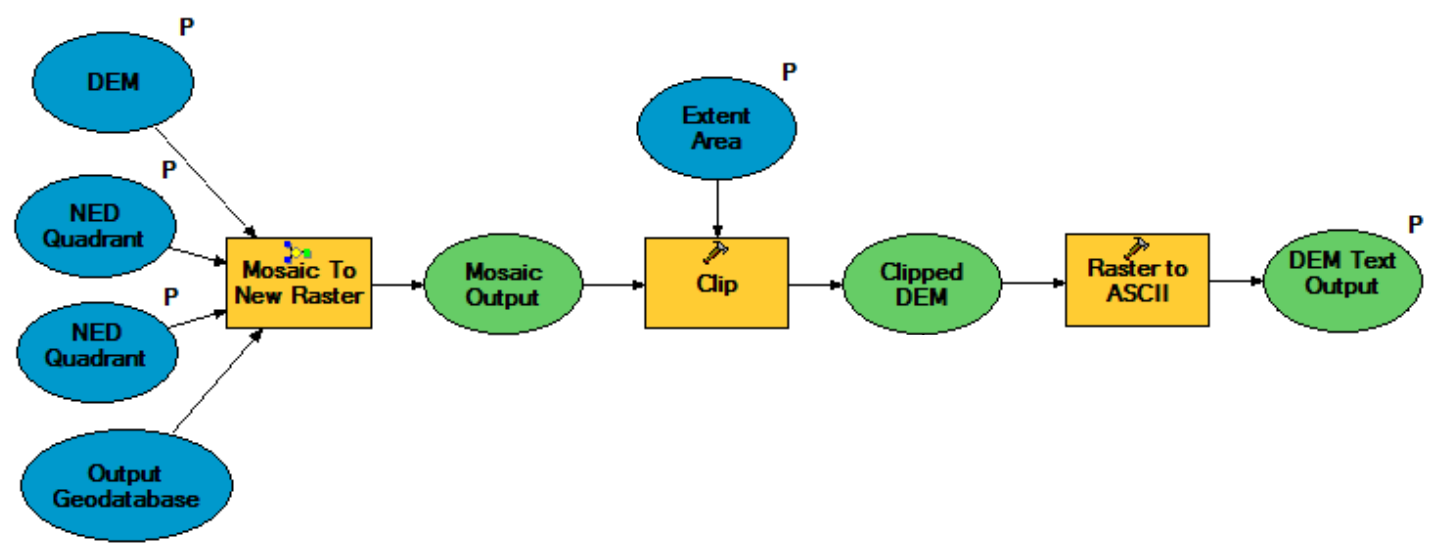

Figure 5.2 DEM Model

\subsubsection{Slope}

As shown in Figure 5.3, after the model produced the DEM output, the Slope tool was used to create the Slope raster dataset. The Output Measurement setting in the slope tool was set to degrees as required in the SLAMM User Manual. The Raster to ASCII tool was used to convert the slope raster to an ASCII file. Again, the Slope text output was also set as a parameter because the text file could not be stored in the geodatabase.

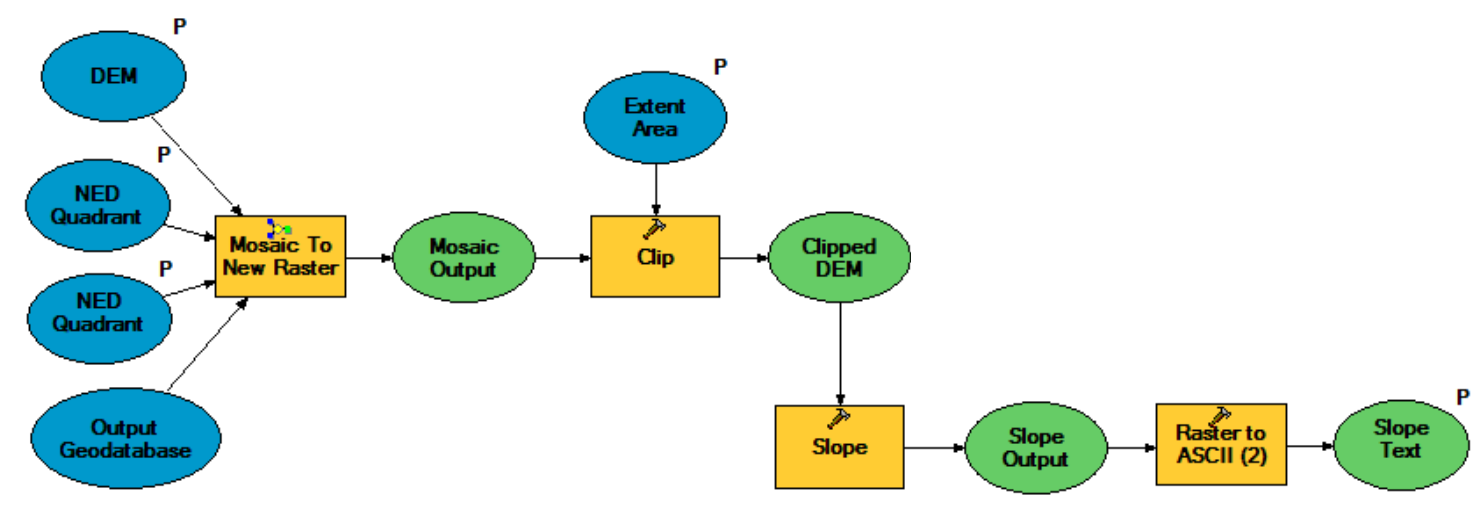

Figure 5.3 Slope Model

\subsection{NWI Model}

This section discusses the ArcMap tools used to create the NWI Model in ModelBuilder. The model will be discussed in two parts, as shown in Figure 5.4. The first part of the model prepares the NWI dataset. The second part of the model classifies the area inside the extent that contains no NWI data and combines the data with the NWI dataset created from the first part of the model. In addition, the model also produces a Dike ASCII file. Finally, this section describes a manual process for classifying the SLAMM codes to increase prediction accuracy. 


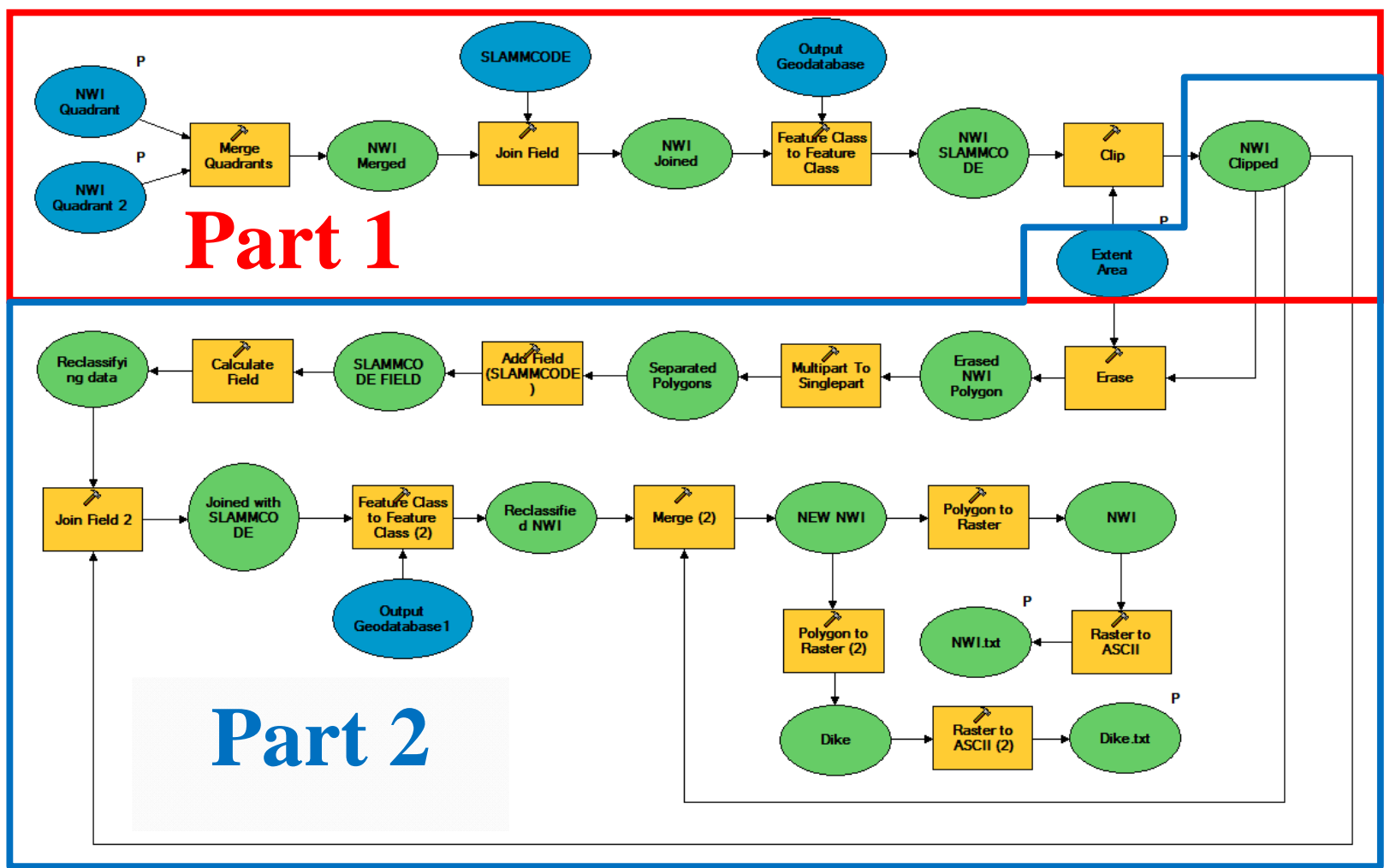

Figure 5.4 NWI Model

\subsubsection{Part One of NWI Model}

Figure 5.5 shows the first part of the model that prepares the NWI dataset.

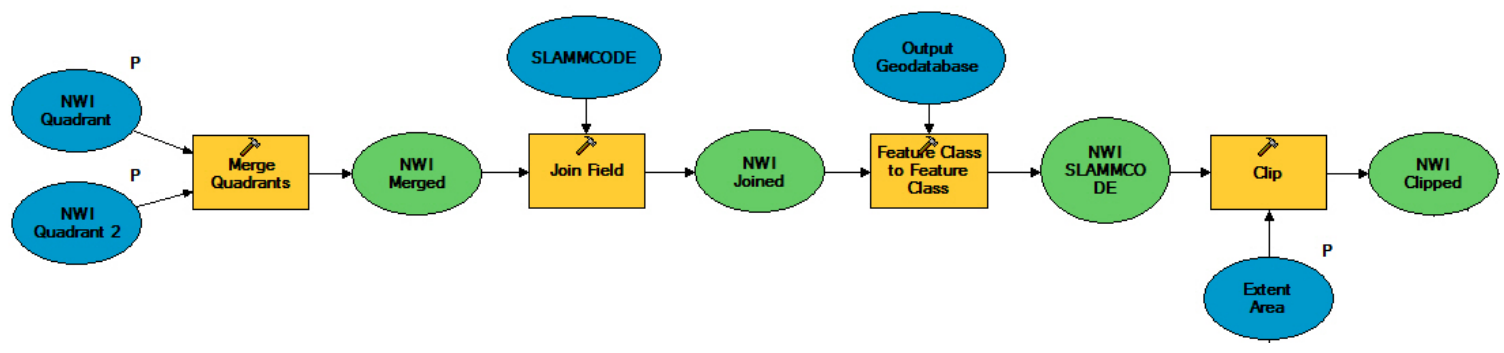

Figure 5.5 Part 1 of NWI Model

The first step in this model was to use the Merge tool to combine the two NWI quadrants stored in the geodatabase, as shown in Figure 5.6. 


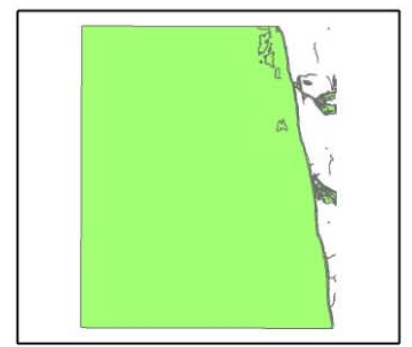

Del_Mar_OE_W

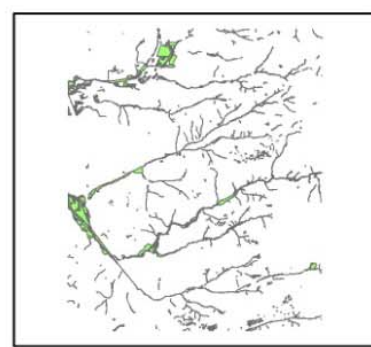

Del_Mar

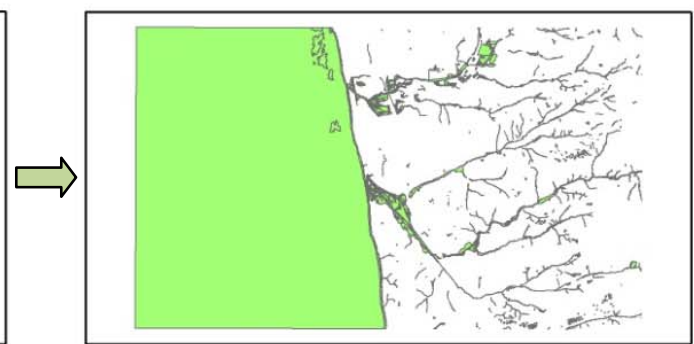

NWI Wetland Polygons

\section{Figure 5.6 Merging NWI Quadrants}

Next, the Join Field tool was used to join the common Attribute field from the NWI attribute table and the NWI_Attrib field from the SLAMM code table, as shown in Figure 5.7. After the tables are joined, the Feature Class to Feature Class tool was used to create a new feature class. Finally, the Clip tool was used to clip the NWI feature class to the extent shapefile stored in the geodatabase.

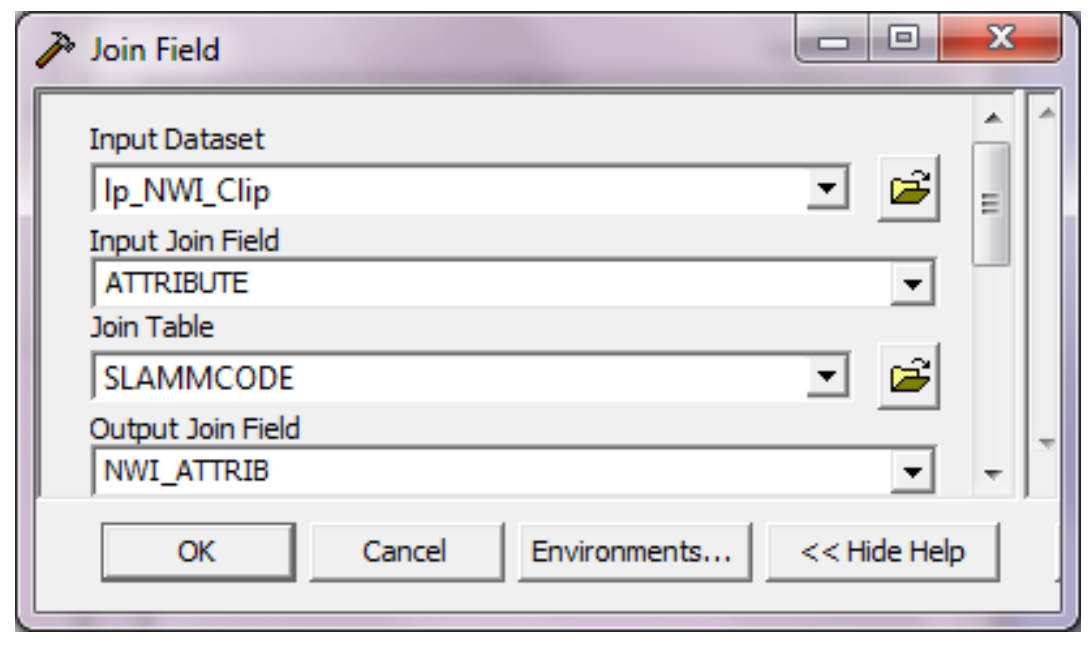

Figure 5.7 Joining NWI Attribute Table to SLAMM Code Table

\subsubsection{Classify Polygon}

The second part of the NWI model, shown in Figure 5.8, classifies the polygons inside the extent area that contain no NWI data, as shown in Figure 5.9 and produces a Dike ASCII file. 


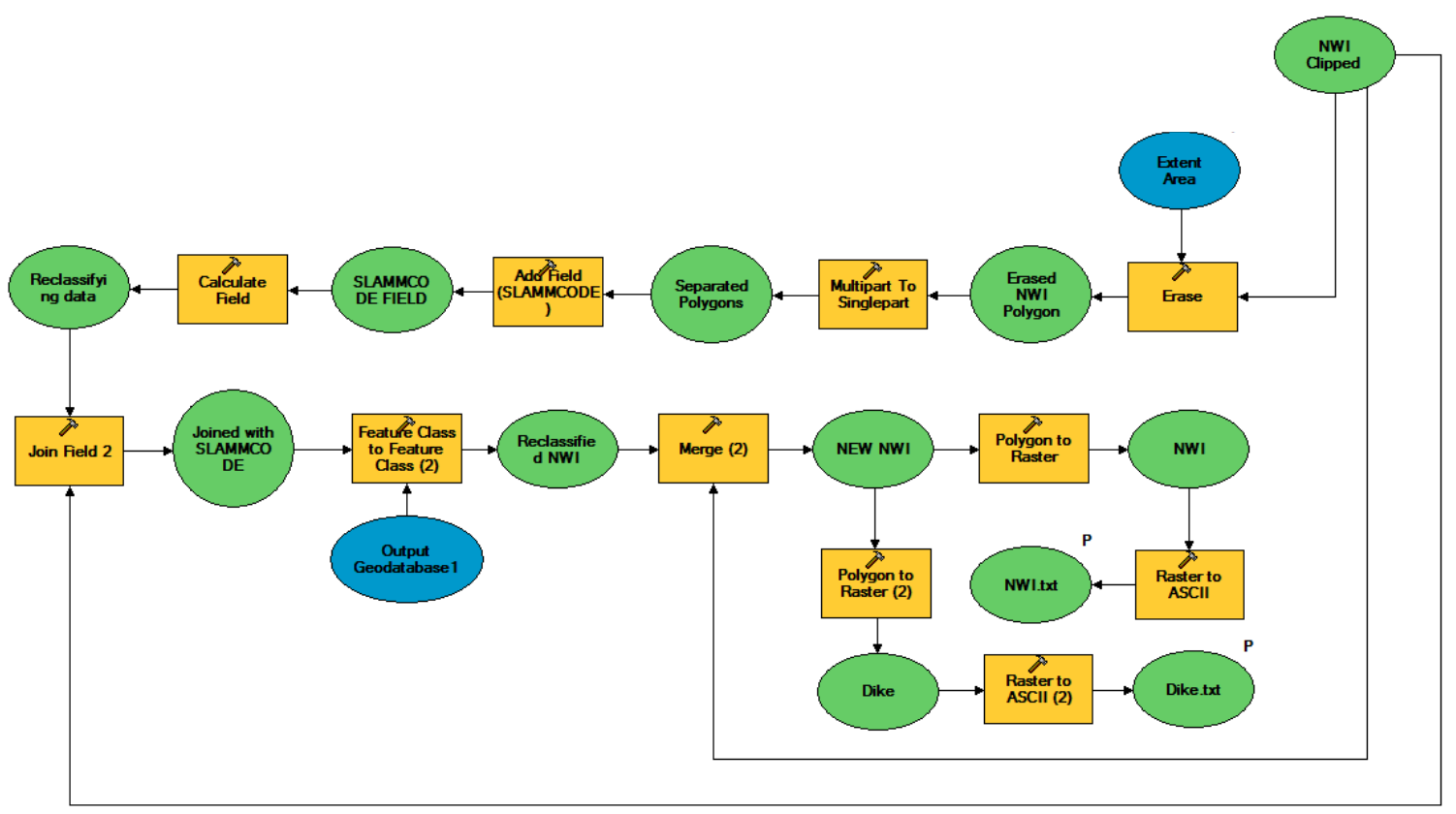

Figure 5.8 Part 2 of NWI Model

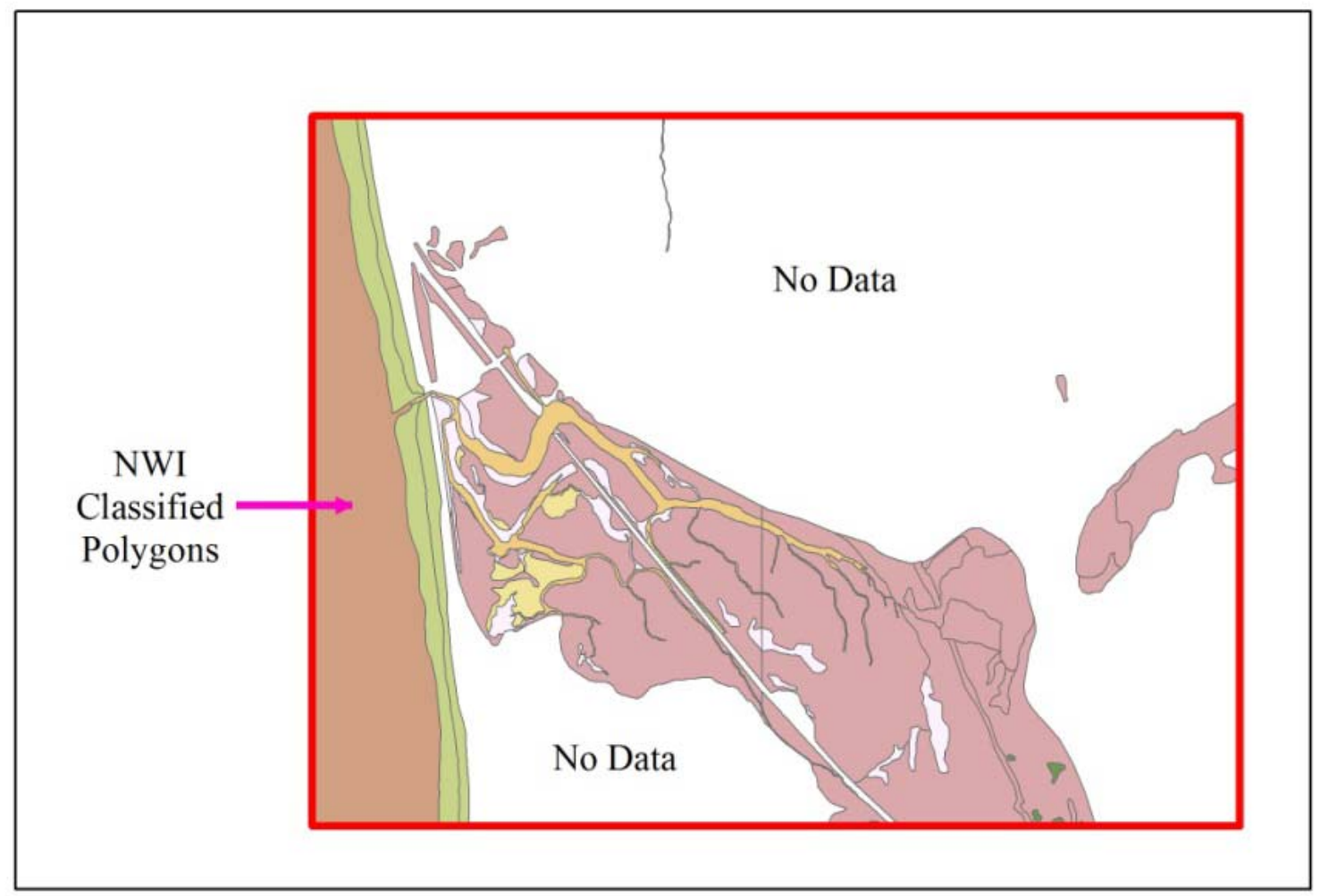

Figure 5.9 NWI Reclassify No Data

The first step was to take the extent shapefile from the geodatabase and erase the classified NWI polygons. The second step was to use the Multipart to Singlepart tool to 
break the single polygon into multiple polygons. The third step was to add the SLAMMCODE field to the attribute table. The field type was set to DOUBLE, precision value of 18, and scale value of 6 to match the configuration in the original NWI dataset. The fourth step was to use the Calculate Field tool to assign the SLAMMCODE field a value of 1, which is categorized as Developed Dry Land in the SLAMM Technical Documentation. Not all polygons that contain no data are developed dry land, but it can be classified manually if necessary.

To prepare the reclassified feature class to be merged with the NWI feature class created from part one of the model, both feature classes must have the same attribute fields. The Join Field tool was used to join the common SLAMMCODE field from both datasets to adopt all fields from the NWI feature class. Next, the Feature Class to Feature Class tool was used to create a new feature class. Then the Merge tool was used to combine the new NWI feature class with the NWI feature class from part one, as shown in Figure 5.10. This step creates the merged NWI feature class to be used if further SLAMM code classification is desired. Next, the Polygon to Raster tool was used to convert the new NWI feature class to a raster dataset. Finally, the Raster to ASCII tool was used to create an ASCII file suitable for input into SLAMM.

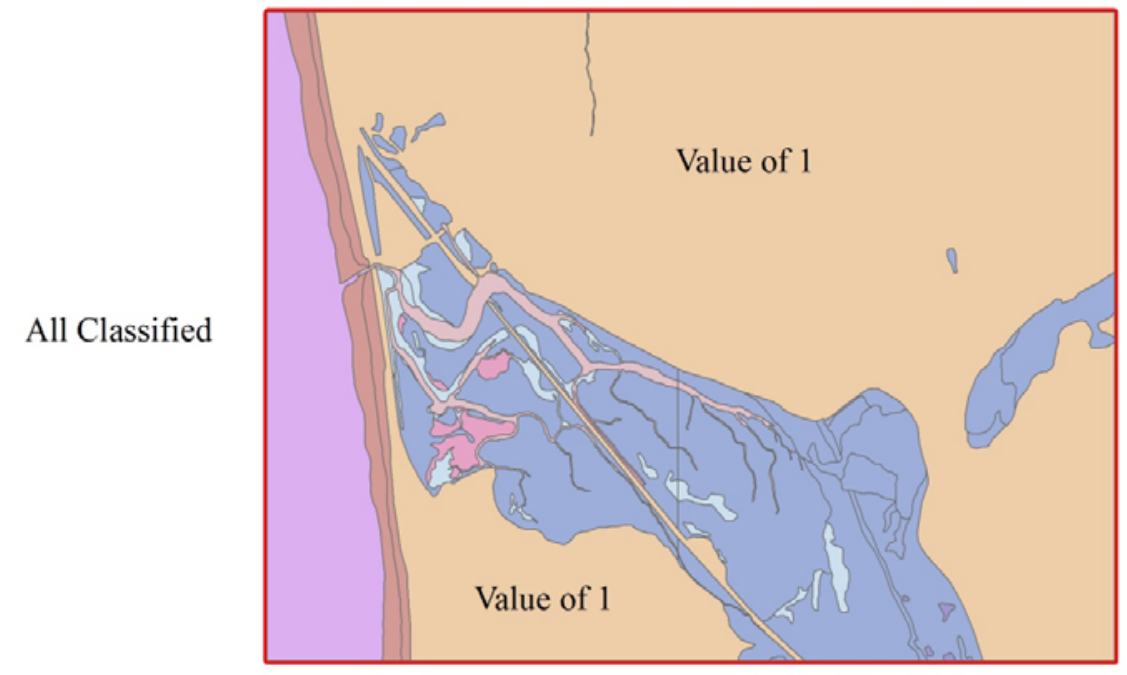

Figure 5.10 New NWI Feature Class

\subsubsection{Dike ASCII}

A dike is a constructed levee or wall designed to regulate water levels. Some study sites may contain dikes. SLAMM accepts the dike dataset as an optional input for SLAMM. This raster dataset contains raster value of 1 for all impounded areas while other areas have a value of 0 . The 2009 SLAMM code table already had the dike value assigned to each SLAMM code. The NWI Model also produces a raster dataset using the Polygon to Raster tool with the Value field set as Diked and Cellsize as 5 meters. The extent in the Environment Settings was set to match the DEM dataset. Then the model converts the raster dataset to an ASCII format using the Raster to ASCII tool. 


\subsubsection{Further SLAMM Code Classification}

For better results, the SLAMM codes from the NWI table should be carefully examined and reclassified to match the appropriate SLAMM categories. To begin, the NWI feature class was compared with a 2009 aerial photo of the area. For example, Figure 5.11 shows the polygons that were misclassified by the model as SLAMM code 1, Developed Dry Land. When examining those polygons closely, most of those polygons should have been classified as SLAMM code 8, Regularly Flooded Marsh, and one polygon should have been classified as SLAMM code 12, Ocean Beach, as shown in Figure 5.12.

\begin{tabular}{|c|c|c|c|c|c|}
\hline & & & & \multicolumn{2}{|c|}{\begin{tabular}{|l|l|l|}
$口$ & 回 & $\mathbf{X}$ \\
\end{tabular}} \\
\hline SLAMMCODE & OBJECTID_1 & ATTRIBUTE & WETLAND_TY & & $\Delta$ \\
\hline 1 & 0 & & & & \\
\hline 1 & 0 & & & & \\
\hline 1 & 0 & & & & \\
\hline 1 & 0 & & & & \\
\hline 1 & 0 & & & & \\
\hline 1 & 0 & & & & \\
\hline 1 & 0 & & & & \\
\hline 1 & 0 & & & & \\
\hline 1 & 0 & & & & \\
\hline 1 & 0 & & & & \\
\hline 1 & 0 & & & & 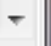 \\
\hline \multicolumn{6}{|c|}{1} \\
\hline put of 159 Select & & tions - & & & \\
\hline
\end{tabular}

Figure 5.11 Reclassified Polygon to SLAMM Code 1 (Developed Dry Land)

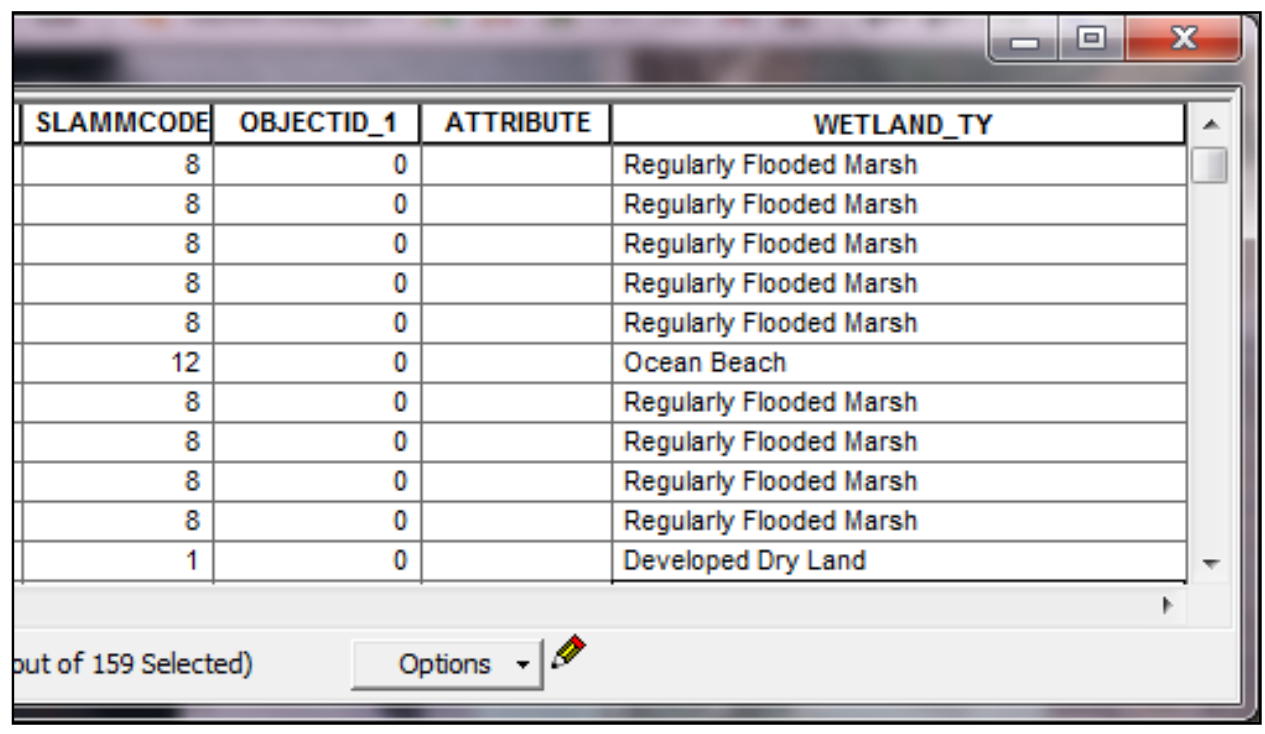

Figure 5.12 Further SLAMM Code Classification 
The next step was to examine the rest of the table to ensure each polygon was properly classified. A number of polygons were misclassified as SLAMM code 0 (Figure 5.13). These polygons were assigned a value of 0 because the attribute codes from the NWI dataset did not match the NWI attribute codes in the SLAMM code table. To correct this, the polygons were manually reclassified by matching the Wetland_TY description with the NWI classification table from the SLAMM Technical Documentation to assign the correct SLAMM code (Figure 5.14).

\begin{tabular}{|r|r|l|l|}
\hline \multicolumn{5}{|c|}{} \\
\hline \hline \multicolumn{5}{|c|}{ SLAMMCODE } & OBJECTID_1 & ATTRIBUTE & \\
\hline 0 & 0 & E2SBM & Estuarine and Marine Wetland \\
\hline 0 & 0 & E2SBM & Estuarine and Marine Wetland \\
\hline 0 & 0 & E2SBM & Estuarine and Marine Wetland \\
\hline 0 & 0 & E2SBM & Estuarine and Marine Wetland \\
\hline 0 & 0 & E2SBM & Estuarine and Marine Wetland \\
\hline 0 & 0 & E2SBM & Estuarine and Marine Wetland \\
\hline 0 & 0 & E2SBM & Estuarine and Marine Wetland \\
\hline 0 & 0 & E2SBM & Estuarine and Marine Wetland \\
\hline 0 & 0 & E2US/EMP & Estuarine and Marine Wetland \\
\hline 0 & 0 & E2US/EMP & Estuarine and Marine Wetland \\
\hline 0 & 0 & PEM/SSR & Freshwater Emergent Wetland \\
\hline 0 & 0 & PEM/USAX & Freshwater Emergent Wetland \\
\hline 0 & 0 & PEMA & Freshwater Emergent Wetland \\
\hline 0 & 0 & PEMAx & Freshwater Emergent Wetland \\
\hline 0 & 0 & PEMC & Freshwater Emergent Wetland \\
\hline 0 & 0 & PEMC & Freshwater Emergent Wetland \\
\hline 0 & 0 & PEMCX & Freshwater Emergent Wetland \\
\hline 0 & 0 & PEMCX & Freshwater Emergent Wetland \\
\hline 0 & 0 & PFO/EMA & Freshwater Forested/Shrub Wetland \\
\hline 0 & 0 & PFOA & Freshwater Forested/Shrub Wetland \\
\hline
\end{tabular}

Figure 5.13 SLAMM Code Misclassification 


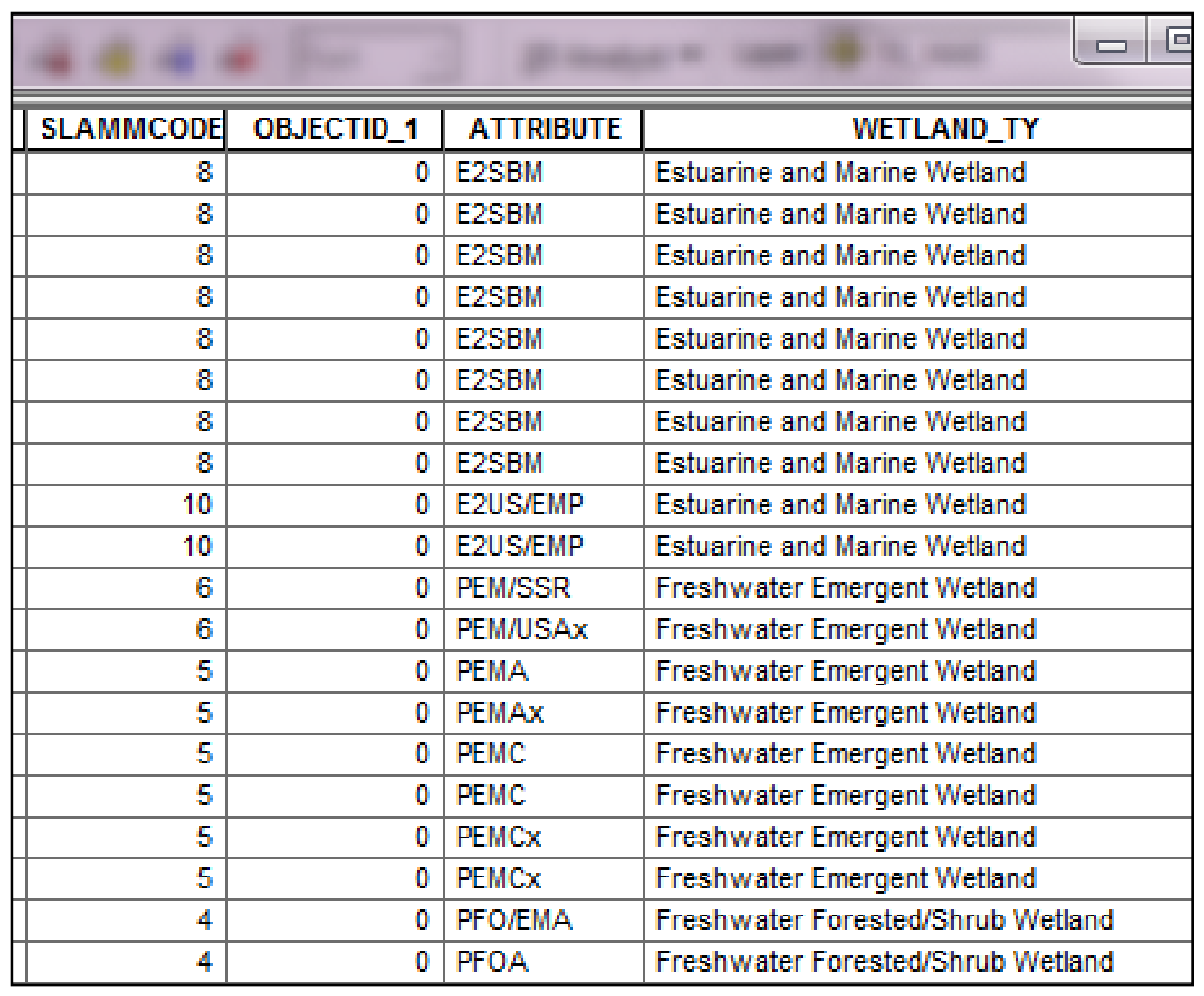

\section{Figure 5.14 Corrected Classification}

To ensure that all polygons were classified correctly, the NWI polygon layer was compared with an aerial photo of the area. Figure 5.15 illustrates that some areas within the polygon classified as Developed Dry Land were in fact part of the estuary. 


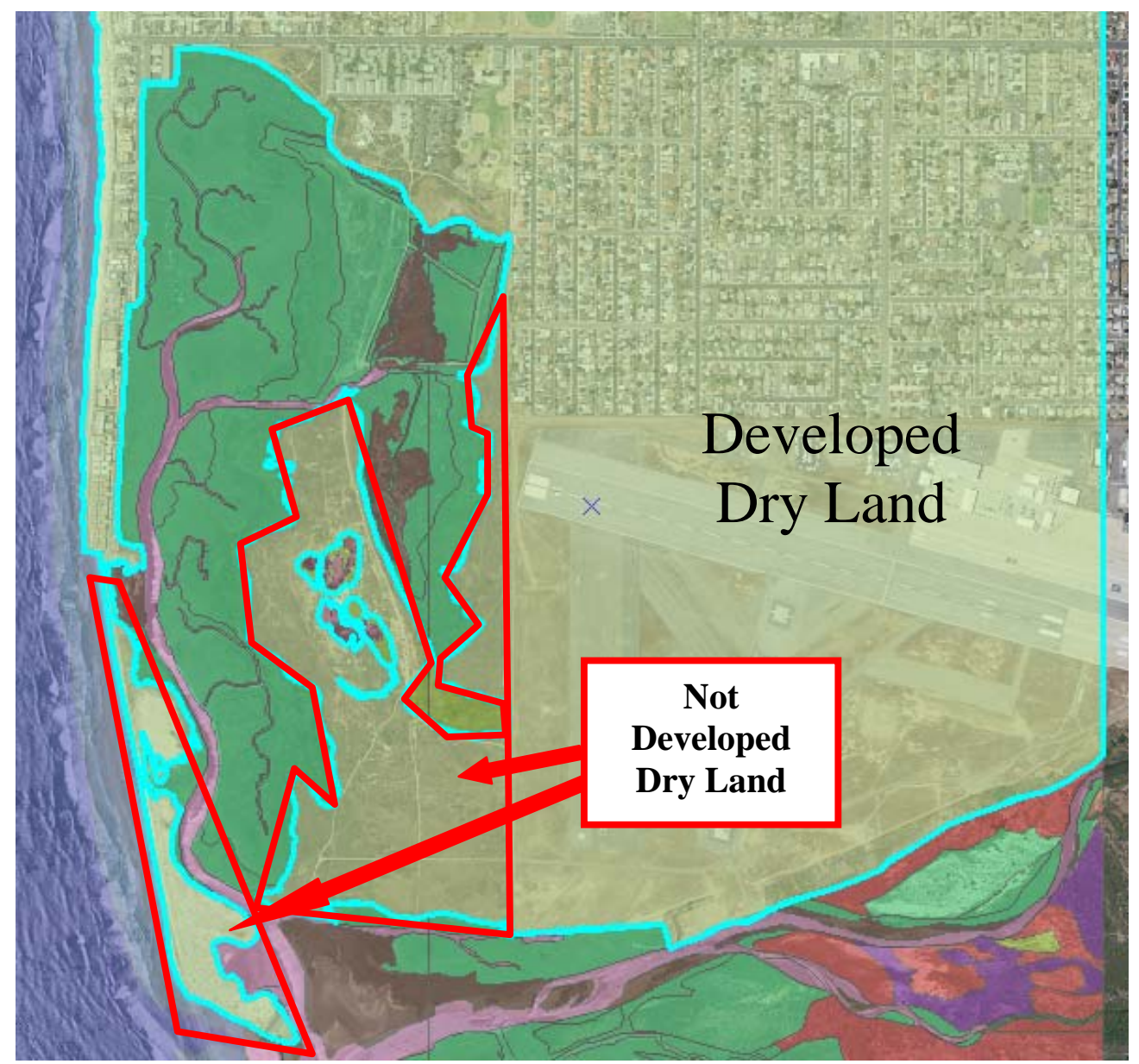

Figure 5.15 Misclassification of Developed Dry Land

To separate the areas that are not Developed Dry Land, the Cut Polygon Features in the Editor tool was used to separate the polygons and the correct SLAMM code was assigned to each polygon, as shown in Figures 5.16 and 5.17. 


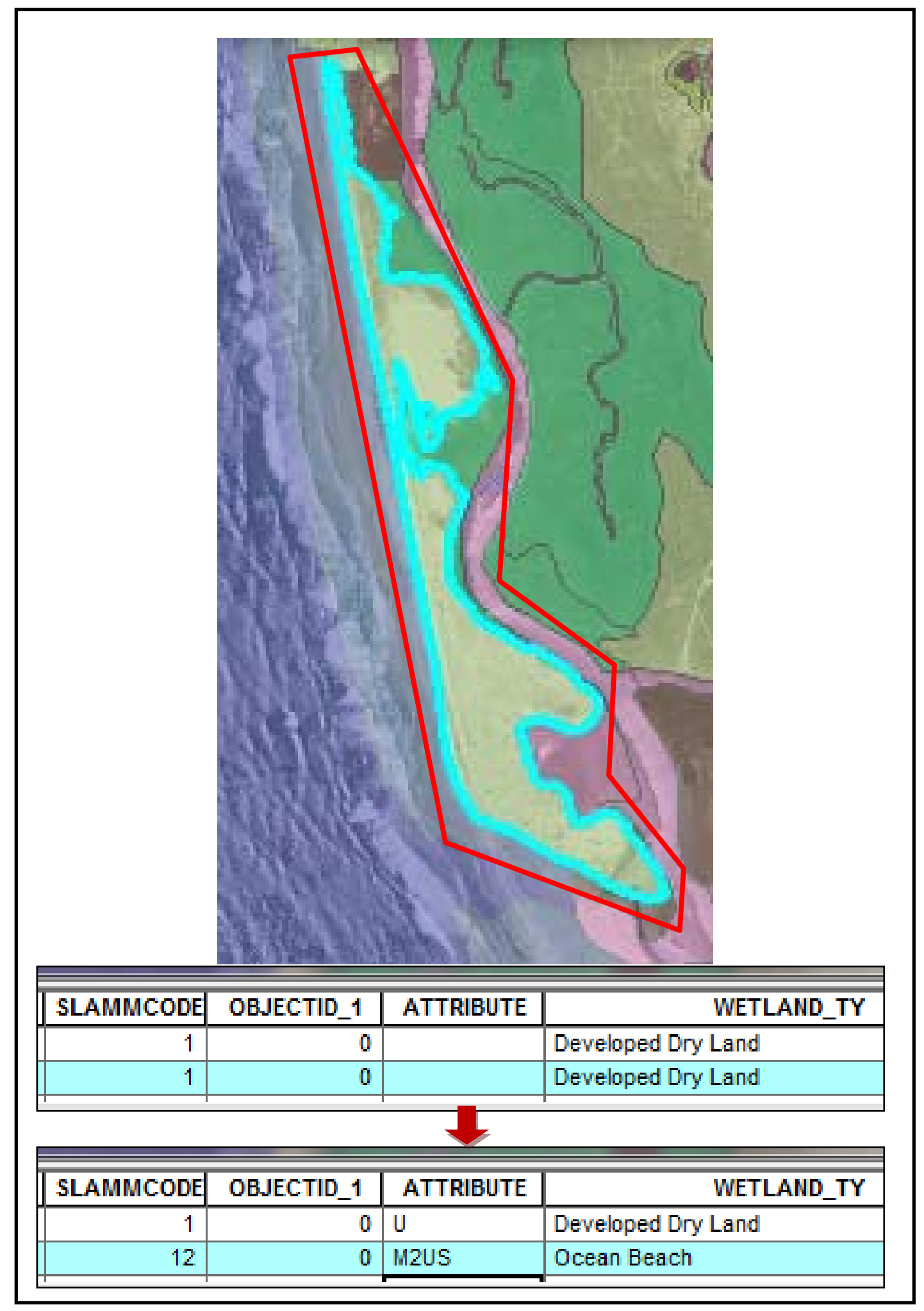

Figure 5.16 One Polygon Reclassified as Ocean Beach 


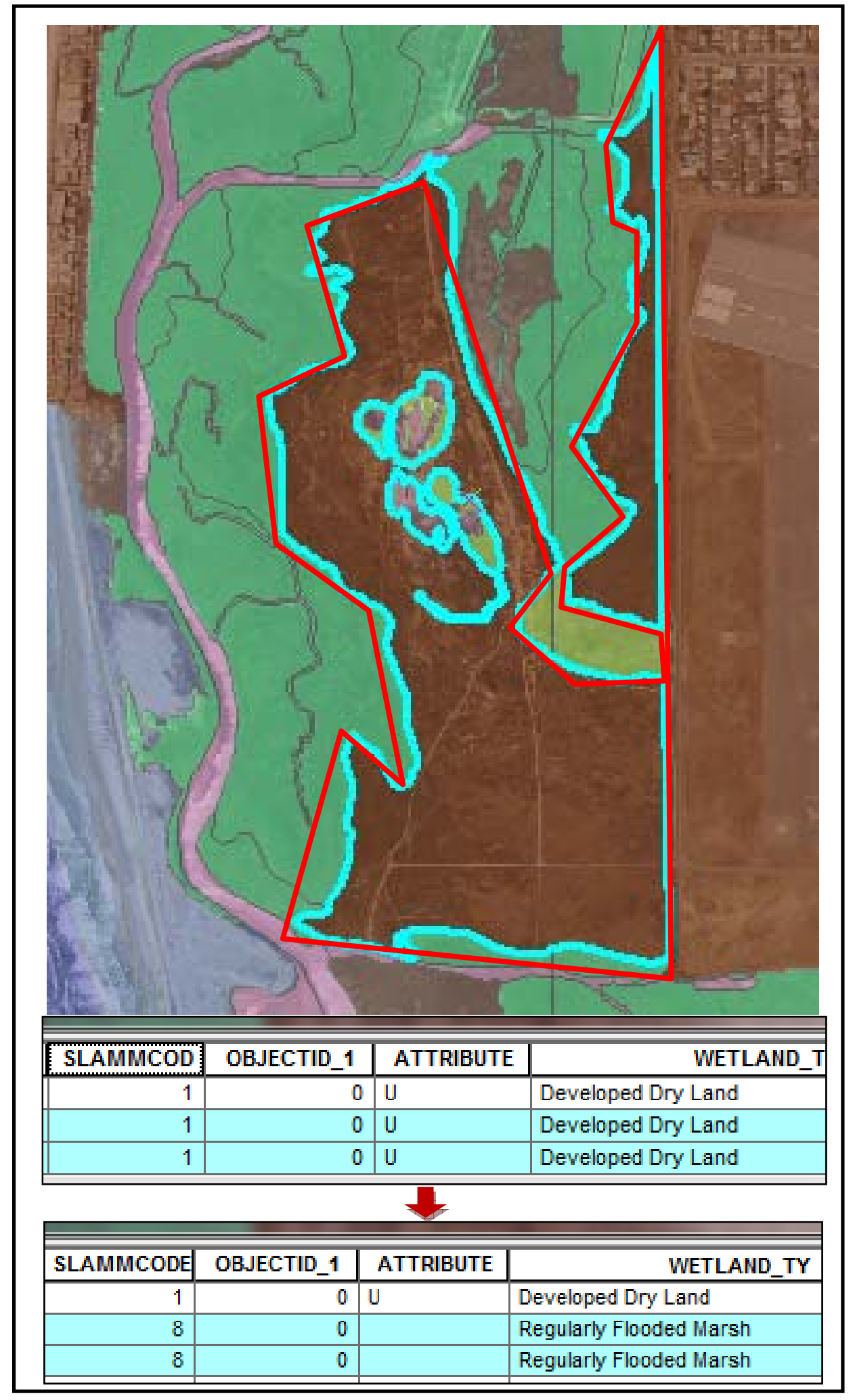

Figure 5.17 Two Polygons Reclassified as Regularly Flooded Marsh 
Once the classification process was complete, the Polygon to Raster tool was used to convert the NWI polygon to a raster dataset with the cell size set to 5 meters. The extent was set to match the DEM dataset in the Environment Settings, as shown in Figure 5.18. Finally, the Raster to ASCII tool was used to create the ASCII dataset for SLAMM input.

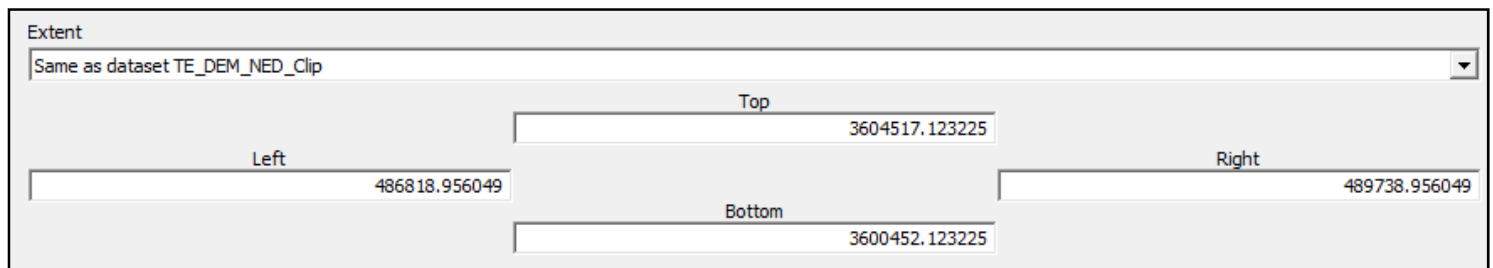

Figure 5.18 Set Extent in Environment Settings

When the NWI dataset is classified correctly, the SLAMM simulation models produce a table in a .csv file format with twenty-six SLAMM categories for each sea level scenario and specified year. It also provides the predicted number of hectares that can be used to calculate the predicted loss/gain of acreage for each SLAMM category.

\subsubsection{SLAMM Application}

This section discusses the process for running the SLAMM application after the GIS models produced the required ASCII files. It contains three sections including file setup, parameter setup, and execution setup.

\subsubsection{File Setup}

To run the SLAMM application, the first step is to input four ASCII files created by the GIS models - dem.txt, nwi.txt, slope.txt, and dike.txt (optional) - as shown in Figure 5.19. After the data were selected, the Re-check Files' Validity button is selected to verify that all four data have the same number of rows and columns. If not, SLAMM will not run and it will produce a "range check error" message. Once the data are verified, an output file name is specified. The Track All Cells option and the Count button were selected to verify that memory utilization is less than the system's limit, which is $2 \mathrm{~GB}$. 


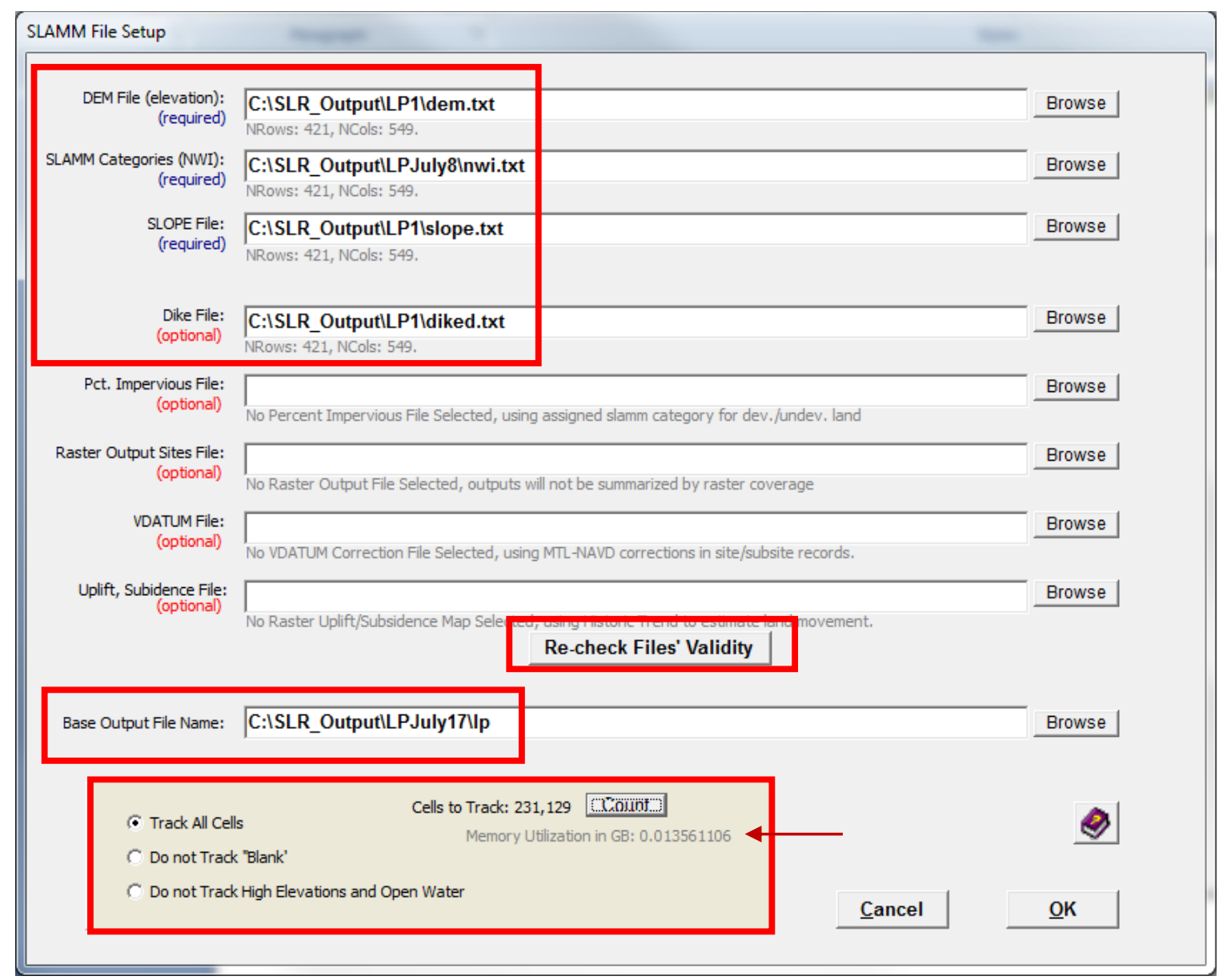

Figure 5.19 SLAMM File Setup

\subsubsection{Parameter Setup}

In order for SLAMM to run properly, the parameters have to be specified with the dates and values listed below, as shown in Figure 5.20:

- NWI Photo Date: 2009

- DEM Date: 2005

- Direction Offshore: West

- Historic Trend (millimeters/year): 1.778 (from IPCC report)

- $\quad$ Mean Tidal Level (MTL) - NAVD88 (m):

o Los Peñasquitos Lagoon

$3.170 \mathrm{~m}-1.389 \mathrm{~m}=1.781 \mathrm{~m}$ (from NOAA Tidal and Currents Datum

Report shown in Figure 5.21)

o Tijuana Estuary

$1.7 \mathrm{~m}-.93 \mathrm{~m}=0.77 \mathrm{~m}$ (from NOAA Tidal and Currents Datum

Report shown in Figure 5.22)

- $\quad$ GT Great Diurnal Tide Range (m):

o Los Peñasquitos Lagoon 
1.624 m (from NOAA Tidal and Currents Datum Report shown in Figure 5.21)

o Tijuana Estuary

1.637 m (from NOAA Tidal and Currents Datum Report shown in Figure 5.22)

For better results, it is best to fill in the rest of the parameters as shown in Figure 5.20.

\begin{tabular}{|l|l|}
\hline Edit Sites and Subsites \\
\begin{tabular}{|l|l|}
\hline Parameter & Global \\
\hline Description & LP \\
\hline NWI Photo Date (YrrY) & 2009 \\
\hline DEM Date (YrrY) & 2005 \\
\hline Direction Offshore [n,s,e,w] & West \\
\hline Historic Trend (mm/yr) & 1.778 \\
\hline MTL-NAVD88 (m) & 0.781 \\
\hline GT Great Diurnal Tide Range (m) & 1.624 \\
\hline Salt Elev. (m above MTL) & 0 \\
\hline Marsh Erosion (horz. m /yr) & 0 \\
\hline Swamp Erosion (horz. m /yr) & 0 \\
\hline T.Flat Erosion (horz. m /yr) & 0 \\
\hline Reg. Flood Marsh Accr (mm/yr) & 0 \\
\hline Irreg. Flood Marsh Accr (mm/yr) & 0 \\
\hline Tidal Fresh Marsh Accr (mm/yr) & 0 \\
\hline Beach Sed. Rate (mm/yr) & 0 \\
\hline Freq. Overwash (years) & False \\
\hline Use Elev Pre-processor [True,False] & 0 \\
\hline
\end{tabular}
\end{tabular}

Figure 5.20 SLAMM Parameter Setup for Sites and Subsites 


\section{Data Units:}

- Feet - Meters

Apply Change

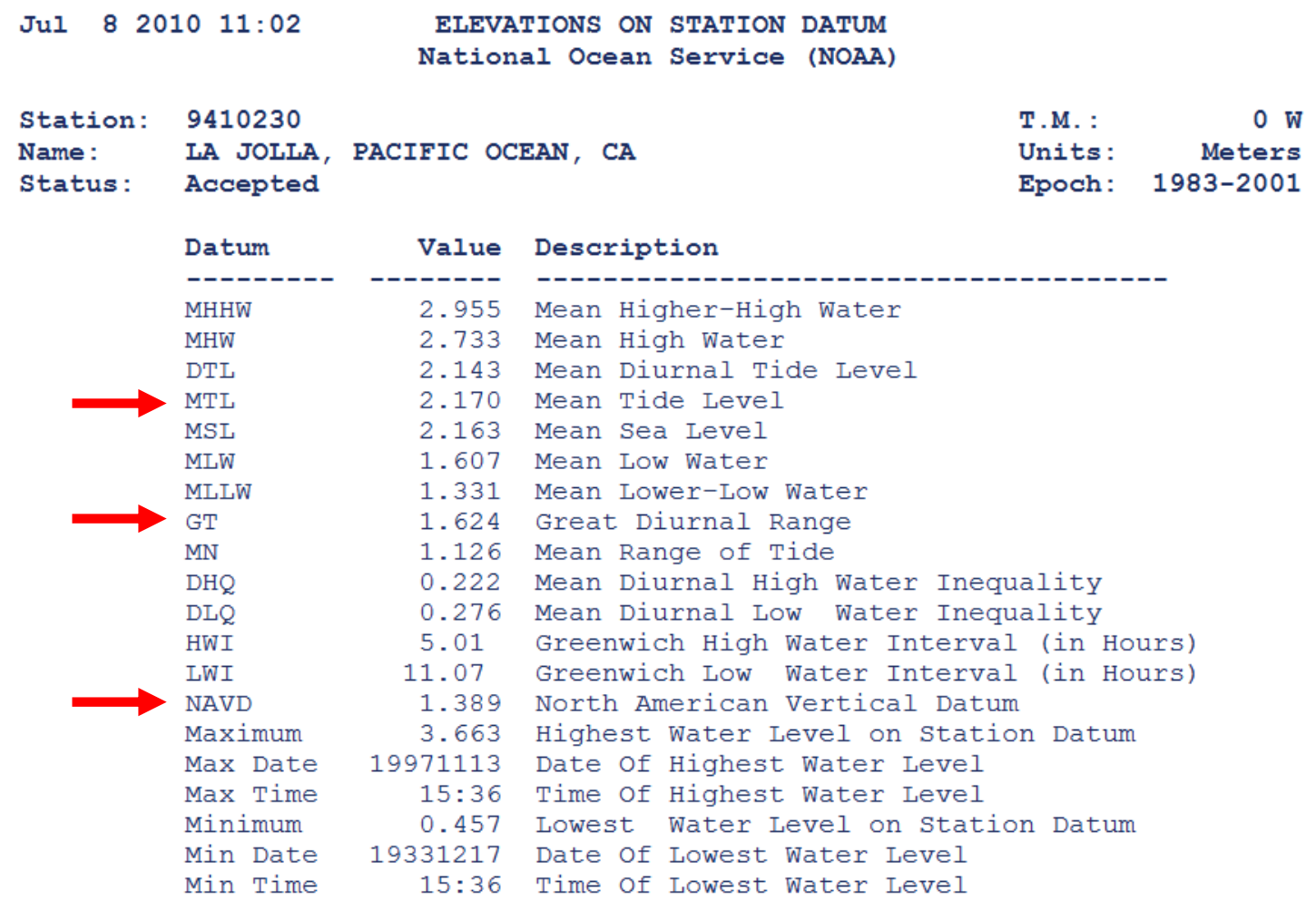

Figure 5.21 NOAA Tidal and Currents Report for La Jolla, CA Station (NOAA, 2001a) 


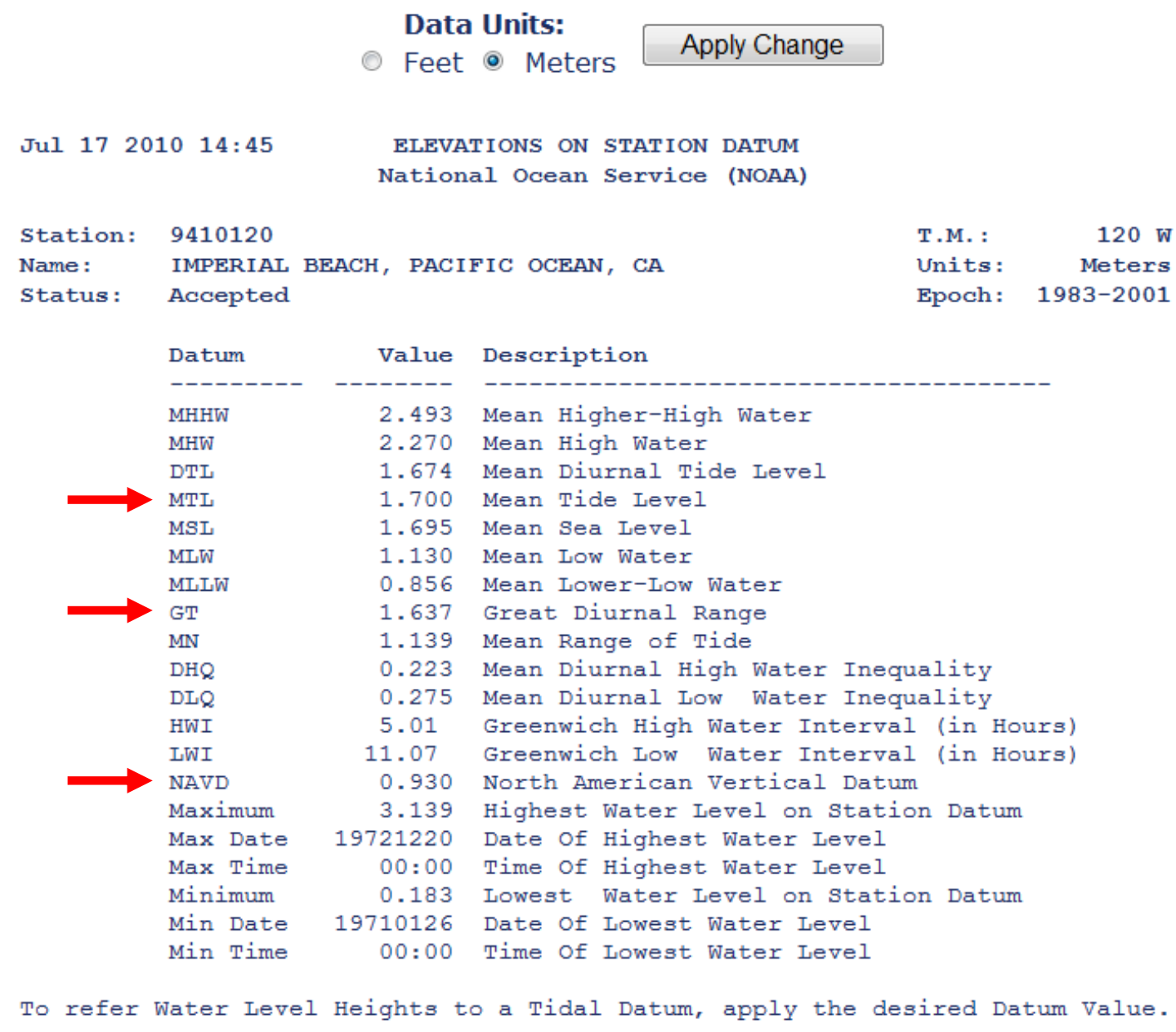

Figure 5.22 NOAA Tidal and Currents Report for Imperial Beach, CA Station (NOAA, 2001b)

\subsubsection{Execution Setup}

The execution setup in the SLAMM application allows the user to specify which simulations method the model should run in terms of sea level rise (SLR) scenarios, protection scenarios, year of simulation, and maps and outputs, as shown in Figure 5.23. 


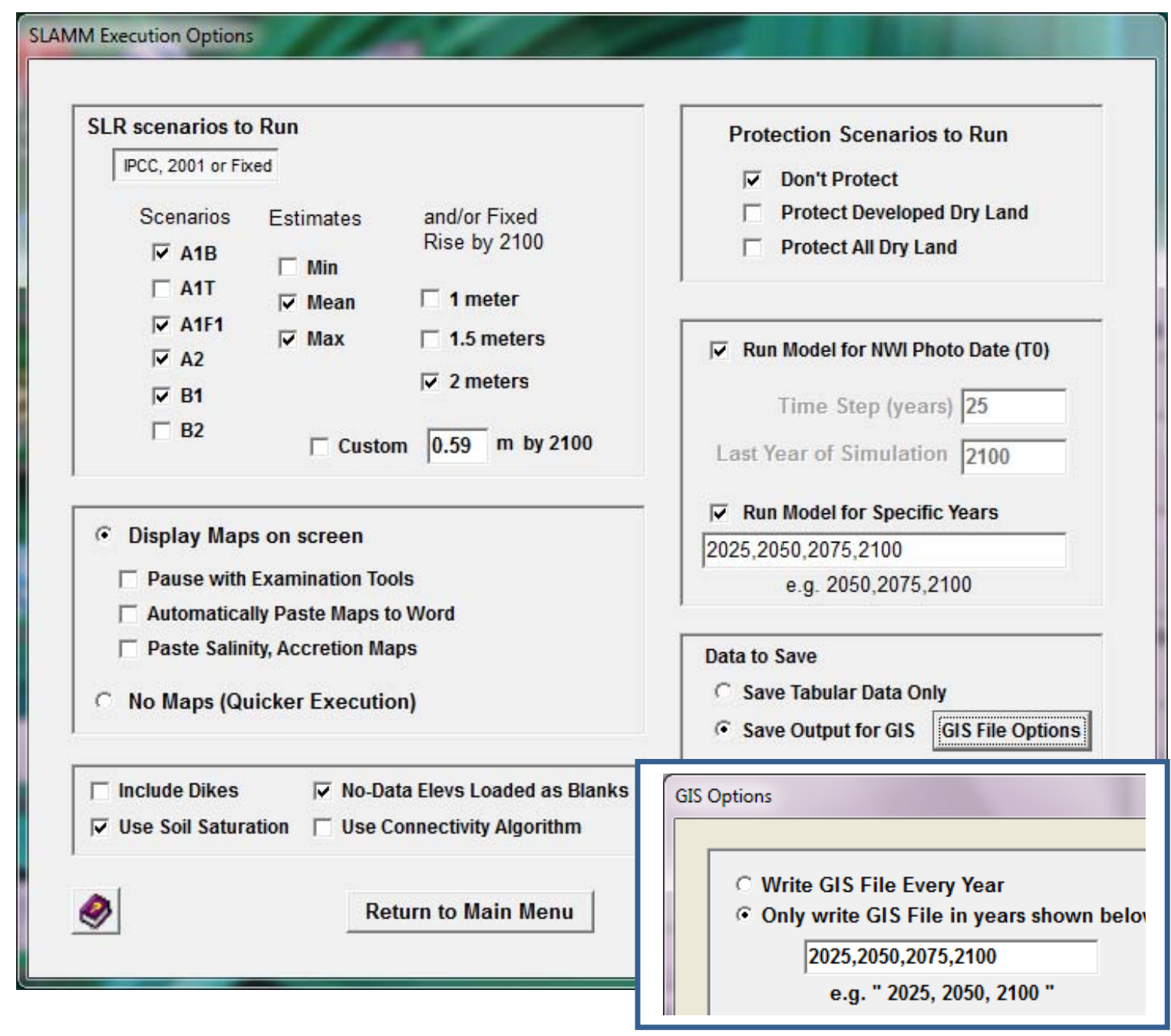

\section{Figure 5.23 SLAMM Execution Setup}

For this project, the client selected five different sea level rise scenarios, including mean and max estimates of the A1B, A1FI, A2, and B1 scenarios, as well as the 2-meter scenario. The sea level rise scenarios are based on the 2000 IPCC Special Reports of Emissions Scenarios (SRES) (Clough, 2010). The SRES contains various sources driven by climate change that are influenced by future population, economy, technology, energy, land use, and agriculture. Table 3 summarizes the sea level rise scenarios used for this project. 
Table 3. IPCC SRES (Topfer, 2000)

\begin{tabular}{|l|l|}
\hline SRES & Description \\
\hline A1 storyline & $\begin{array}{l}\text { The A1 storyline and scenario family describes a future world of } \\
\text { very rapid economic growth, global population that peaks in mid- } \\
\text { century and declines thereafter, and the rapid introduction of new } \\
\text { and more efficient technologies. Major underlying themes are } \\
\text { convergence among regions, capacity building, and increased } \\
\text { cultural and social interactions, with a substantial reduction in } \\
\text { regional differences in per capita income. The A1 scenario family } \\
\text { develops into three groups that describe alternative directions of } \\
\text { technological change in the energy system. The three A1 groups } \\
\text { are distinguished by their technological emphasis: fossil intensive } \\
\text { (A1FI), non-fossil energy sources (A1T), or a balance across all } \\
\text { sources (A1B). }\end{array}$ \\
\hline A2 storyline & $\begin{array}{l}\text { The A2 storyline and scenario family describes a very } \\
\text { heterogeneous world. The underlying theme is self-reliance and } \\
\text { preservation of local identities. Fertility patterns across regions } \\
\text { converge very slowly, which results in continuously increasing } \\
\text { global population. Economic development is primarily regionally } \\
\text { oriented and per capita economic growth and technological } \\
\text { change are more fragmented and slower than in other storylines. }\end{array}$ \\
\hline B1 storyline & $\begin{array}{l}\text { The B1 storyline and scenario family describes a convergent } \\
\text { world with the same global population that peaks in midcentury } \\
\text { and declines thereafter, as in the A1 storyline, but with rapid } \\
\text { changes in economic structures toward a service and information } \\
\text { economy, with reductions in material intensity, and the } \\
\text { introduction of clean and resource-efficient technologies. The } \\
\text { emphasis is on global solutions to economic, social, and } \\
\text { environmental sustainability, including improved equity, but } \\
\text { without additional climate initiatives. }\end{array}$ \\
\hline
\end{tabular}

The execution setup in SLAMM was also configured with other parameters. In the Protection scenarios selection box, “don't protect” was selected. This option allows the user to protect developed dry land. Since the purpose of this project was to model wetlands, the client was not concerned with protecting developed dry land. NWI photo date was selected because the application needs to know the date of the start of the simulation. The model was run with specific years 2025, 2050, 2075, and 2100. The output data were saved as output for GIS for the years 2025, 2050, 2075, and 2100. 


\subsection{SLAMM Exchange Format to Feature Class Model}

The SLAMM Exchange Format to Feature Class model was used to process ASCII outputs from the SLAMM application, as shown in Figure 5.24. First, the model converts the ASCII file to raster. Second, the model defines the projection of the raster dataset to NAD83 UTM Zone 11N in meters.

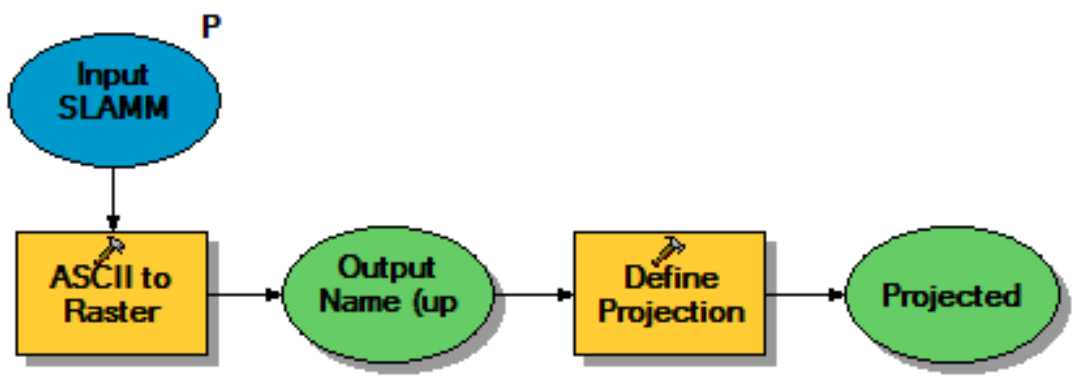

\section{Figure 5.24 SLAMM Exchange Format to ArcMap Raster}

\subsection{Summary}

This chapter provides detailed discussions of the various methods used for the implementation of this project. It contains five major sections, including the methods used for acquiring data, the tools used for building the three GIS models, the steps and parameters required to run the SLAMM application, and methods to retrieve the SLAMM exchange data into ArcGIS for analysis. 


\section{Chapter 6 - Results and Analysis}

This chapter discusses the GIS tools developed to process the data for the SLAMM inputs, the results and analyses for the Los Peñasquitos Lagoon and the Tijuana Estuary, the differences in the sea level rise scenarios, and the differences between the study sites. It concludes with challenges experienced during the project and a summary.

\subsection{GIS Tools}

Three models were built using ArcMap ModelBuilder to prepare data for the SLAMM inputs and to retrieve the SLAMM exchange format file. The DEM and Slope Model can process any elevation raster dataset as long as the resolution is no finer than 5 meters. However, since the model was developed using standard ArcMap tools, the client could set the model to define other resolutions.

The NWI Model was designed to produce the NWI and dike ASCII format files as SLAMM inputs. It also produces the NWI merged feature class for further SLAMM code classification. When the NWI merged feature class is manually classified, the user must manually convert the feature class to a raster and then into the ASCII format. Using this method the SLAMM simulation process will automatically produce a .csv file that contains the predicted hectares for each SLAMM category for each sea level rise scenario and year selected, as shown in Table 4. These data can be utilized to calculate the predicted loss and gain for each category. 


\begin{tabular}{|c|c|c|c|c|c|c|c|c|}
\hline Site Desc. & Scenario & Parameters & Year & Protectior & SLAMMCode & Hectares & SLAMMText & SLR (eustatic) \\
\hline LP & Fixed & 2 meter & 2100 & Protect $\mathrm{N}$ & 1 & 309.7179 & Developed Dry Land & 1.7997 \\
\hline LP & Fixed & 2 meter & 2100 & Protect $\mathrm{N}$ & 2 & 0 & Undeveloped Dry Land & 1.7997 \\
\hline LP & Fixed & 2 meter & 2100 & Protect $\mathrm{N}$ & 3 & 60.2202 & Swamp & 1.7997 \\
\hline LP & Fixed & 2 meter & 2100 & Protect $\mathrm{N}$ & 4 & 0 & Cypress Swamp & 1.7997 \\
\hline LP & Fixed & 2 meter & 2100 & Protect $\mathrm{N}$ & 5 & 0 & Inland Fresh Marsh & 1.7997 \\
\hline LP & Fixed & 2 meter & 2100 & Protect $\mathrm{N}$ & 6 & 6.0178 & Tidal Fresh Marsh & 1.7997 \\
\hline LP & Fixed & 2 meter & 2100 & Protect $\mathrm{N}$ & 7 & 3.6726 & Trans. Salt Marsh & 1.7997 \\
\hline LP & Fixed & 2 meter & 2100 & Protect $\mathrm{N}$ & 8 & 4.5266 & Regularly Flooded Marsh & 1.7997 \\
\hline LP & Fixed & 2 meter & 2100 & Protect $N$ & 9 & 0 & Mangrove & 1.7997 \\
\hline LP & Fixed & 2 meter & 2100 & Protect $\mathrm{N}$ & 10 & 2.1732 & Estuarine Beach & 1.7997 \\
\hline LP & Fixed & 2 meter & 2100 & Protect $\mathrm{N}$ & 11 & 21.9175 & Tidal Flat & 1.7997 \\
\hline LP & Fixed & 2 meter & 2100 & Protect $\mathrm{N}$ & 12 & 0.0664 & Ocean Beach & 1.7997 \\
\hline LP & Fixed & 2 meter & 2100 & Protect $\mathrm{N}$ & 13 & 0 & Ocean Flat & 1.7997 \\
\hline LP & Fixed & 2 meter & 2100 & Protect $\mathrm{N}$ & 14 & 0.0265 & Rocky Intertidal & 1.7997 \\
\hline LP & Fixed & 2 meter & 2100 & Protect $\mathrm{N}$ & 15 & 0 & Inland Open Water & 1.7997 \\
\hline LP & Fixed & 2 meter & 2100 & Protect $\mathrm{N}$ & 16 & 0 & Riverine Tidal & 1.7997 \\
\hline LP & Fixed & 2 meter & 2100 & Protect $\mathrm{N}$ & 17 & 70.276 & Estuarìne Open Water & 1.7997 \\
\hline LP & Fixed & 2 meter & 2100 & Protect $\mathrm{N}$ & 18 & 0 & Tidal Creek & 1.7997 \\
\hline LP & Fixed & 2 meter & 2100 & Protect $\mathrm{N}$ & 19 & 71.5541 & Open Ocean & 1.7997 \\
\hline LP & Fixed & 2 meter & 2100 & Protect $\mathrm{N}$ & 20 & 22.6253 & Irreg. Flooded Marsh & 1.7997 \\
\hline LP & Fixed & 2 meter & 2100 & Protect $\mathrm{N}$ & 21 & 0 & Not Used & 1.7997 \\
\hline LP & Fixed & 2 meter & 2100 & Protect $\mathrm{N}$ & 22 & 0.1882 & Inland Shore & 1.7997 \\
\hline LP & Fixed & 2 meter & 2100 & Protect $\mathrm{N}$ & 23 & 0 & Tidal Swamp & 1.7997 \\
\hline LP & Fixed & 2 meter & 2100 & Protect $\mathrm{N}$ & 24 & 4.84 & Blank & 1.7997 \\
\hline LP & Fixed & 2 meter & 2100 & Protect $\mathrm{N}$ & 25 & 0 & Vegetated Tìdal Flat & 1.7997 \\
\hline LP & Fixed & 2 meter & 2100 & Protect $\mathrm{N}$ & 26 & 0 & Backshore & 1.7997 \\
\hline
\end{tabular}

Table 4. SLAMM CSV Output Viewed in Excel

If the NWI datasets are not manually re-classified, the analyses are inherently inaccurate due to misclassifications in the NWI data, as shown in Figure 6.1. The pink areas in the map on the left of Figure 6.1 were misclassified as SLAMM code 24 (Blank) or SLAMM code 0, which is not a valid SLAMM code. These two SLAMM codes do not represent actual land types, therefore, the SLAMM simulation process was unable to predict and transform these areas. Figure 6.2 illustrates the results of the simulation run with inaccurate and accurate NWI classifications. The areas in white on the inaccurate map were not included in the simulation. Therefore, this model should only be used for rough estimates. 


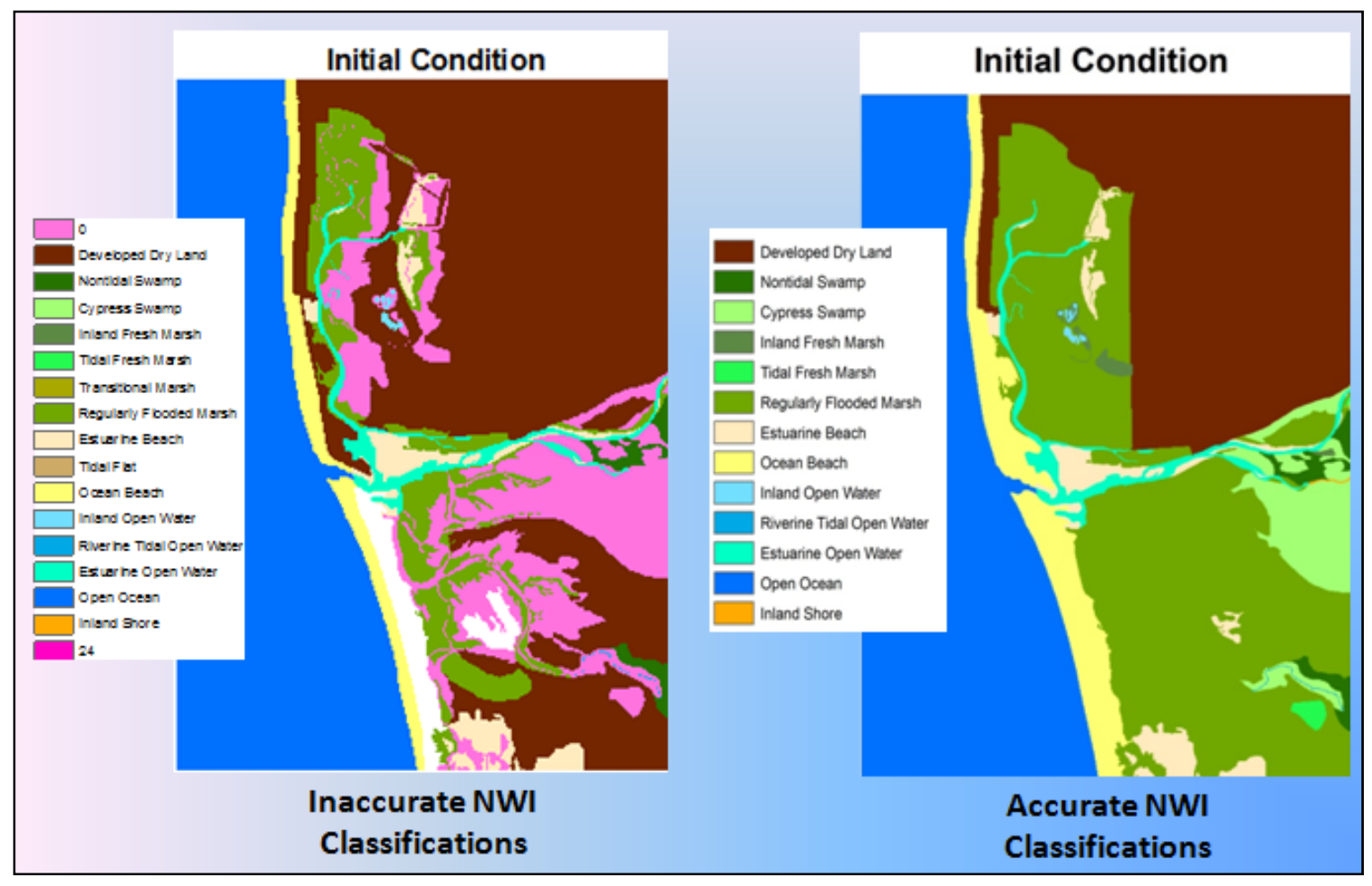

Figure 6.1 Inaccurate vs. Accurate NWI Classifications

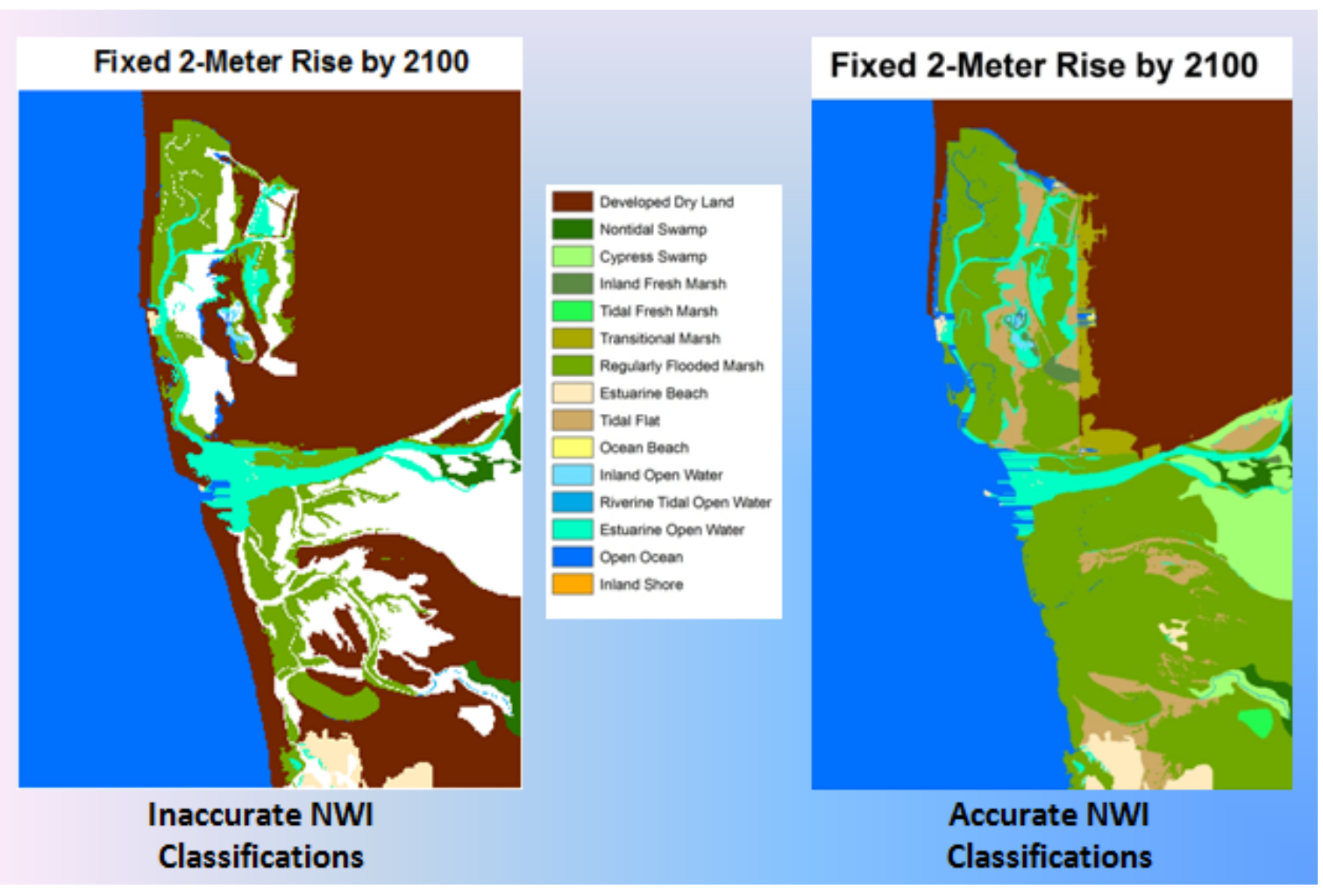

Figure 6.2 2-Meter Rise Accuracy Comparison 
The SLAMM Exchange Format to Raster Model retrieves the SLAMM output data, converts the data to raster, and projects the data to the proper projection. The raster output data could be used to create maps for analysis.

\subsection{Los Peñasquitos Lagoon}

The output from the SLAMM simulations for Los Peñasquitos Lagoon shows twenty-six categories (see Appendix A). Of the twenty-six SLAMM categories, the five sea level rise scenarios - A1FI, A1B, A2, B1, and 2-meter - display changes in eleven categories and no changes in the other fifteen categories. Table 5 summarizes the results of the eleven categories for all five scenarios for the year 2100. The A1FI, A1B, A2, and B1 scenarios display similar changes in all eleven categories, while the 2-meter scenario displays significantly different changes in all categories except Ocean Beach. For example, the Swamp category displays an average 0.75 acre decrease in the four similar scenarios, while the 2-meter scenarios displays a 9.07 acres decrease. All scenarios show complete loss of Ocean Beach.

Table 5. Los Peñasquitos Lagoon Predictions of Acreage Loss/Gain by 2100

\begin{tabular}{|c|c|c|c|c|c|c|c|c|c|c|}
\hline $\begin{array}{l}\text { SLAMM } \\
\text { Code }\end{array}$ & SLAMM Categories & A1B_Mean & A1B_Max & A1FI_Mean & A1FI_Max & A2_Mean & A2_Max & B1_Mean & B1_Max & 2-Meter \\
\hline 1 & Developed Dry Land & -0.56 & -0.80 & -0.64 & -0.78 & -0.57 & -0.82 & -0.44 & -0.80 & -7.67 \\
\hline 3 & Swamp & -0.65 & -0.84 & -0.75 & -0.83 & -0.69 & -0.87 & -0.50 & -0.84 & -9.07 \\
\hline 6 & Tidal Fresh Marsh & -3.78 & -4.13 & -4.13 & -4.13 & -4.13 & -4.14 & -3.28 & -4.13 & -63.86 \\
\hline 7 & Trans. Salt Marsh & 0.08 & 0.04 & 0.10 & 0.01 & 0.15 & 0.07 & 0.19 & 0.04 & 8.86 \\
\hline 8 & Regularly Flooded Marsh & -117.94 & -121.09 & -120.26 & -122.79 & -119.02 & -120.87 & -115.40 & -121.09 & -169.24 \\
\hline 10 & Estuarine Beach & -3.92 & -3.93 & -3.92 & -3.93 & -3.92 & -3.94 & -3.87 & -3.93 & -18.38 \\
\hline 11 & Tidal Flat & 120.01 & 124.31 & 122.64 & 126.09 & 120.91 & 123.96 & 115.10 & 124.31 & 51.02 \\
\hline 12 & Ocean Beach & -14.14 & -14.13 & -14.14 & -14.13 & -14.14 & -14.12 & -14.14 & -14.13 & -13.98 \\
\hline 17 & Estuarine Open Water & 5.76 & 5.92 & 5.79 & 5.87 & 5.78 & 6.04 & 5.78 & 5.92 & 148.70 \\
\hline 19 & Open Ocean & 14.60 & 14.67 & 14.63 & 14.67 & 14.61 & 14.68 & 14.42 & 14.67 & 18.14 \\
\hline 20 & Irreg. Flooded Marsh & 0.54 & 0.00 & 0.68 & -0.04 & 1.03 & 0.01 & 2.15 & 0.00 & 55.82 \\
\hline
\end{tabular}

In the four scenarios, the Regularly Flooded Marsh and Tidal Flat categories display the largest change and appear to have an inverse relationship. As the Regularly Flooded Marsh decreases, the Tidal Flat increases. Figures 6.3 and 6.4 show a comparison of Regular Flooded Marsh and Tidal Flat in twenty-five year increments for all scenarios. Figure 6.3 illustrates a significant decrease in acreage for the Regularly Flooded Marsh beginning in 2050, while Figure 6.4 shows a significant increase in acreage for the Tidal Flat over the same period. These charts coincide with the maps illustrated in Figures 6.5 and 6.6. The map in Figure 6.5 shows the initial condition of the study site, which contains no Tidal Flat category. In contrast, by 2100 most of the Regularly Flooded Marsh area changed to Tidal Flat, as shown in Figure 6.6. 


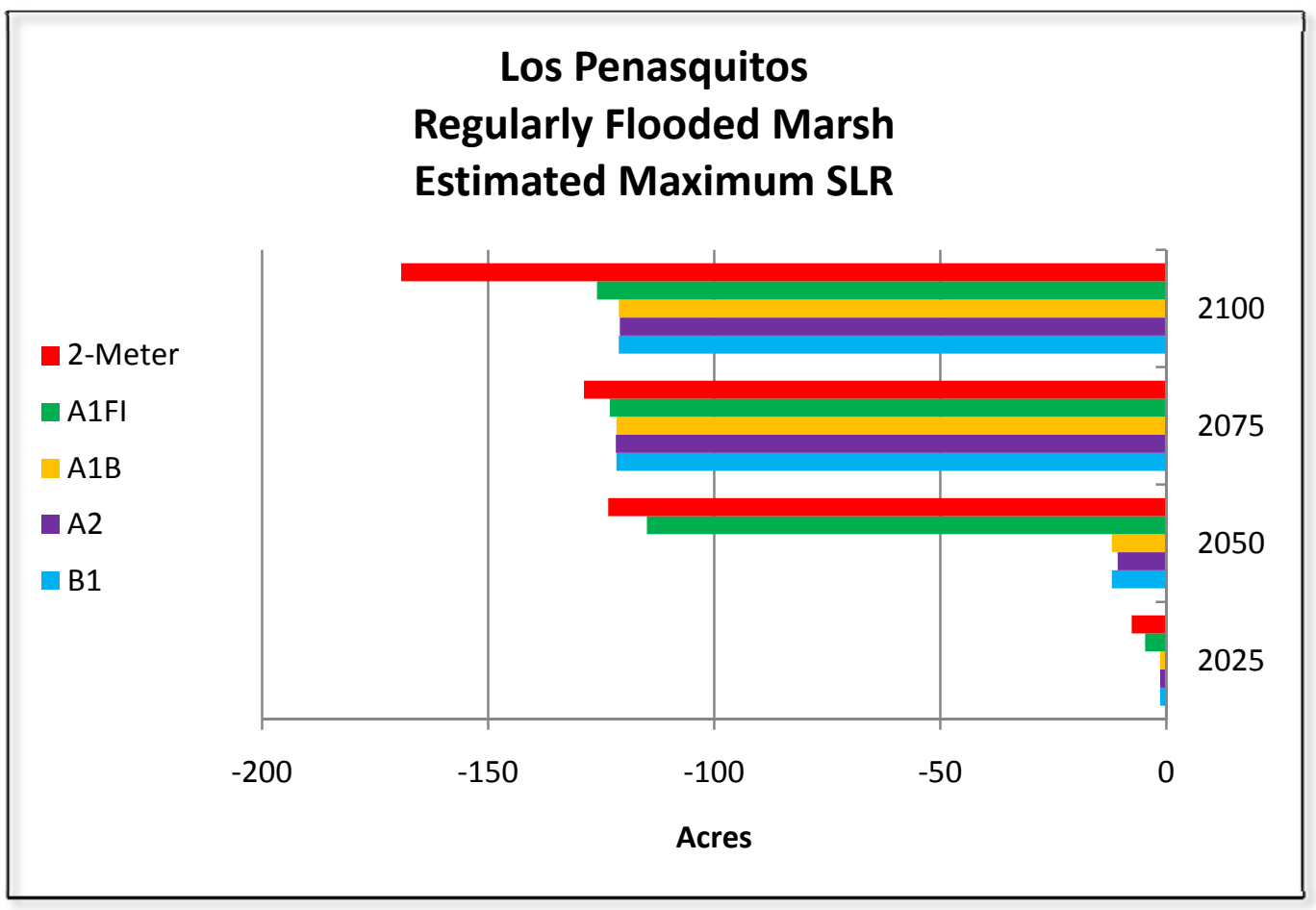

Figure 6.3 Los Peñasquitos Regularly Flooded Marsh for all SLR scenarios

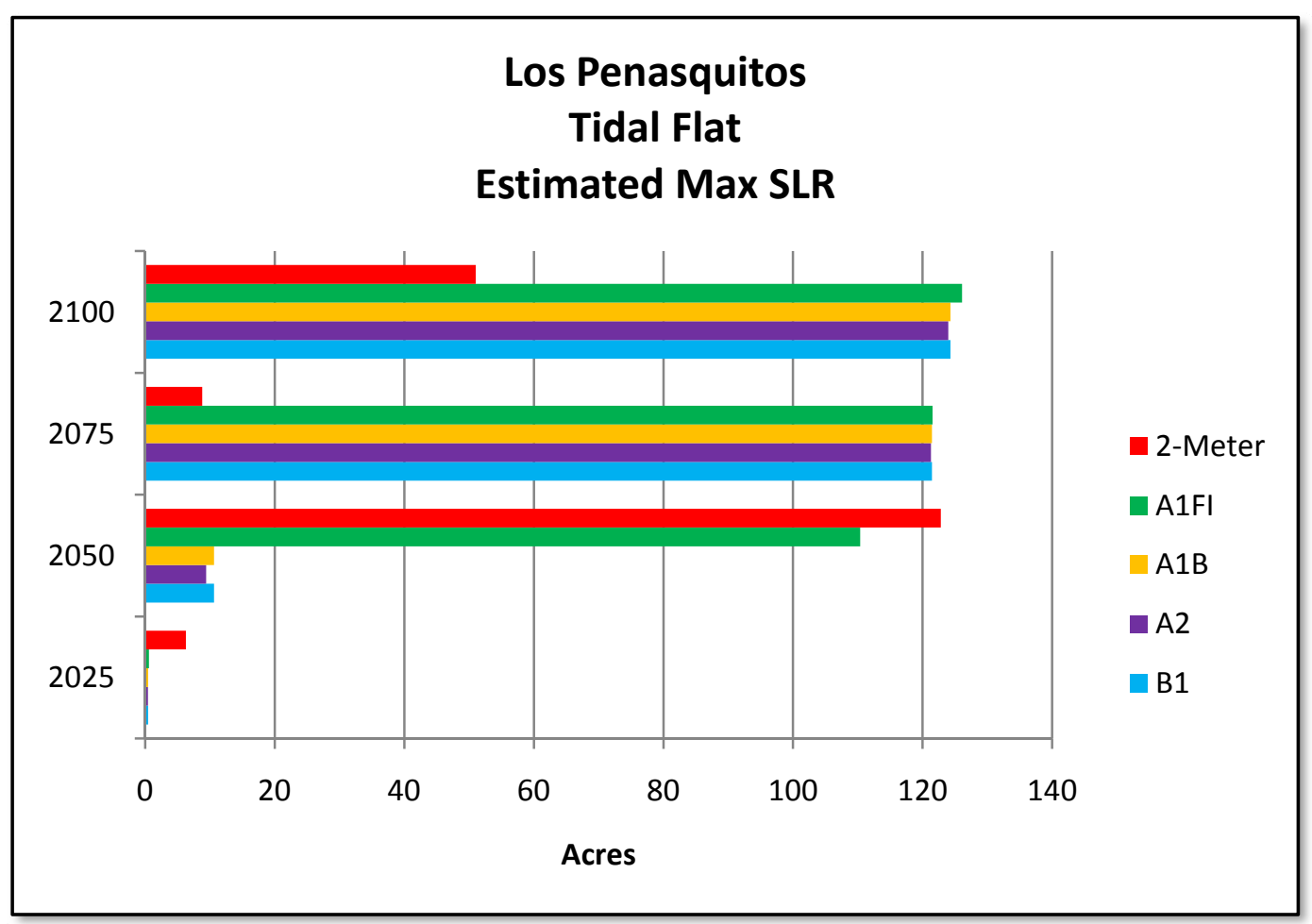

Figure 6.4 Los Peñasquitos Tidal Flat for all SLR scenarios 
Initial Condition

Developed Dry Land

Nontidal Swamp

Tidal Fresh Marsh

Regularly Flooded Marsh

Estuarine Beach

Ocean Beach

Rocky Intertidal

Estuarine Open Water

Open Ocean

Inland Shore

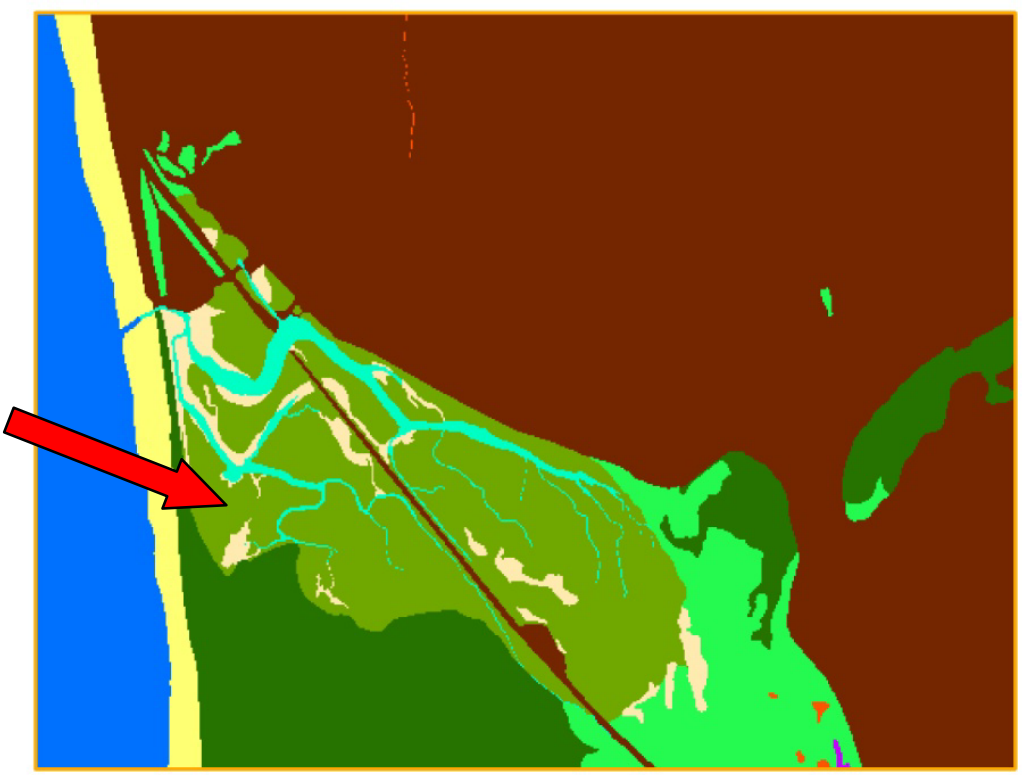

Figure 6.5 Los Peñasquitos Initial Condition

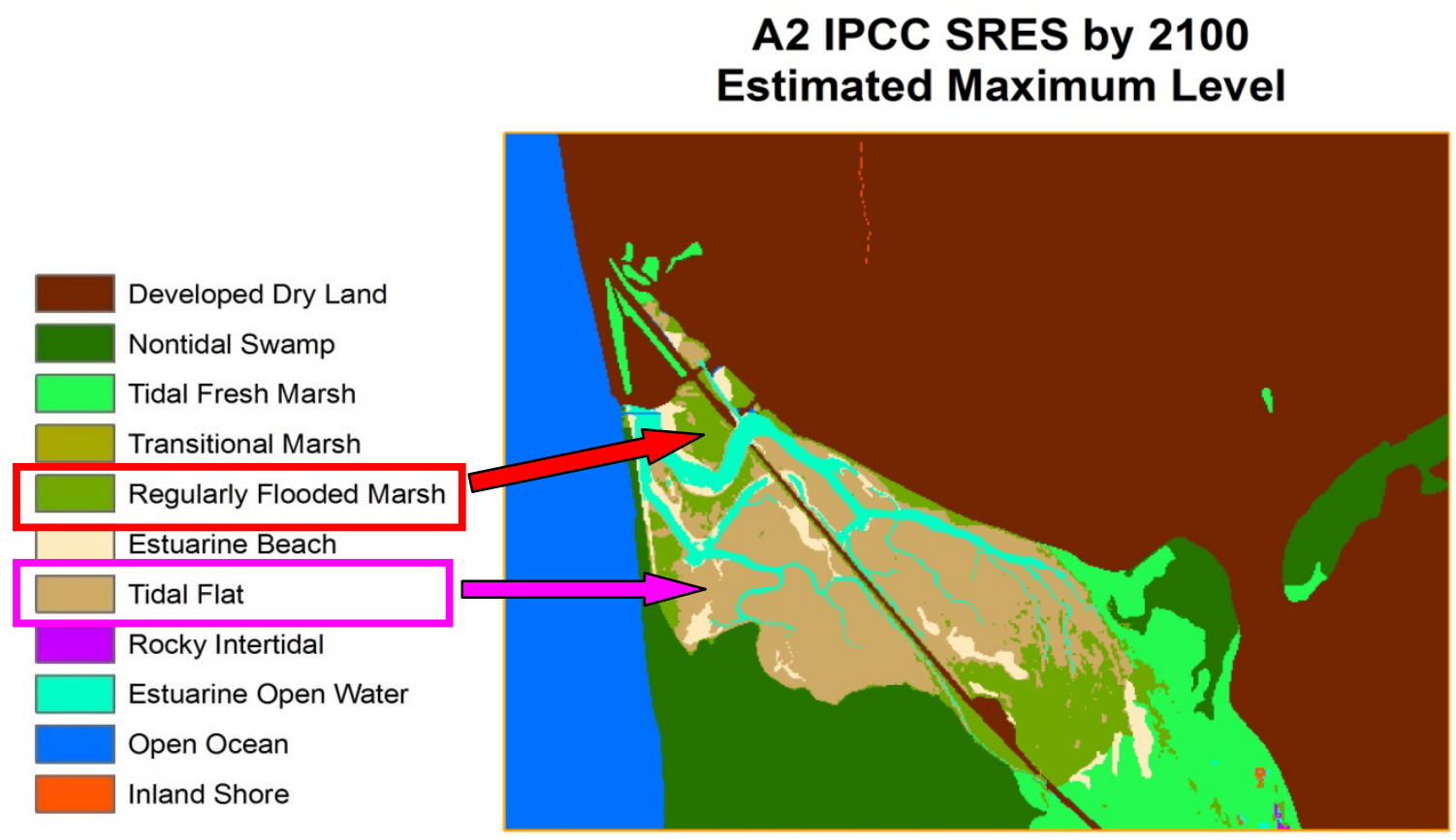

Figure 6.6 Los Peñasquitos A2 Scenario by 2100

The 2-meter scenario displays a larger decrease in Regularly Flooded Marsh, but a smaller increase in Tidal Flat. Much of this difference is due to a large increase in 
Estuarine Open Water, as shown in Figure 6.7. Additionally, the Tidal Fresh Marsh transforms into Transitional Marsh and Irregularly Flooded Marsh.

Fixed 2-Meter Rise by 2100
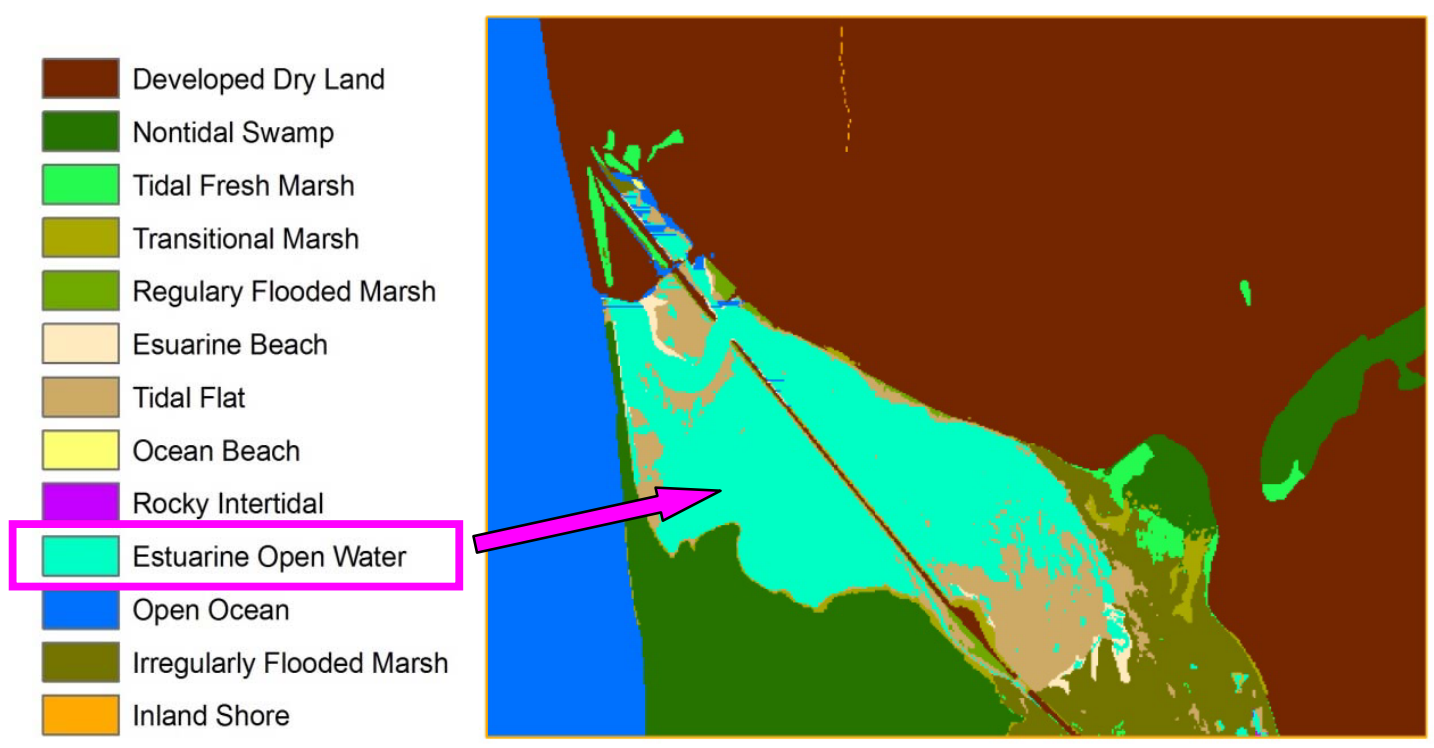

Figure 6.7 Los Peñasquitos 2-Meter Rise Scenario by 2100

\subsection{Tijuana Estuary}

The output from the SLAMM simulations for the Tijuana Estuary shows a similar pattern as the Los Peñasquitos Lagoon (see Appendix B). Of the twenty-six SLAMM categories, the five scenarios display similar changes in nine categories, and no changes in the other 17. Table 6 summarizes the results of the nine categories for all five scenarios for 2100 .

Table 6. Tijuana Estuary Predictions of Acreage Loss/Gain by 2100

\begin{tabular}{|c|l|r|r|r|r|r|r|r|r|r|}
\hline $\begin{array}{c}\text { SLAMM } \\
\text { Code }\end{array}$ & \multicolumn{1}{|c|}{ SLAMM Categories } & $\begin{array}{c}\text { A1B } \\
\text { Mean }\end{array}$ & $\begin{array}{c}\text { A1B } \\
\text { Max }\end{array}$ & $\begin{array}{c}\text { A1FI } \\
\text { Mean }\end{array}$ & $\begin{array}{c}\text { A1FI } \\
\text { Max }\end{array}$ & $\begin{array}{c}\text { A2 } \\
\text { Mean }\end{array}$ & $\begin{array}{c}\text { A2 } \\
\text { Max }\end{array}$ & $\begin{array}{c}\text { B1 } \\
\text { Mean }\end{array}$ & $\begin{array}{c}\text { B1 } \\
\text { Max }\end{array}$ & $\begin{array}{c}\text { Meter } \\
2 \text { Met }\end{array}$ \\
\hline 1 & Developed Dry Land & -3.90 & -4.61 & -4.43 & -4.60 & -4.16 & -4.63 & -3.25 & -4.55 & -56.73 \\
\hline 7 & Trans. Salt Marsh & 0.21 & 0.01 & 0.25 & 0.00 & 0.38 & 0.03 & 0.77 & 0.11 & 32.65 \\
\hline 8 & Regularly Flooded Marsh & -21.09 & -22.87 & -22.45 & -22.89 & -21.69 & -22.83 & -19.55 & -22.80 & -145.01 \\
\hline 10 & Estuarine Beach & -3.62 & -3.63 & -3.63 & -3.63 & -3.62 & -3.64 & -3.53 & -3.64 & -41.78 \\
\hline 11 & Tidal Flat & 22.11 & 24.22 & 23.52 & 24.25 & 22.60 & 24.12 & 19.76 & 24.03 & 117.24 \\
\hline 12 & Ocean Beach & -60.13 & -60.13 & -60.13 & -60.13 & -60.13 & -60.13 & -60.03 & -60.13 & -59.63 \\
\hline 17 & Estuarine Open Water & -6.67 & -7.01 & -7.08 & -7.06 & -6.67 & -6.98 & -6.55 & -7.08 & 55.49 \\
\hline 19 & Open Ocean & 73.21 & 74.20 & 74.07 & 74.19 & 73.40 & 74.23 & 72.51 & 74.19 & 99.54 \\
\hline 22 & Inland Shore & -0.12 & -0.13 & -0.13 & -0.13 & -0.13 & -0.14 & -0.12 & -0.13 & -0.43 \\
\hline
\end{tabular}

The A1FI, A1B, A2, and B1 scenarios display similar changes in all nine categories. This study site shows an inverse relationship between the Regularly Flooded Marsh and Tidal 
Flat categories. Approximately 22 acres of Regularly Flooded Marsh were transformed to Tidal Flat. By 2100, the Ocean Beach in all scenarios completely disappears, as shown in Figures 6.8 and 6.9.

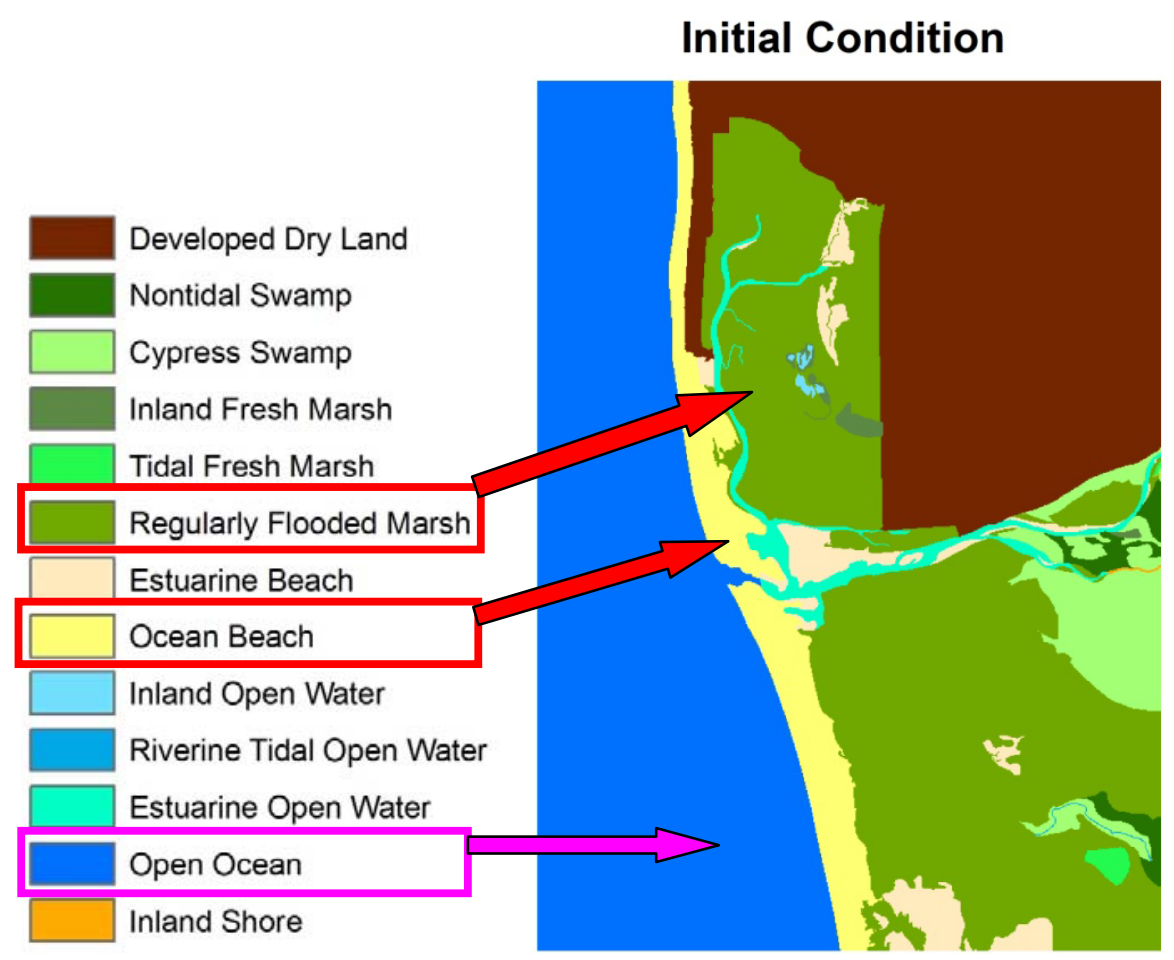

Figure 6.8 Tijuana Estuary Initial Condition 
A2 IPCC SRES by 2100

Estimated Maximum Level

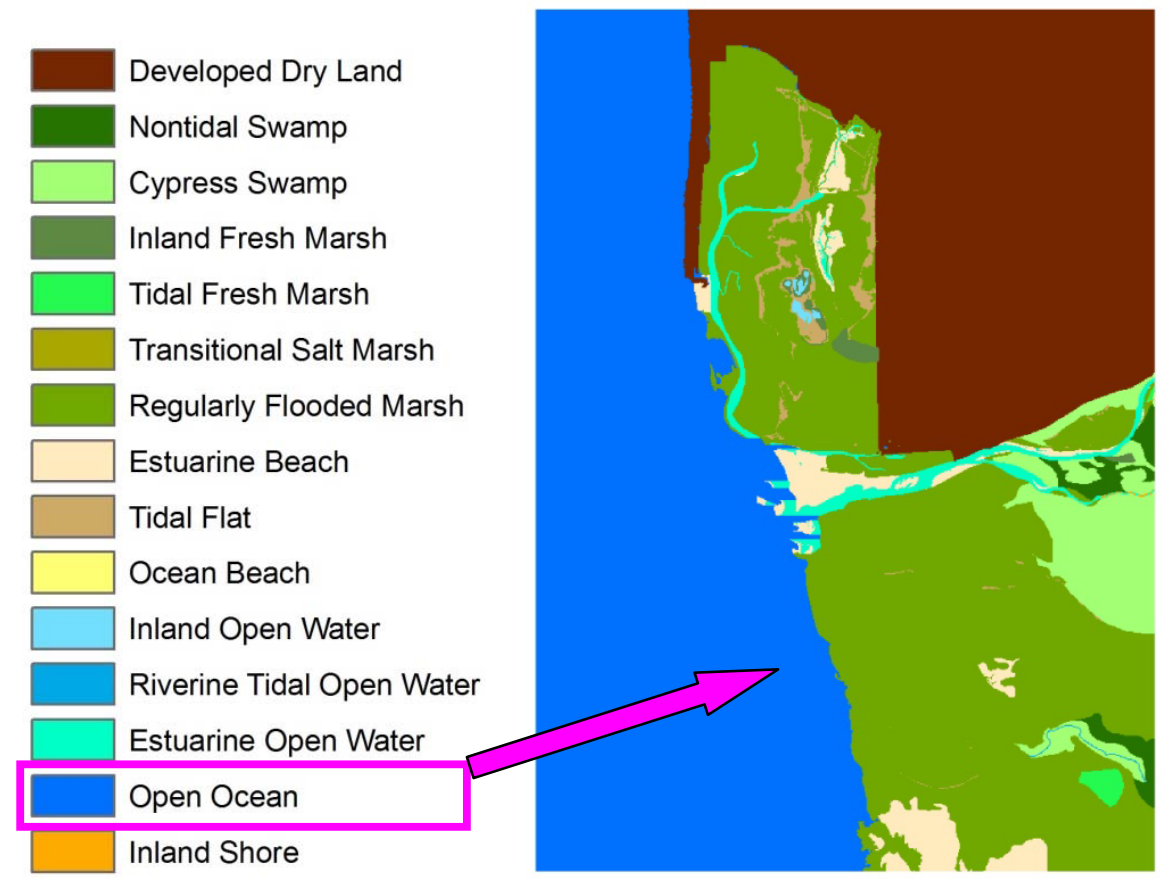

Figure 6.9 Tijuana Estuary A2 Scenario by 2100

The 2-meter scenario displays significant changes in all categories except Inland Shore. For example, the Estuarine Beach category displays a decrease of 3.6 acres in the other four scenarios, while the 2-meter scenario shows a decrease of 41.8 acres. The 2meter scenario shows a loss of Developed Dry Land that is over ten times the loss predicted by the other four scenarios. The Transitional Salt Marshes increased by over 32 acres covering Developed Dry Land. Over 145 acres of the Regularly Flooded Marsh were transformed into Tidal Flat and Transitional Salt Marsh. Estuarine Beaches are completely flooded with Estuarine Open Water, as shown in Figure 6.10. 
Fixed 2-Meter Rise by 2100

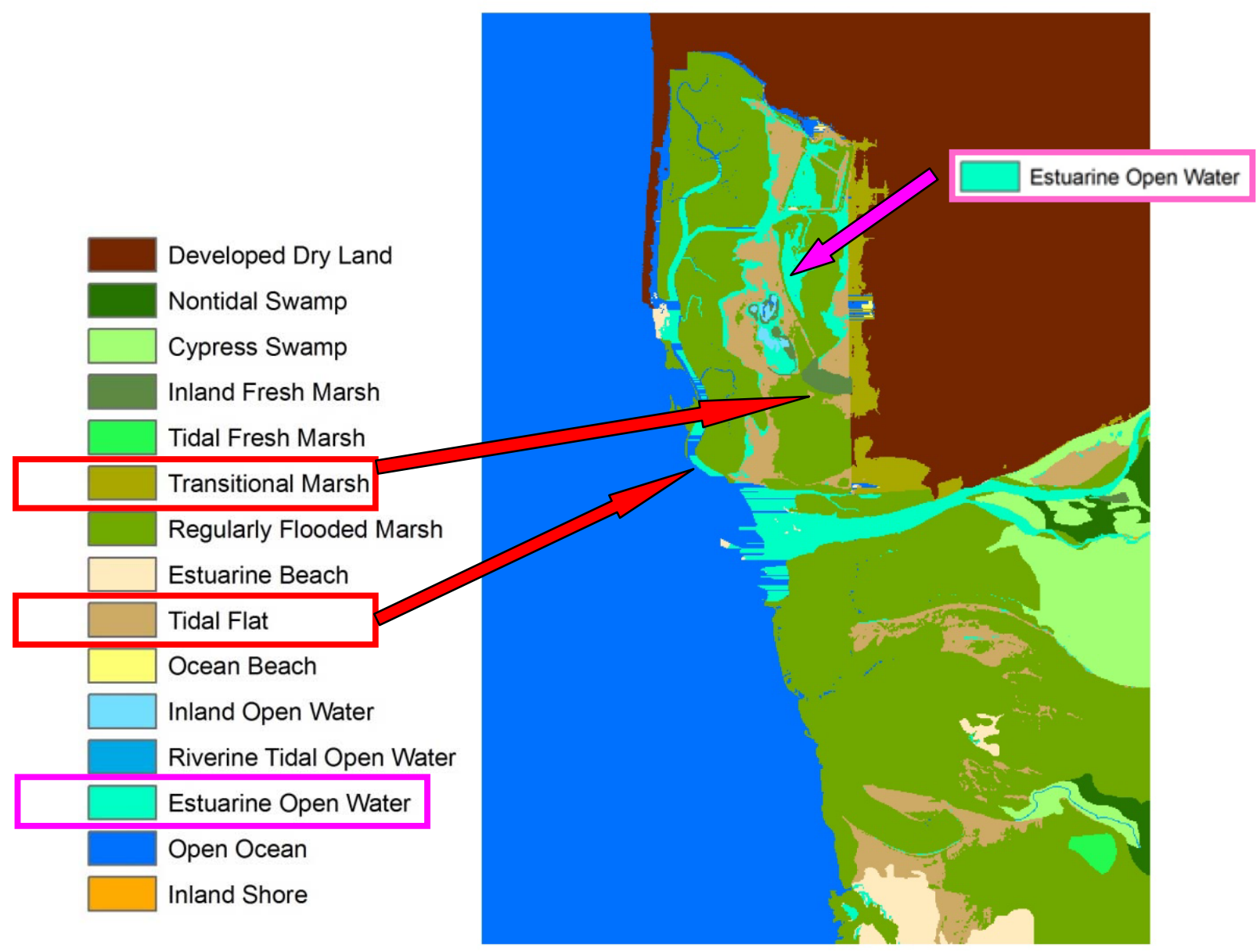

Figure 6.10 Tijuana Estuary 2-Meter Rise Scenario by 2100

\subsection{Discussion}

The large differences predicted by the four scenarios and the 2-meter scenario can probably be attributed to the large difference in the amounts of sea level rise in the different scenarios. The A1B, A1FI, A2, and B1 scenarios all predict the sea level rise to be between 0.5 and 0.8 meters, which is less than half the rise in the 2-meter scenario, as shown in Table 7. 
Table 7. SLAMM Inputs Based on IPCC, 2001 (Eustatic Sea Level Rise in meters) (Clough, 2010)

\begin{tabular}{|r|r|r|r|r|r|r|r|r|}
\hline & \multicolumn{4}{|c|}{ Mean } & \multicolumn{4}{|c|}{ Max } \\
\cline { 2 - 10 } & A1B & \multicolumn{1}{|c|}{ A1FI } & \multicolumn{1}{|c|}{ A2 } & B1 & A1B & A1FI & A2 & \multicolumn{1}{l|}{ B1 } \\
\hline 2025 & 0.076 & 0.0755 & 0.0745 & 0.0755 & 0.128 & 0.137 & 0.1265 & 0.128 \\
\hline 2050 & 0.167 & 0.172 & 0.157 & 0.15 & 0.284 & 0.299 & 0.269 & 0.259 \\
\hline 2075 & 0.2785 & 0.323 & 0.277 & 0.2325 & 0.4845 & 0.491 & 0.478 & 0.4125 \\
\hline 2100 & 0.387 & 0.491 & 0.424 & 0.31 & 0.694 & 0.671 & 0.743 & 0.567 \\
\hline
\end{tabular}

It is also interesting to note the difference in the categories changed between the two study sites. Both areas are expected to transform Regularly Flooded Marsh into Tidal Flats and Ocean Beaches to Open Ocean. However, when comparing the initial conditions to the 2-meter scenario, the Los Peñasquitos Lagoon will experience inundation as the sea level rises, while the Tijuana Estuary will primarily experience erosion as the Ocean Beach transform into Open Ocean. These differences are probably due to the difference in landform classifications and geographic characteristics of a lagoon and an estuary.

The client selected the four IPCC scenarios to determine if there was a significant difference between the scenarios' predictions. However, in order to identify the appropriate IPCC scenarios to use for the study areas, additional research is required in demographics, business and industry, agriculture, and land use change.

\subsection{Challenges}

Some of the challenges encountered during this project included processing LiDAR data and finding the correct methods to process data for the SLAMM application. It was a challenge using ArcGIS LiDAR Analyst Extension to process the LiDAR data, especially when the options were not functioning correctly. For example, the NAD83 Geographic Coordinate System could only be selected with California Zone 6 in meters projection, but not in feet. When California Zone 6 in feet projection was selected, both options were reset to unknown. In addition, the unit was incorrectly labeled as degrees instead of meters when the NAD83 Geographic Coordinate System was selected. The solution was to set the Geographic Coordinate System to NAD83, Projection as unknown, Vertical Datum to NAVD88, and Vertical Units in foot for the input data. Then bring the bareearth DEM into ArcMap to define the correct projection.

Processing the data required for the SLAMM application was the most challenging task. The SLAMM Technical Documentation provided information about the types of data required, but there were no specific instructions on how to prepare those data for SLAMM input. After several attempts at processing the data, the client provided contact information for SLAMM experts from other U.S. Fish and Wildlife Service offices. Delissa Padilla from the Virginia office was able to provide instructions on how to process the data for SLAMM, but further work was required to discover the best methods to process the data. 


\subsection{Summary}

This chapter discusses the tools resulting from this project and the predicted impact on the Los Peñasquitos Lagoon and the Tijuana Estuary. It also provided discussions of the differences in the sea level rise scenarios, the study sites, and challenges experienced during the project. 


\section{Chapter 7 - Conclusions and Future Work}

At the predicted 1.4 meters sea level rise by 2100, California coastal wetlands are threatened to be permanently damaged or lost. The goal of this project was to help the Carlsbad Fish and Wildlife Office (CFWO) address the potential effects of sea level rise on two San Diego coastal wetlands. To meet this goal, three GIS tools were developed to process data to be used in the SLAMM application. This section discusses the outcome of the GIS tools and how they met the client's functional and non-functional requirements. It also describes possible future work.

Three GIS tools were developed to automate the data conversion process, prepare the data for input into SLAMM, and to analyze the SLAMM output. The first two GIS tools enable the user to input digital elevation datasets and the NWI datasets for the area of interest to process into ASCII format files. The third tool enables the user to import the SLAMM output into ArcMAP to create maps for analyses. All three GIS models were designed to retrieve and output the data directly into the geodatabase, unless the output data are in ASCII format.

The GIS tools were built using standard ArcMap tools in ModelBuilder, which can be modified easily if needed. Although the tools are simple to use, the user must have GIS experience to navigate through ArcMap. The user must also be familiar with the data used for the project. Since the models were designed for the SLAMM 6.0.1 beta version, the user may be required to download the latest version. All GIS tools were tested and fully functional. A step-by-step handbook was provided to help guide the users through the functionality of the GIS tools. The project presentation and user training will take place onsite during the staff meeting in September 2010. The client's functional and nonfunctional requirements were met.

For future work, the project scope could be expanded to all coastal regions managed by the Fish and Wildlife Service, or even the entire United States or world. To accomplish this expansion, the parameters required in the SLAMM Edit Sites and Subsites menu could be gathered for all regions of interest, input to a geodatabase, and linked to a region of study for easy analysis and improved accuracy. This expansion could also be turned into a web service where the user could select a coastal region, select the sea level rise scenarios, and then run the models to see the predicted impacts to the selected region. The web service could also include a tool that would allow the user to input demographic, business and industry, agriculture, and land use change information to help narrow down which IPCC sea level rise scenarios would be appropriate for the selected region.

Another possibility for future work is to verify the accuracy of the SLAMM application on predicting the changes of coastal wetlands caused by sea level rise. To verify the accuracy, SLAMM could be modeled with older NWI datasets and the mean sea level rise for that given data. Perhaps the past NWI datasets could be obtained from the U.S. Fish and Wildlife Service and the mean sea level rise data could be obtained from NOAA.

Additional future work could be updating the GIS tools created for this project. For example, a LiDAR open source command line utility such as LAStools, could be incorporated into the DEM and Slope Model to perform the LiDAR to bare-earth DEM conversion and eliminate the requirement for the LiDAR Analyst Extension. In addition, 
the SLAMM Exchange Format to Raster Model could be modified to reflect the latest SLAMM capabilities, which outputs raster files directly. Another tool could also be added to calculate the total acreage loss and gain for each SLAMM categories from the SLAMM CSV output.

Overall, the tools developed and the analysis conducted for this project are already being used by the client as part of their decision making process for managing coastal areas. Further expanding the availability and accuracy of these tools would allow coastal managers to predict potential impacts of sea level rise on coastal regions nationwide or globally. 


\section{Works Cited}

Church, J. G. (2007). Intergovernmental Panel on Climate Change (IPCC). Retrieved June 10, 2010, from http://www.ipcc.ch/ipccreports/tar/wg1/pdf/TAR-11.PDF

Clough, J. (2010). Warren Pinnacle Consulting, Inc. Retrieved June 1, 2010, from http://warrenpinnacle.com/prof/SLAMM6/SLAMM6_Technical_Documentation. pdf

Craft, C. C. (2009). Forecasting the effects of accelerated sea-level rise on tidal marsh ecosystem services. The Ecological Society of America, 7 (2), 73-78.

Galbraith, H., Jones, R., Park, R., Clough, J., Herrod-Julius, S., Harrington, B., and Page, G. (2005). Global Climate Change and Seal Level Rise: Potential Losses of Intertidal Habitat for Shorebirds. Newfane: USDA Forest Service.

Green, D. R. and King, S.D. (2001). Applying the Geospatial Technologies to Estuary Environments. In Barlett, D.J. and Smith J.L., GIS for Coastal Zone Management (pp. 239-55). Halifax: CRC Press LLC.

Heberger, M. C. (2009). California Climate Change Center. Retrieved October 15, 2009, from Pacific Institute Organization:

http://pacinst.org/reports/sea_level_rise/report.pdf

NOAA. (2001a). Retrieved July 8, 2010, from Tidal and Currents Datum for La Jolla, CA: http://tidesandcurrents.noaa.gov/data_menu.shtml?stn=9410230 La Jolla, CA\&type=Datums

NOAA. (2001b). Retrieved July 8, 2010, from Tidal and Currents Datum for Imperial Beach, CA: http://tidesandcurrents.noaa.gov/data_menu.shtml?stn=9410120 IMPERIAL BEACH, PACIFIC OCEAN, CA\&type=Datums

NOAA. (2010a). Retrieved June 20, 2010, from Coastal Zone Management: http://oceanservice.noaa.gov/topics/coasts/management/

NOAA. (2010b). Retrieved July 1, 2010, from National Oceanic and Atmospheric Adminstration: http://oceanservice.noaa.gov/facts/estuary.html

Nwilo, P. C. (2001). GIS Applications in Coastal Management: A View from the Developing World. In Barlett, D.J. and Smith J.L., GIS for Coastal Zone Management (pp. 181-193). Halifax: CRC Press LLC.

Pan, P. S. (2001). Monitoring Coastal Environments Using Remote Sensing. In Barlett, D.J. and Smith J.L., GIS for Coastal Zone Management (pp. 35-49). Halifax: CRC Press LLC.

Poulter, B. and Halpin, P.N. (2007). Raster modelling of coastal flooding form sea-level rise. International Journal of Geographical Information Science, 22 (2), 167-182.

Pugh, D. (2004). Changing Sea Levels: Effects of Tides, Weather and Climate. New York: Cambridge.

Topfer, K. (2000). IPCC Special Report Emissions Scenarios. Retrieved June 25, 2010, from Intergovernmental Panel on Climate Control: http://www.ipcc.ch/pdf/special-reports/spm/sres-en.pdf

U.S. FWS. (1999). Retrieved July 31, 2010, from U.S. Fish and Wildlife Service: Important Facts About Habitats Loss and Birds: http://library.fws.gov/pubs/mbd_habitat_loss.pdf

Watson, R. (2002). Intergovernmental Panel on Climate Change (IPCC). Retrieved October 7, 2009, from 
http://www.ipcc.ch/publications_and_data/publications_and_data_technical_pape rs_climate_change_and_water.htm 


\section{Appendix A. SLAMM Results for Los Peñasquitos}

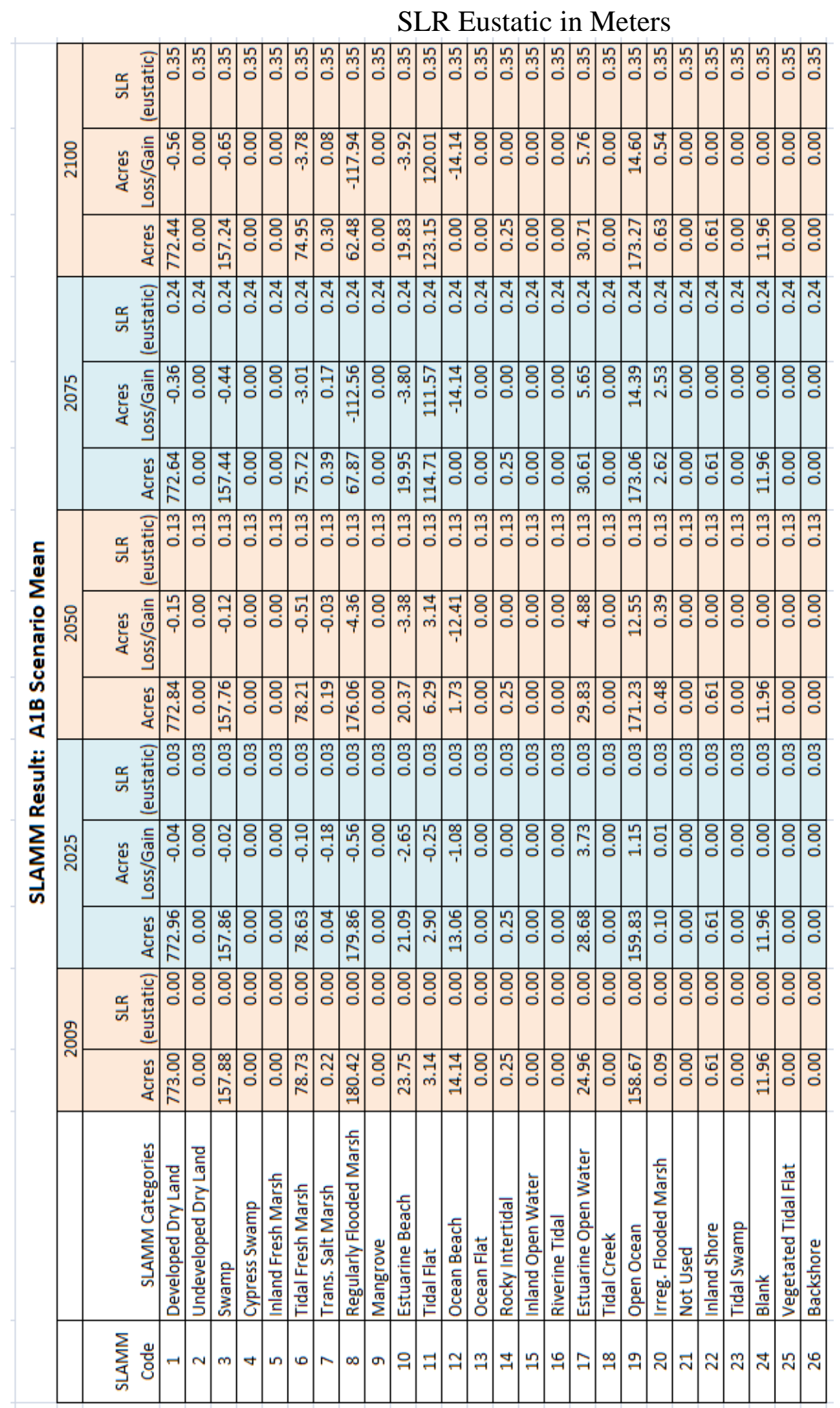




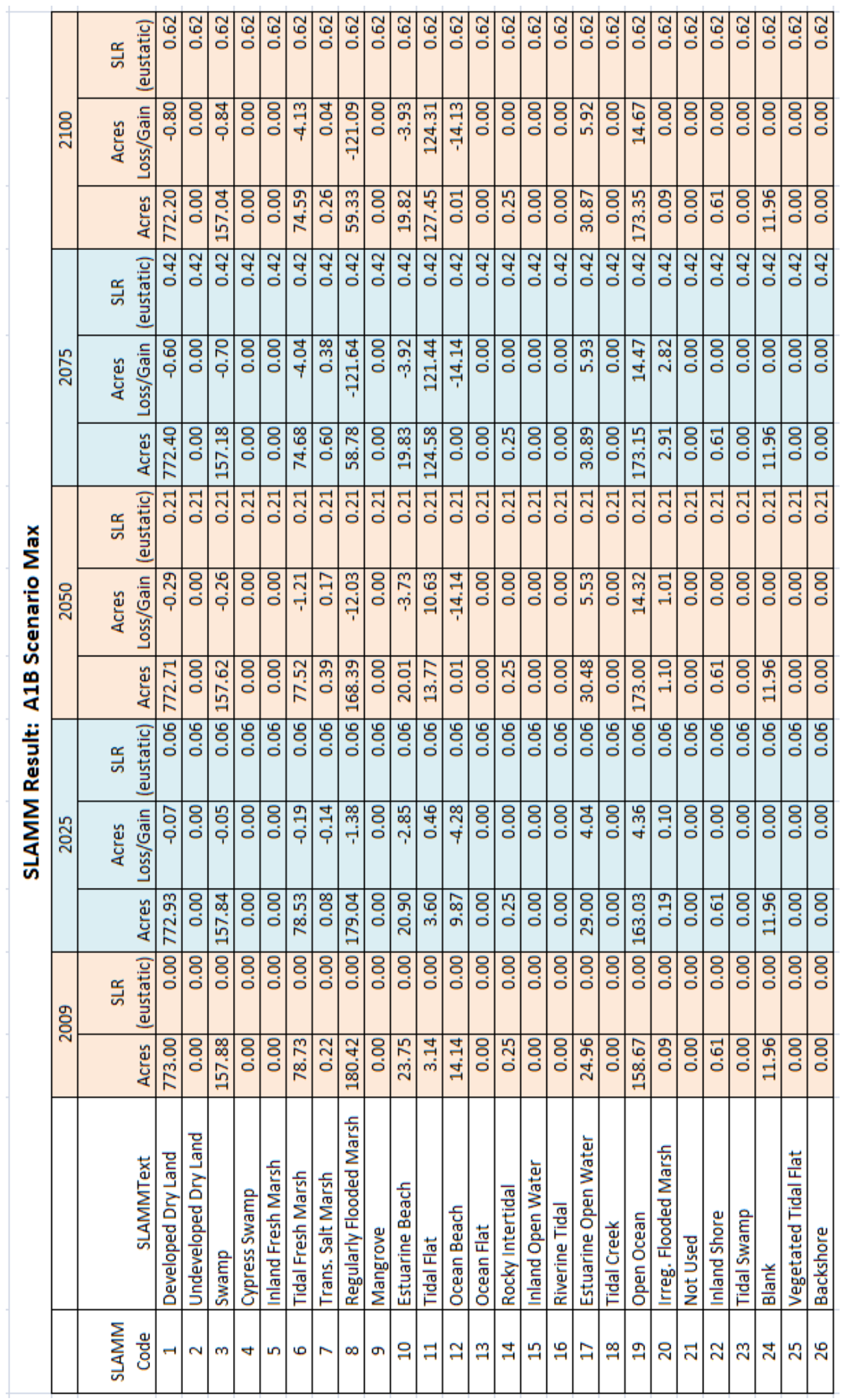




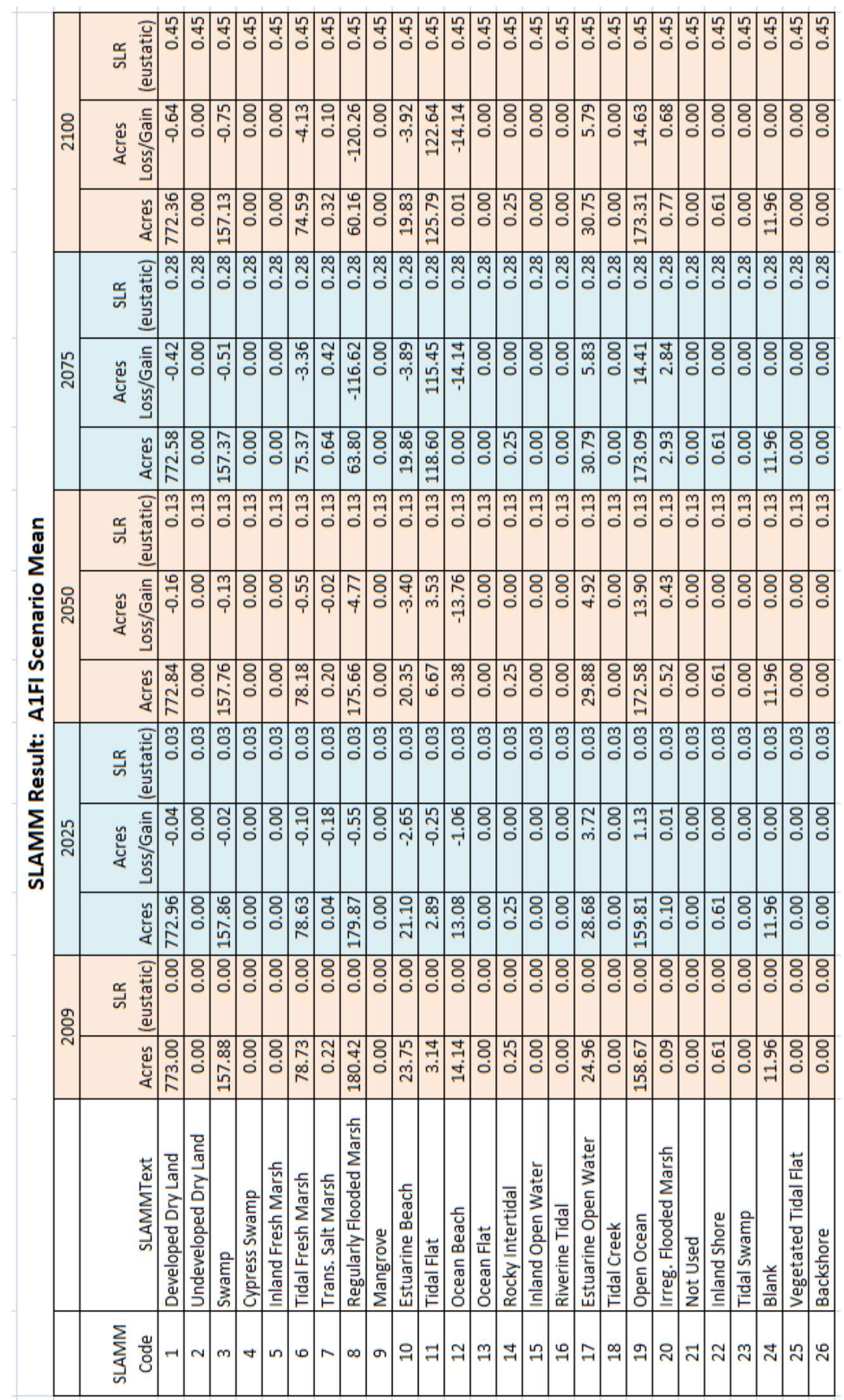




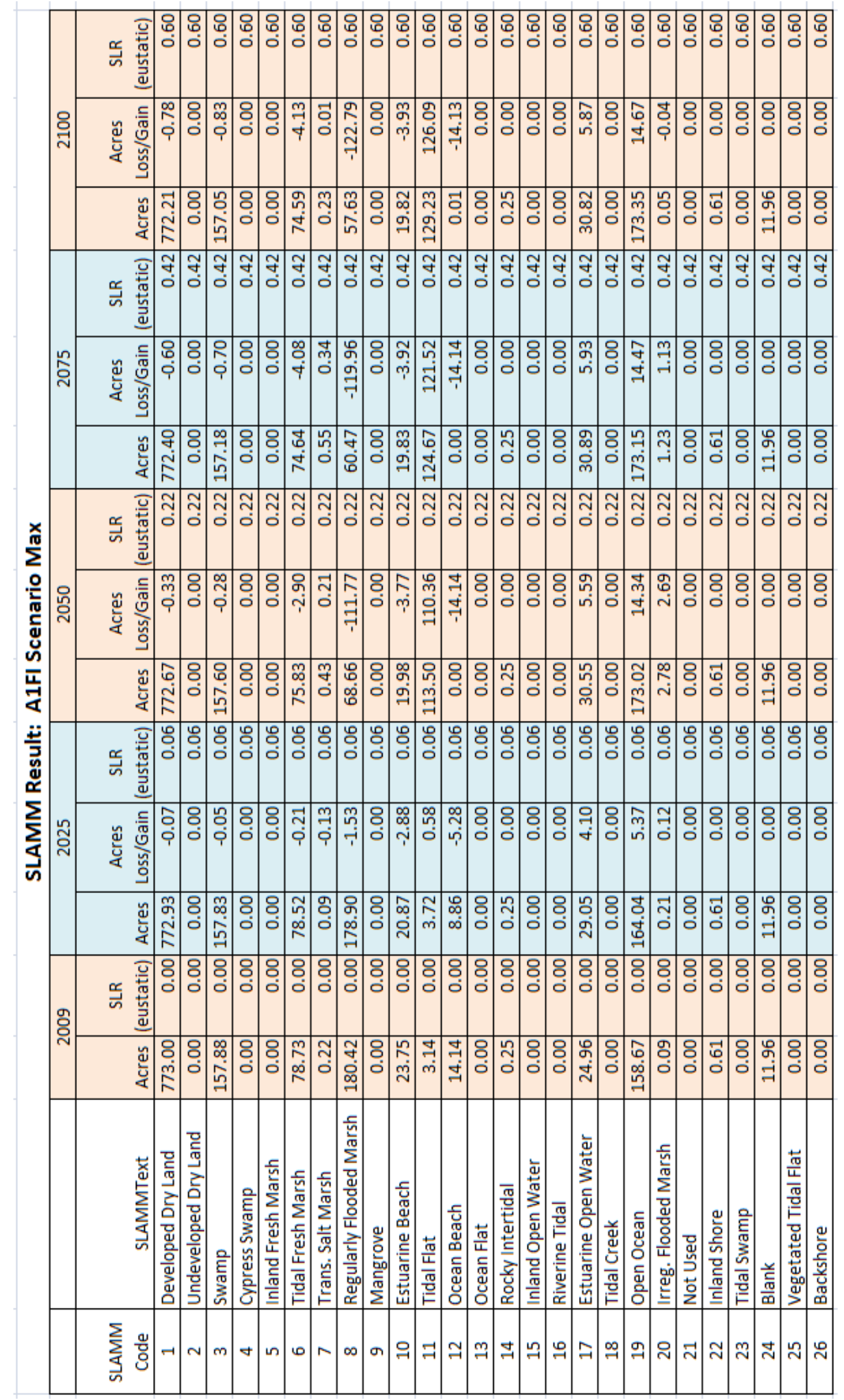




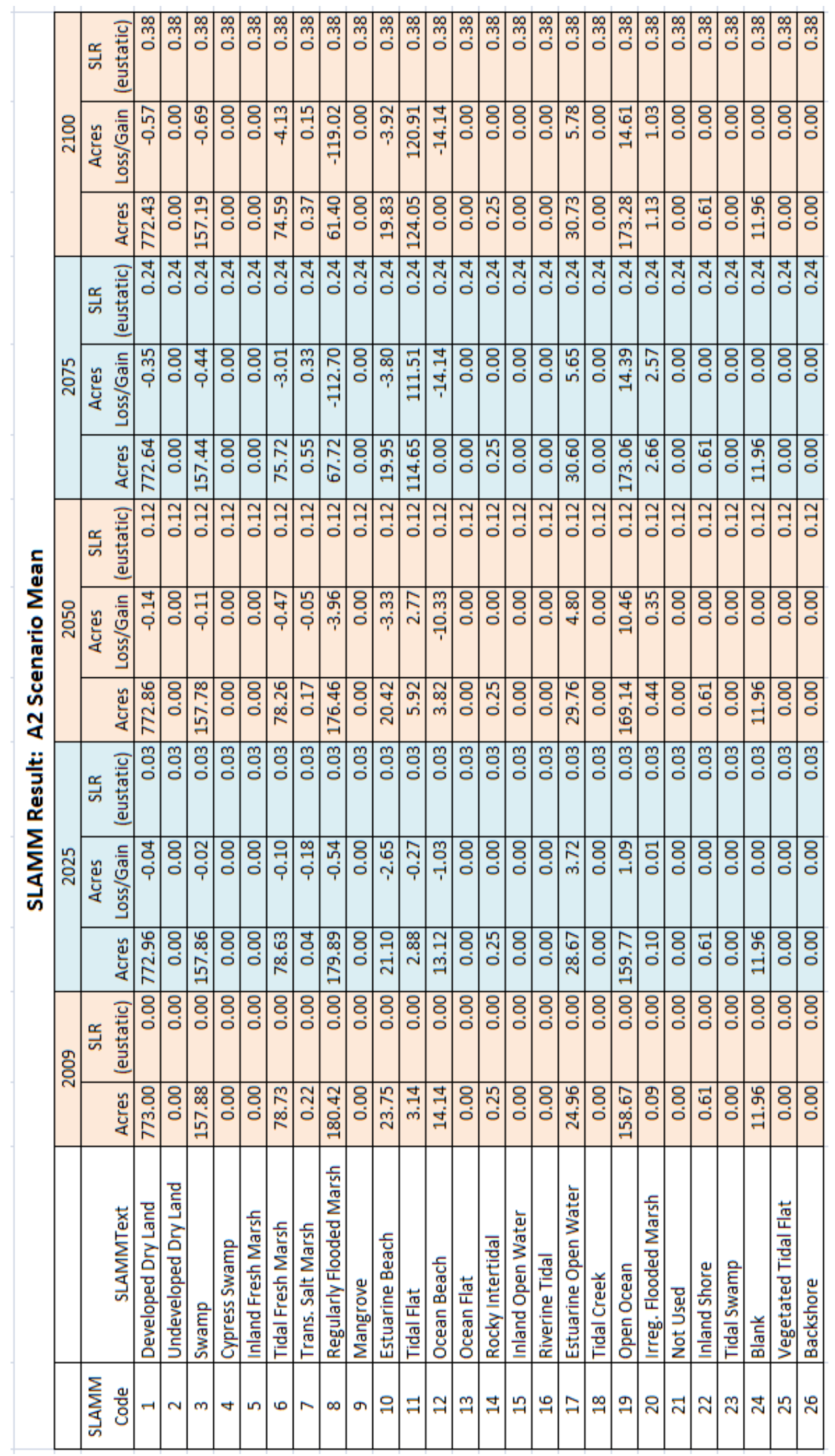




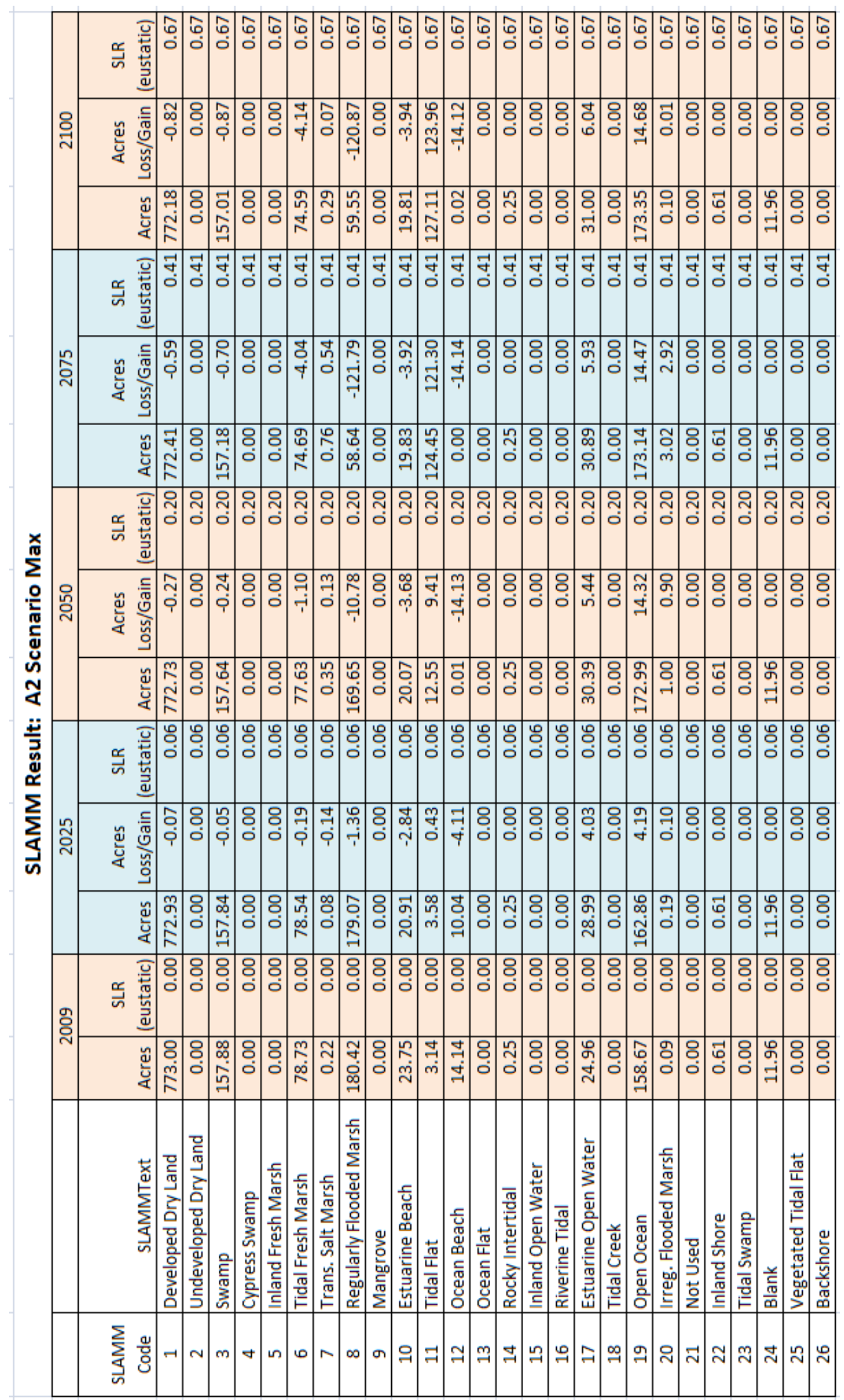




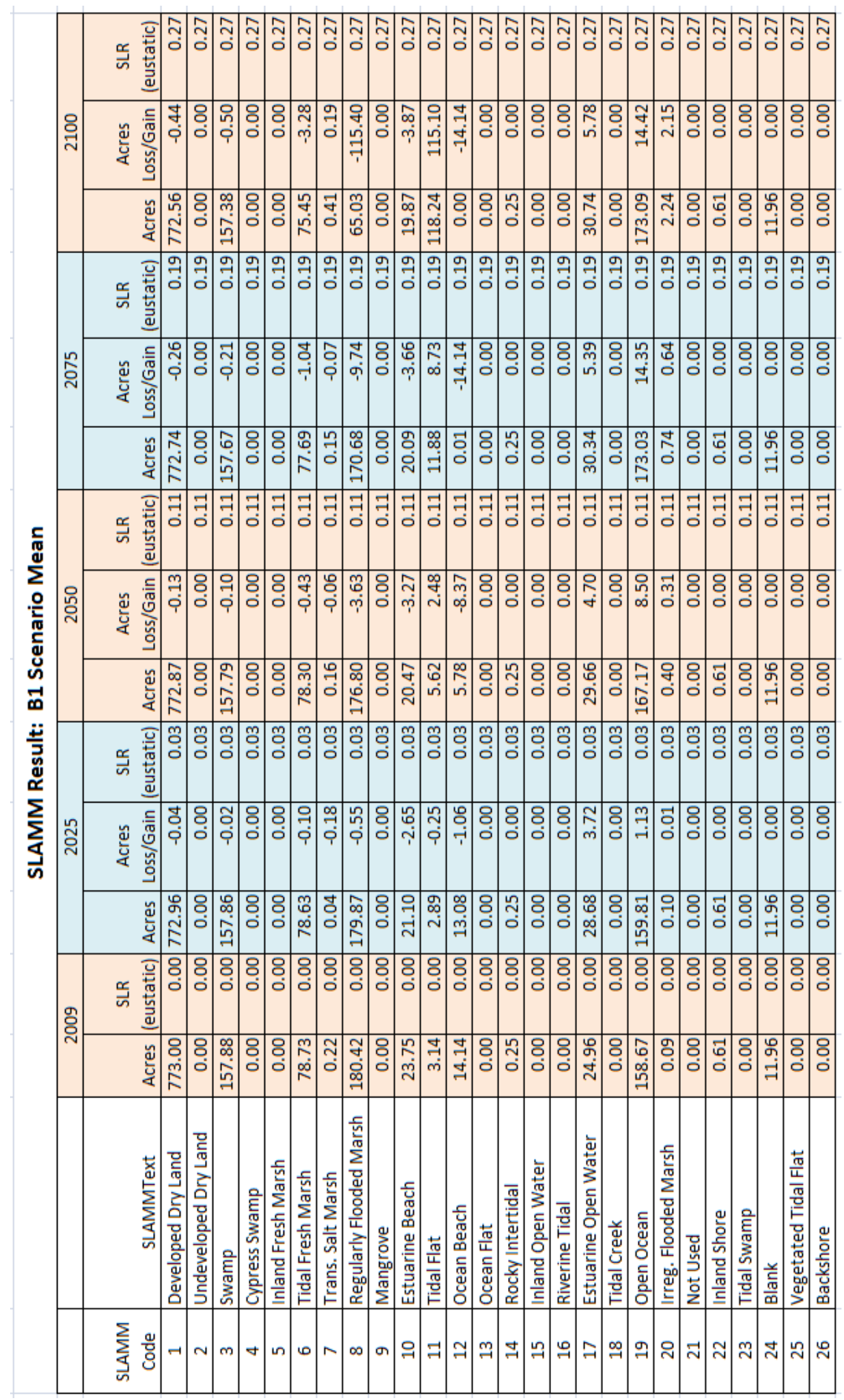




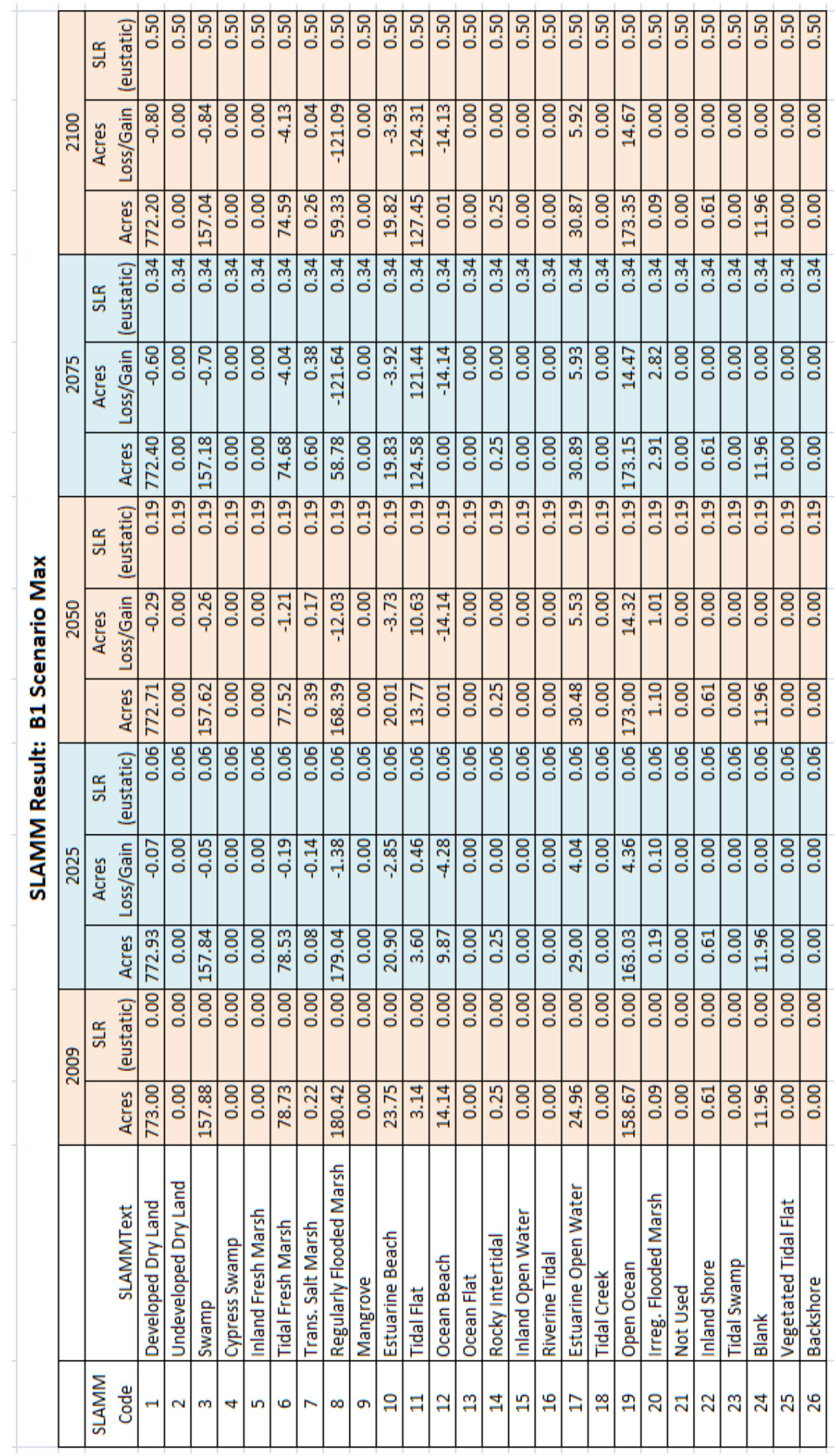




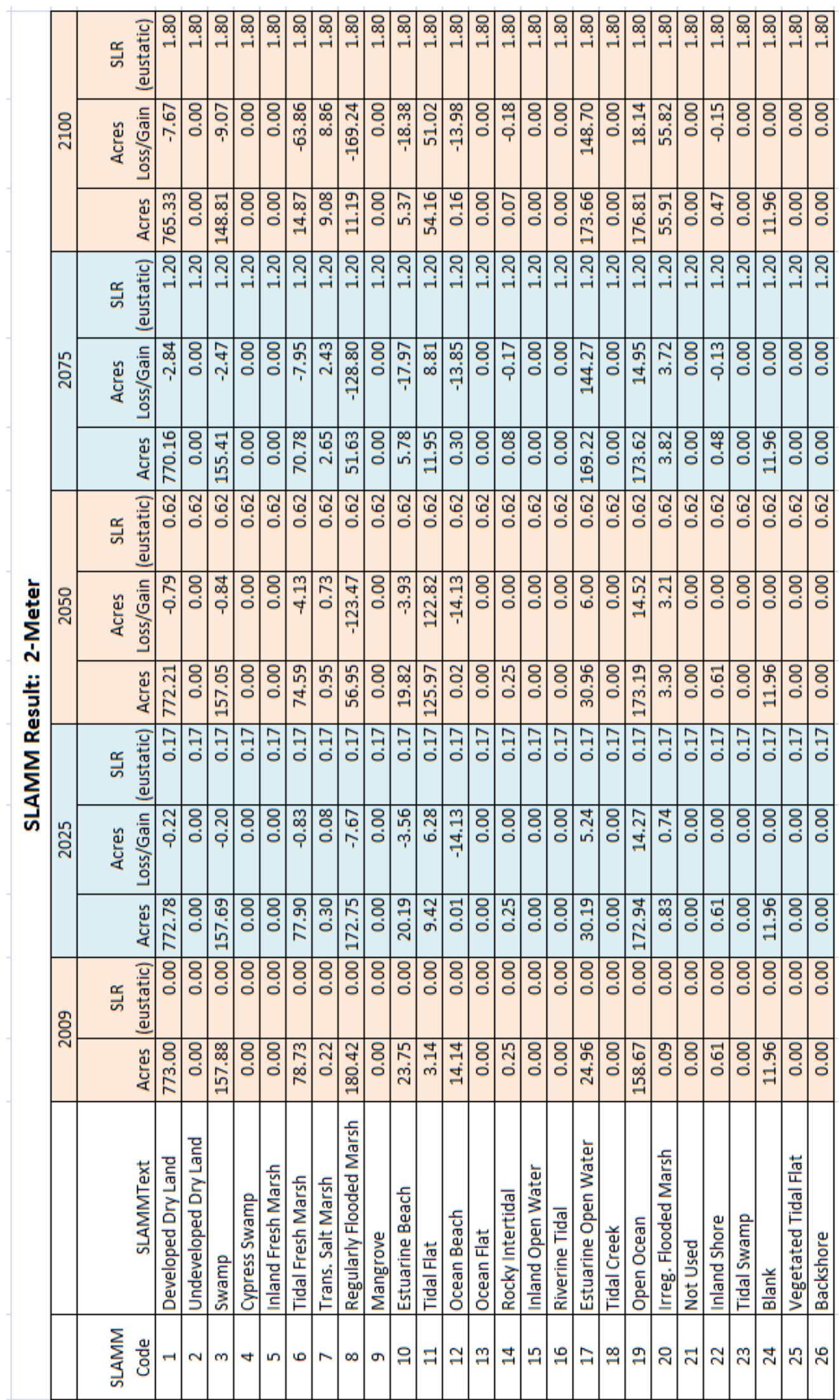




\section{Appendix B. SLAMM Results for Tijuana Estuary}

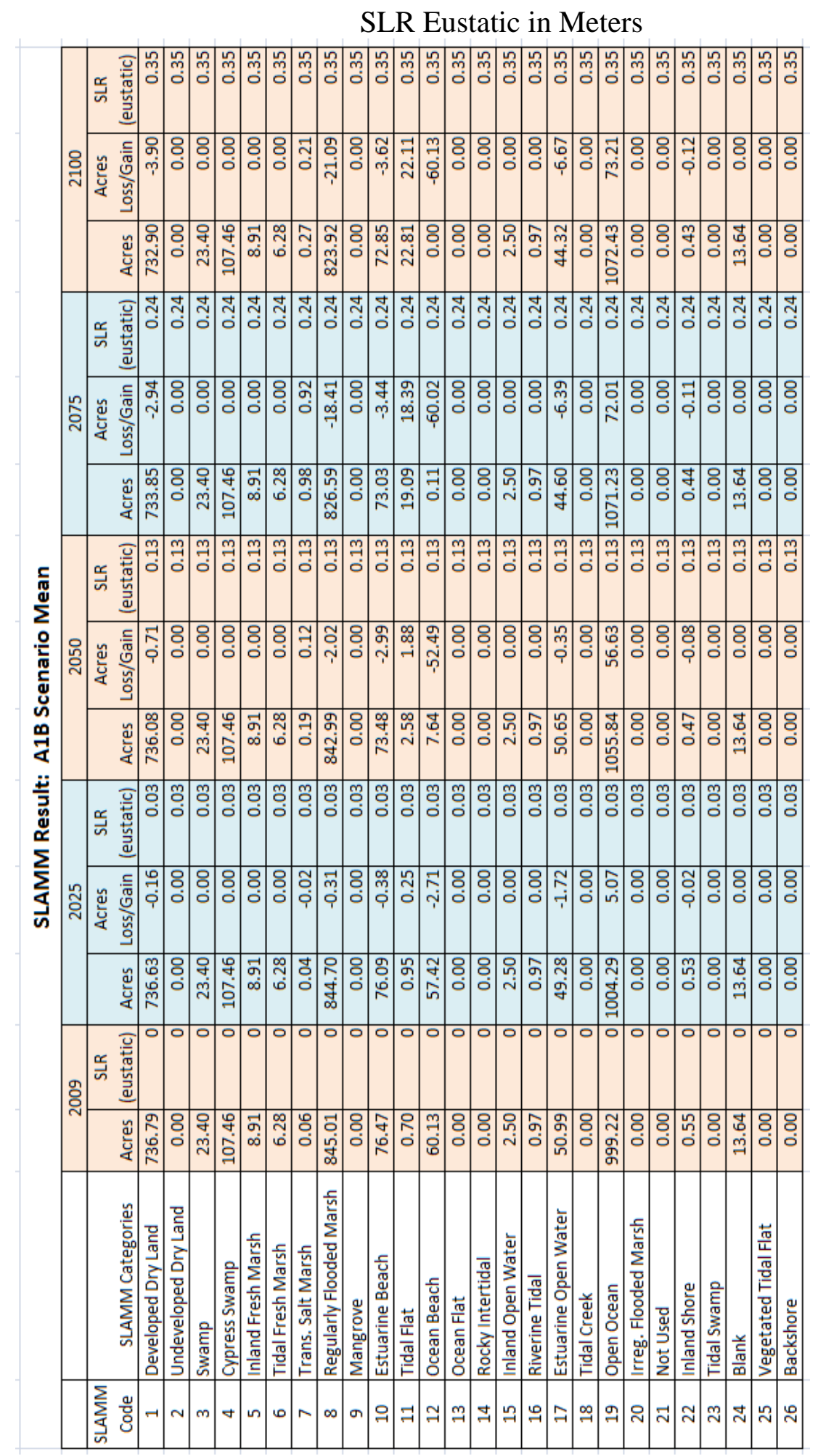




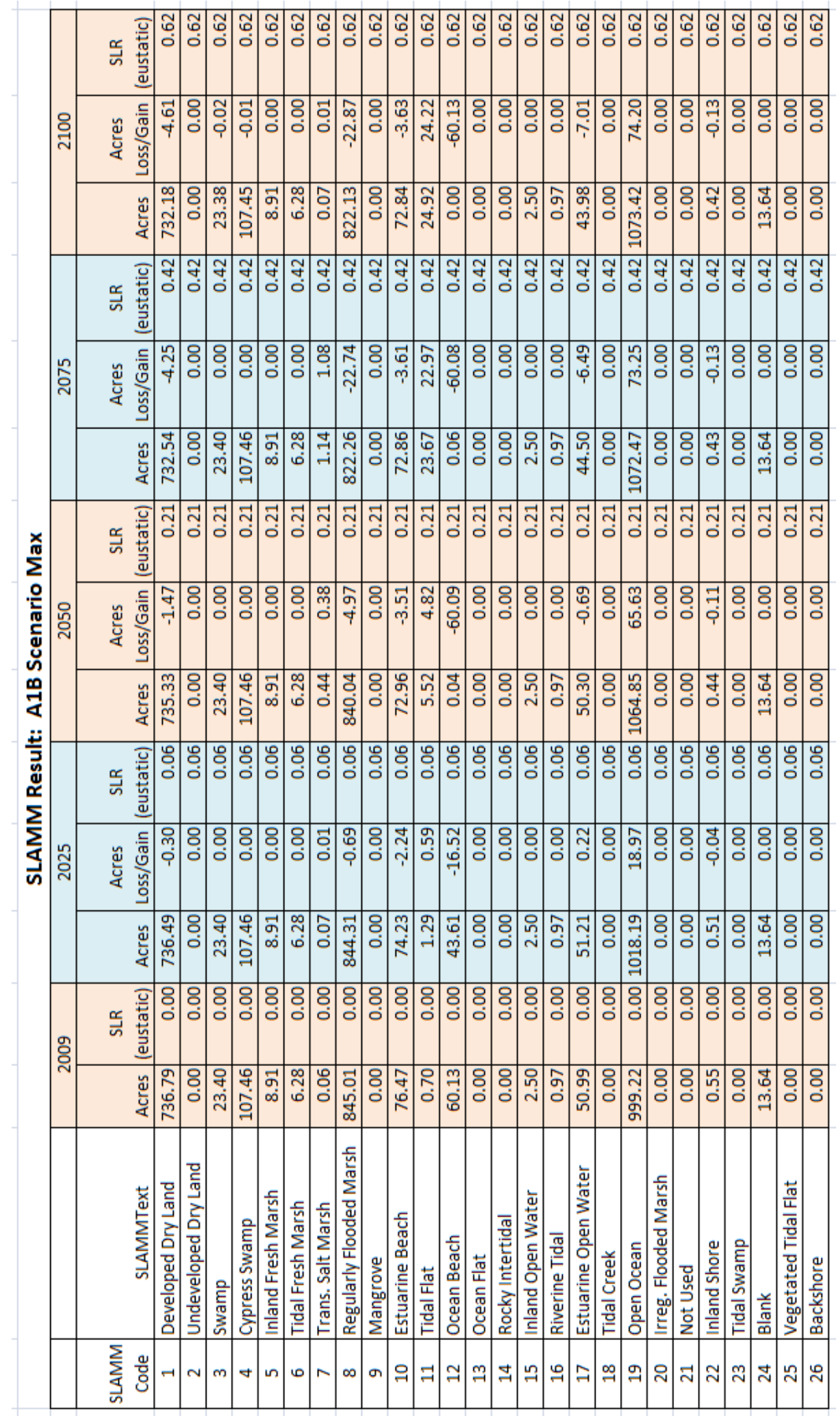




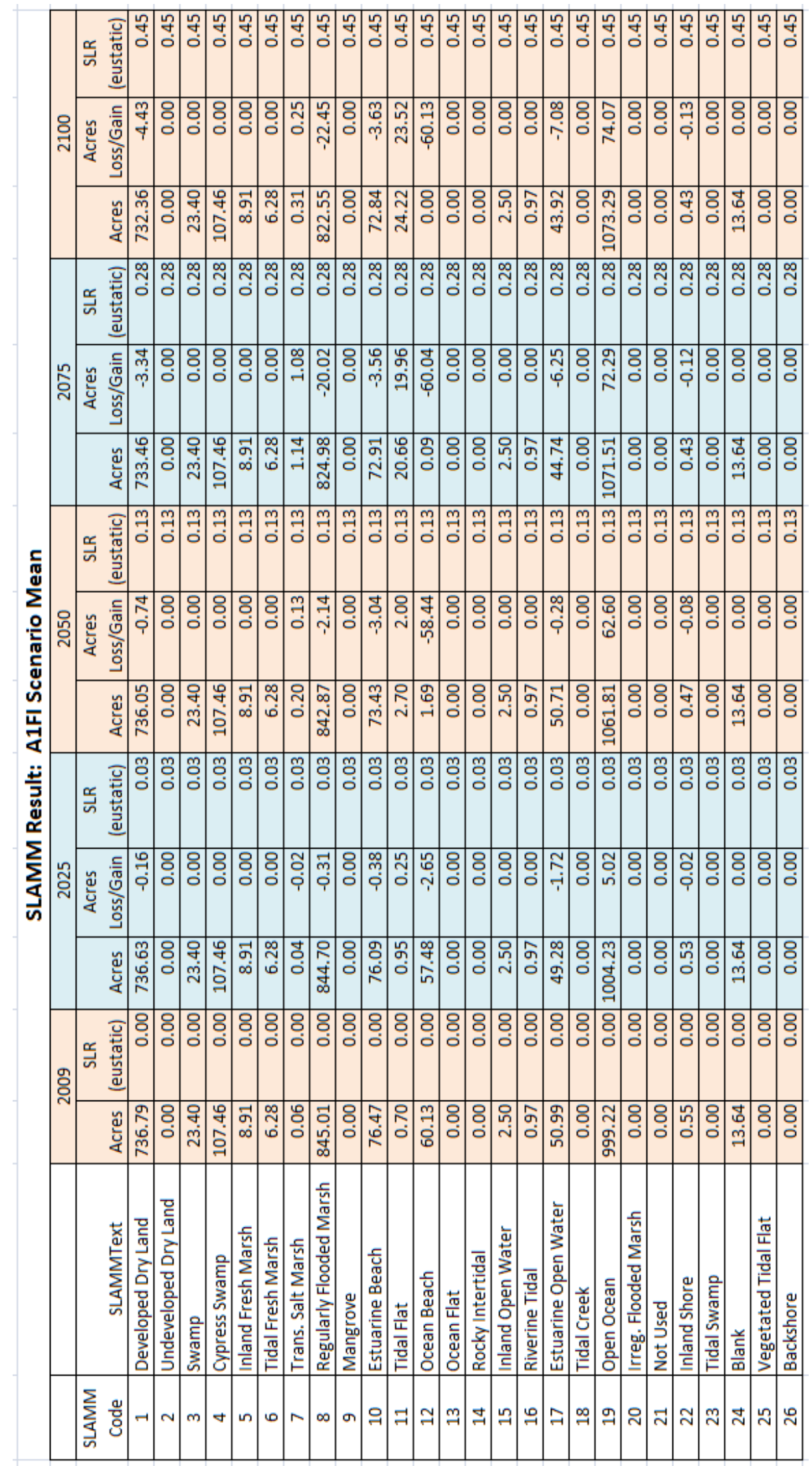




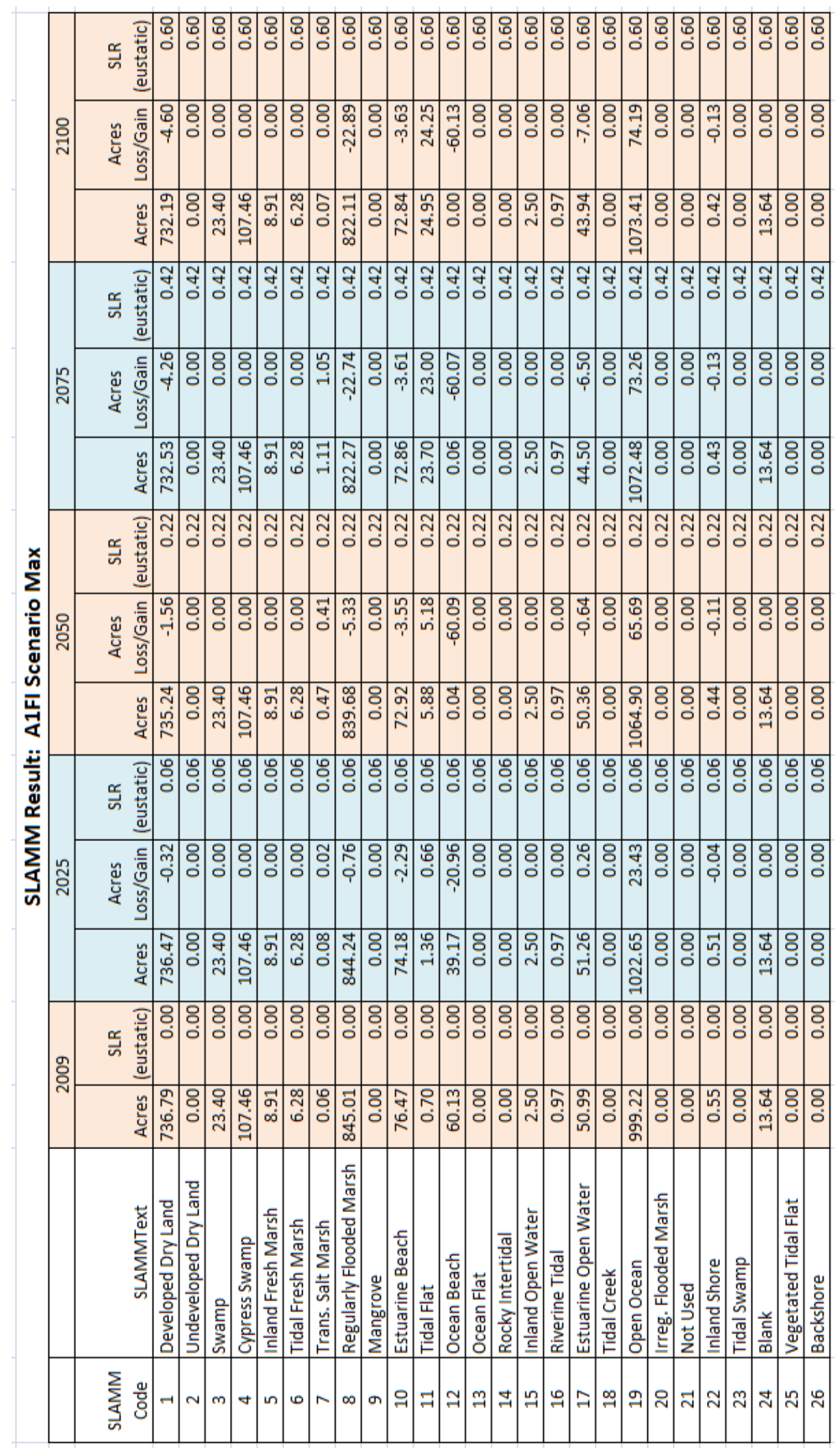




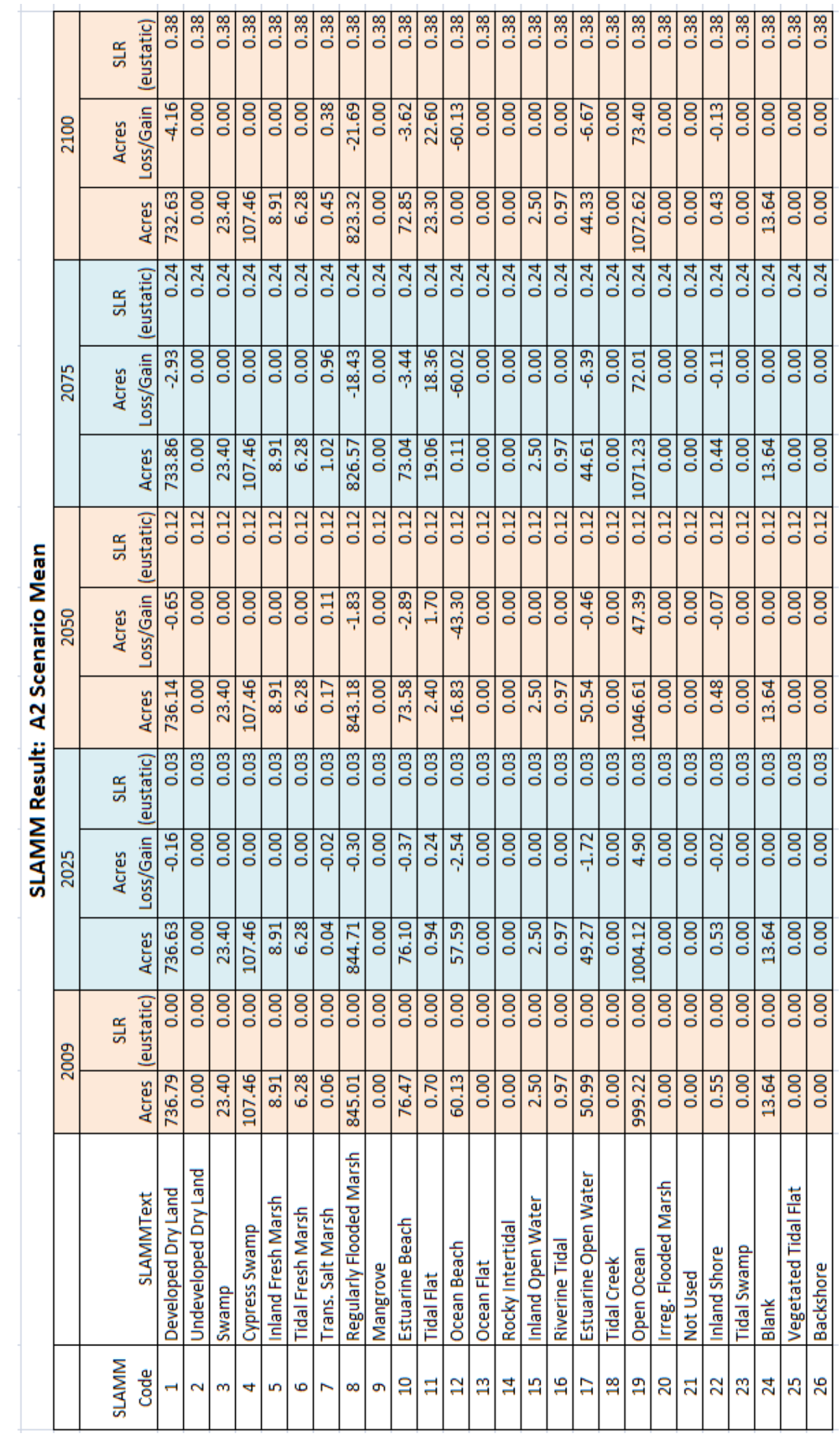




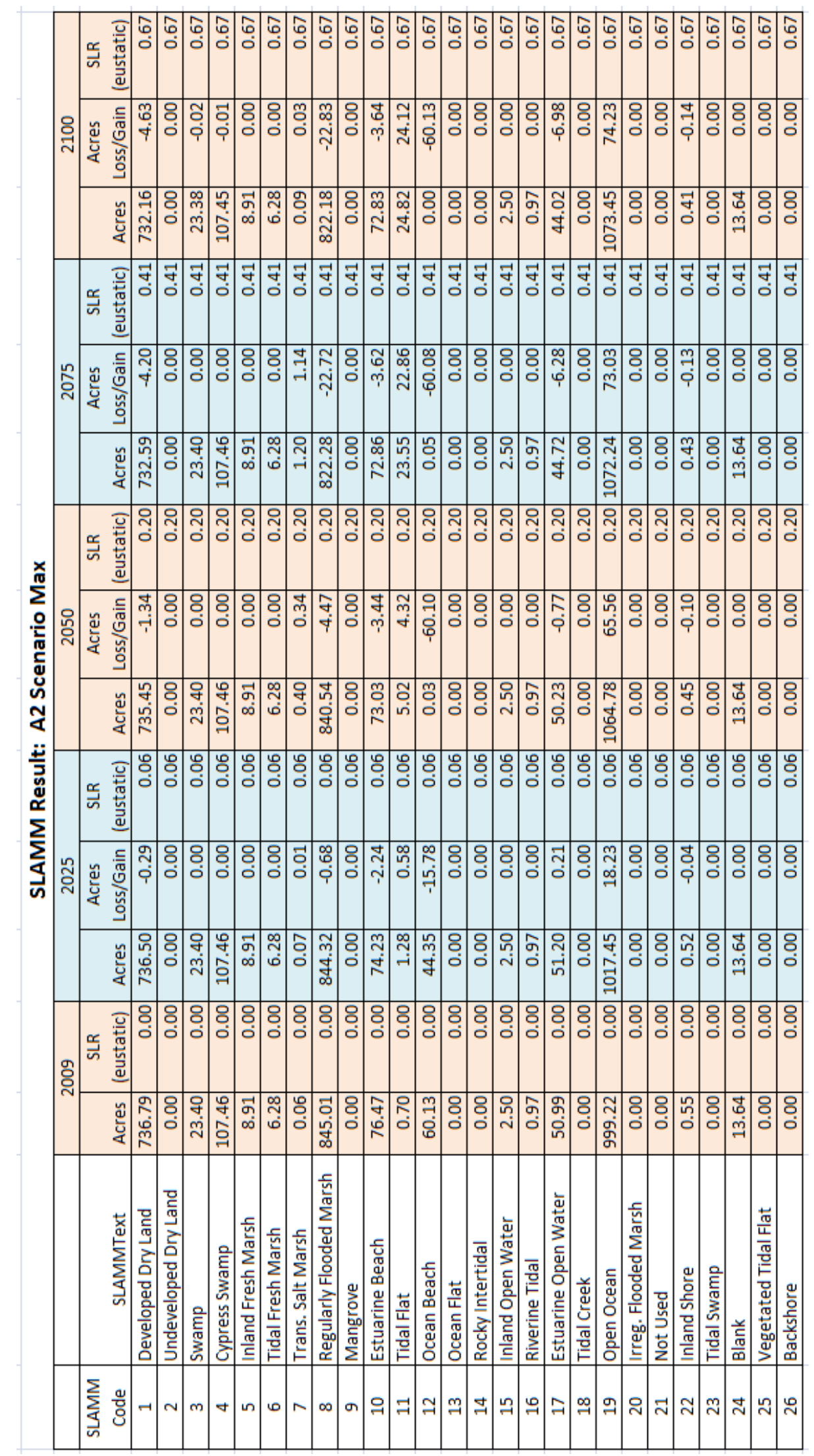




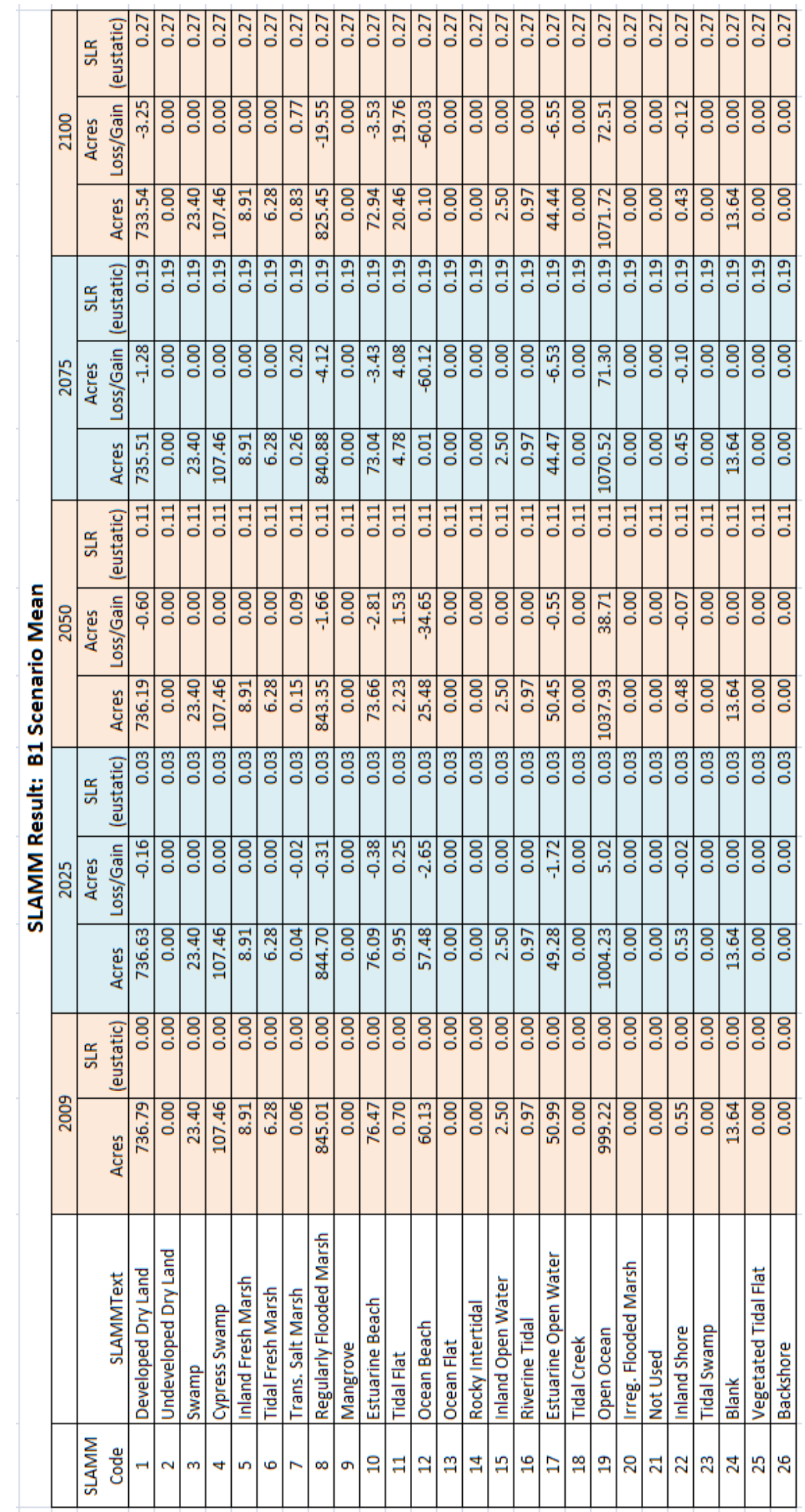




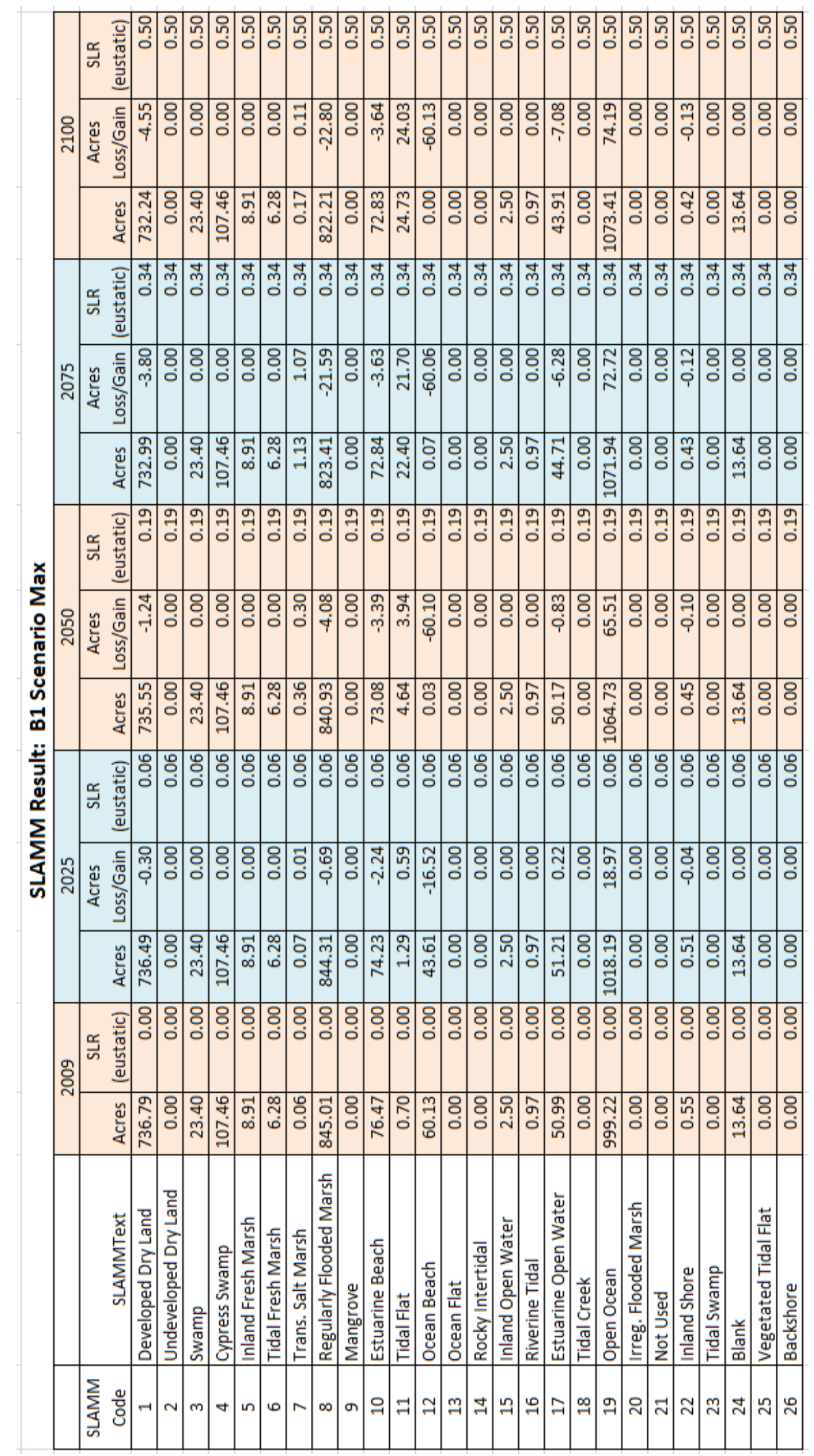




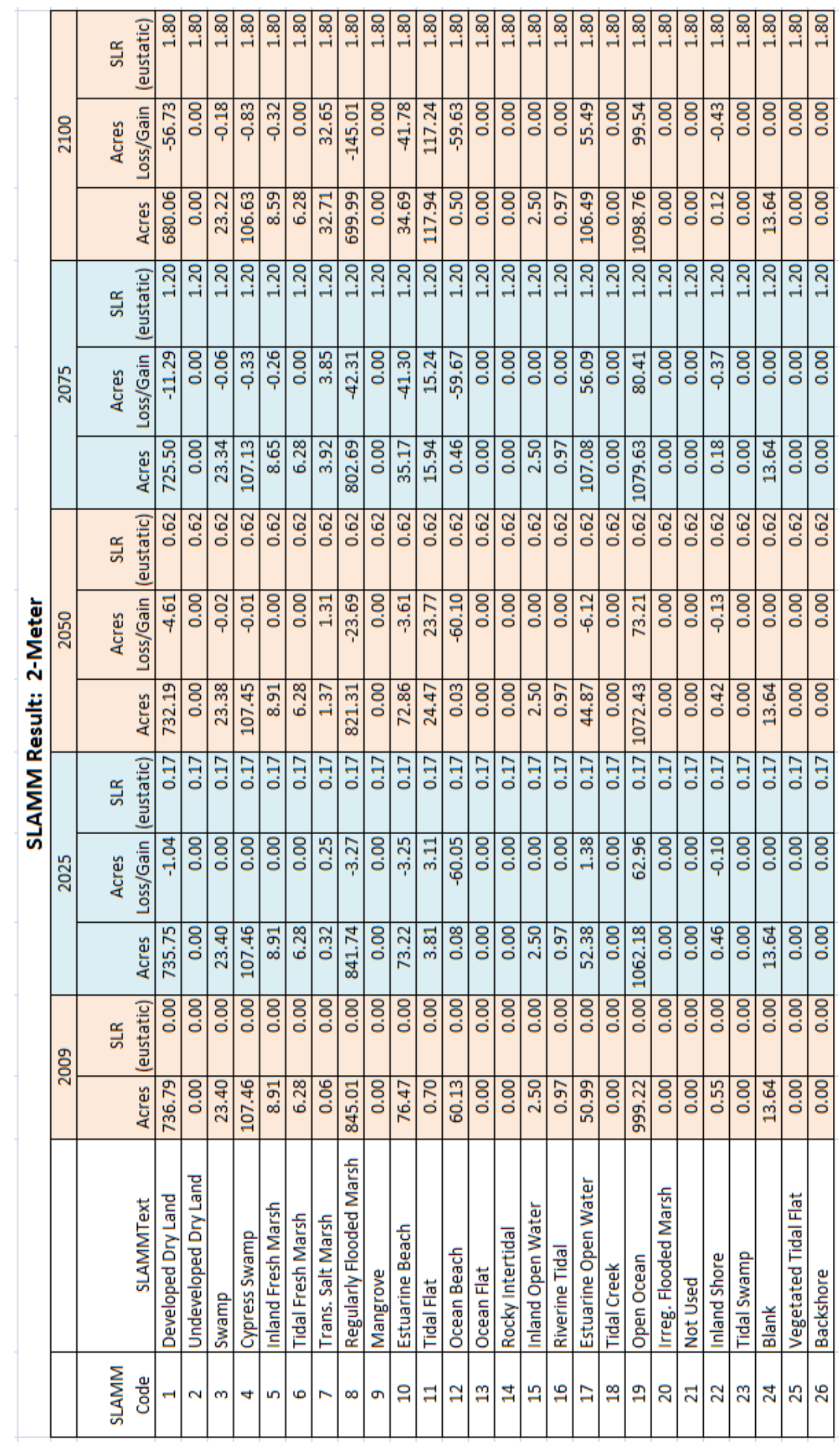




\section{Appendix C. User Guide}

\section{Data}

The data for this project are stored in a file geodatabase for easy access. There are two feature datasets stored in the geodatabase. The feature classes for the study sites - Los Peñasquitos Lagoon and Tijuana Estuary - are stored within their own feature dataset. The file names associated with Los Peñasquitos Lagoon are LP and Del Mar, and for Tijuana Estuary are TE and Imperial Beach.

Los Peñasquitos Lagoon

- NWI datasets: Del_Mar_OE_W_Wetlands_Polygons and Del_Mar_Wetlands_Polygons

- Clip Feature: LP_halfmile_Extent

- NED: Del_Mar_ned03m32117h2 and Del_mar_ned03m32117h3

- DEM: lp_dem

- Extent dataset: lp_dem_extent

Tijuana Estuary

- NWI datasets: Imperial_Beach_OE_W_Wetlands_Polygons and Imperial_Beach_Wetlands_Polygons

- Clip Feature: TE_halfmile_Extent

- NED: Imperial_Beach_ned03m32117h2 and Imperial_Beach_ned03m32117h3

- DEM: TE_dem

- Extent dataset: TE_dem_extent 


\section{File Geodatabase}

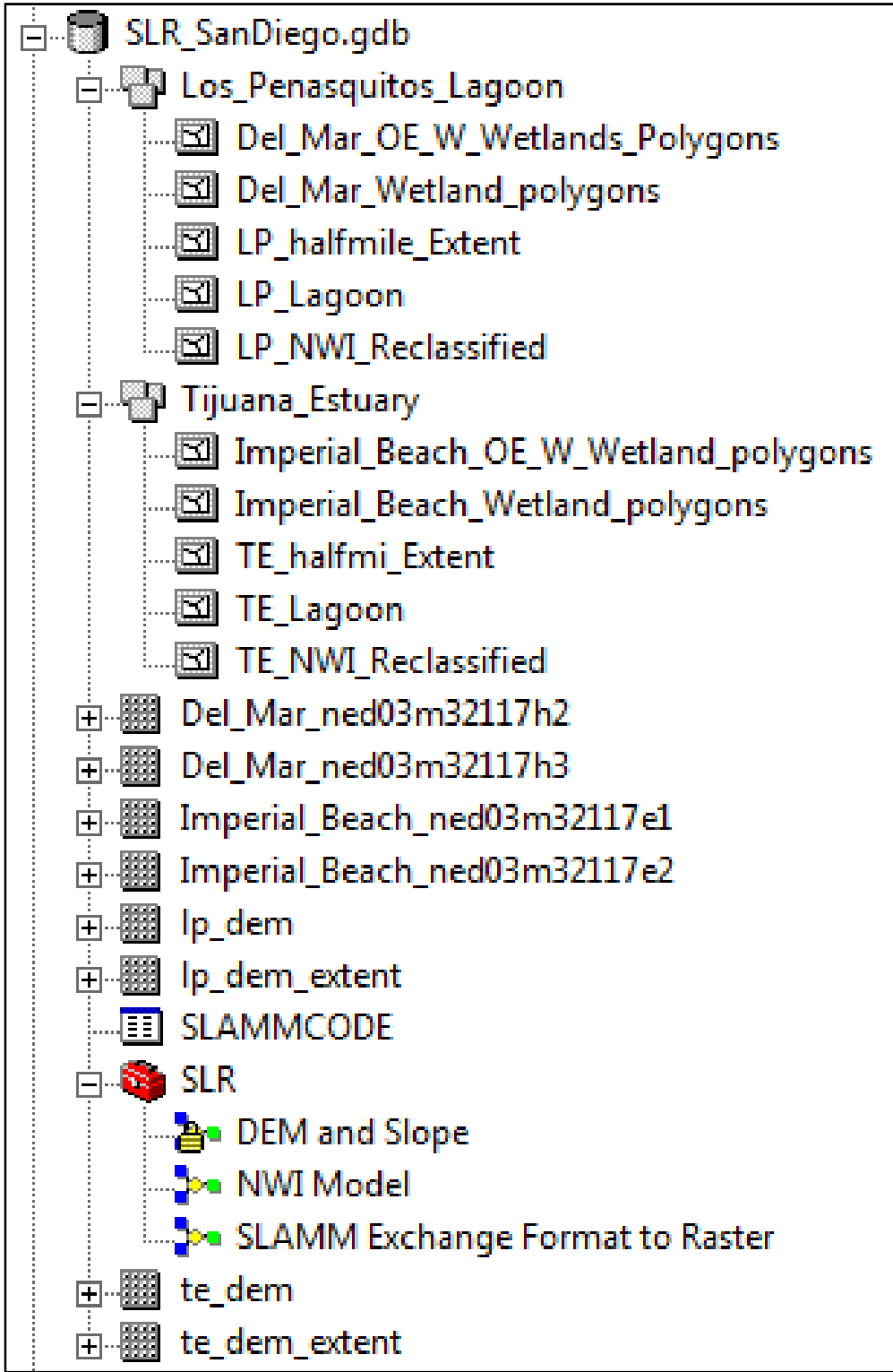

\section{GIS Tools}

Three GIS tools were developed for this project to produce ASCII datasets that can be used as data inputs for the SLAMM application.

1. DEM and Slope Model - processes elevation datasets and produces DEM and Slope ASCII data.

2. NWI Model - processes NWI datasets by assigning the appropriate SLAMM codes to the NWI polygons, classifies non-NWI polygons, and produces NWI and Dike ASCII data. 
3. SLAMM Exchange Format to Raster Model - retrieves SLAMM exchange format into ArcMap environment, converts data to a raster, and defines the projection to NAD83 UTM Zone 11N, meters.

The tools are stored in the file geodatabase and can be add to any ArcGIS session.

\section{Adding the tools to an ArcMap session:}

1. Start or open an ArcMap document.

2. View the geodatabase in ArcCatalog (have both ArcMap and ArcCatalog open side-by-side).

3. Select the SLR toolbox from the geodatabase in ArcCatalog and drag the toolbox to the ArcMap document and place it in the ArcToolbox area.

4. Copy the geodatabase to the c:I drive.

\section{DEM and Slope Model}

1. Start or open and ArcMap document.

2. Add the SLR toolbox to the ArcToolbox.

3. Open the SLR toolbox and double click on the DEM and Slope tool.

4. Input the data as shown below.

a. DEM, NED quadrants, and extent area clip feature.

b. Select output destination for the dem.txt and slope.txt (do not store text file in geodatabase).

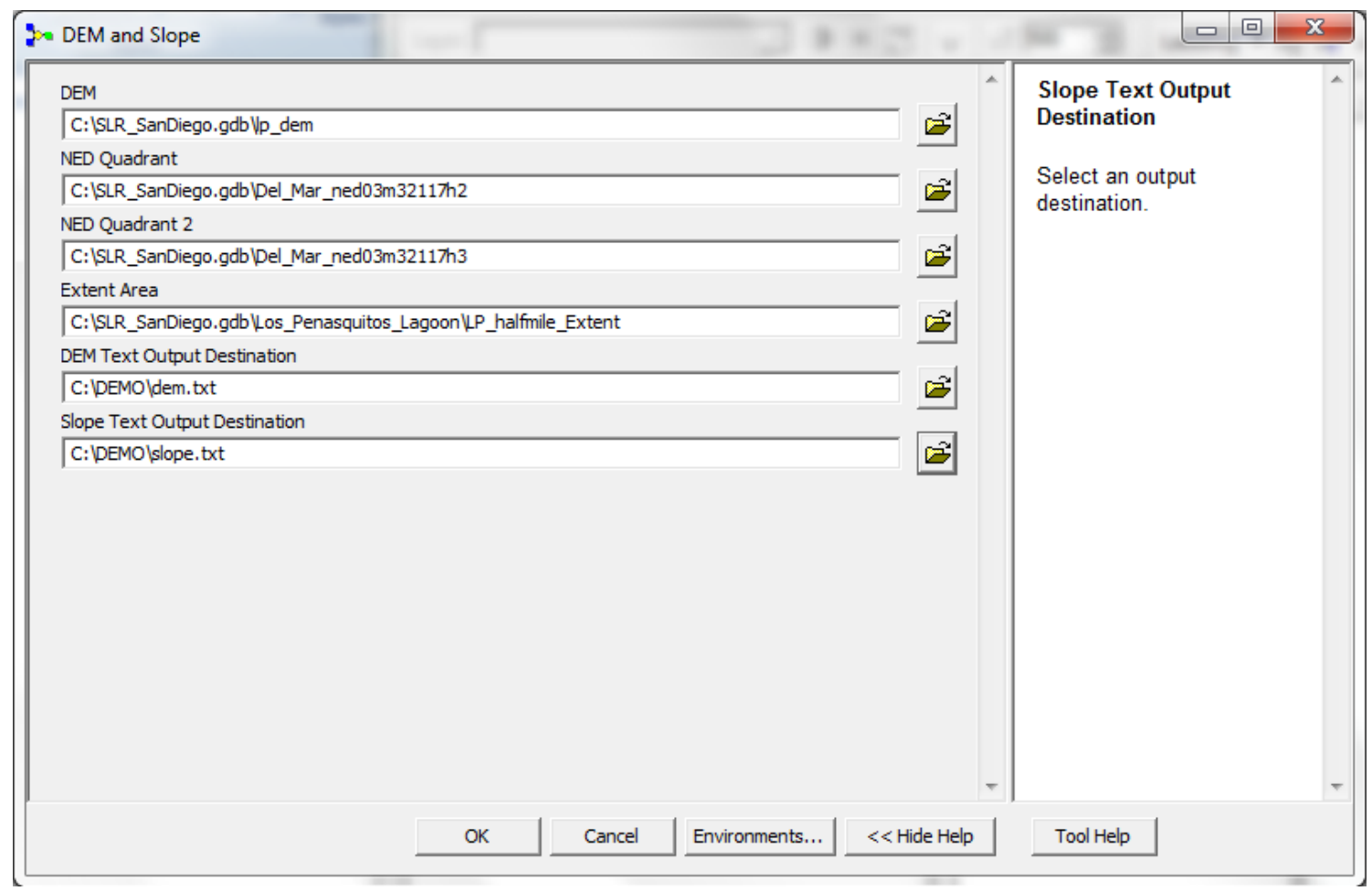

\section{NWI Model}

1. From the ArcMap document, select the SLR toolbox and open the NWI tool 
2. Input the data as shown below.

a. NWI quadrants, extent area.

b. A new NWI feature class will be created and added to the geodatabase or you can specify a destination to save the data. This feature class could be used to manually reclassify the NWI polygons for more accurate results. See Manual NWI Reclassification Section for instructions.

c. Select an output destination for the nwi.txt and dike.txt (do not store text file in geodatabase).

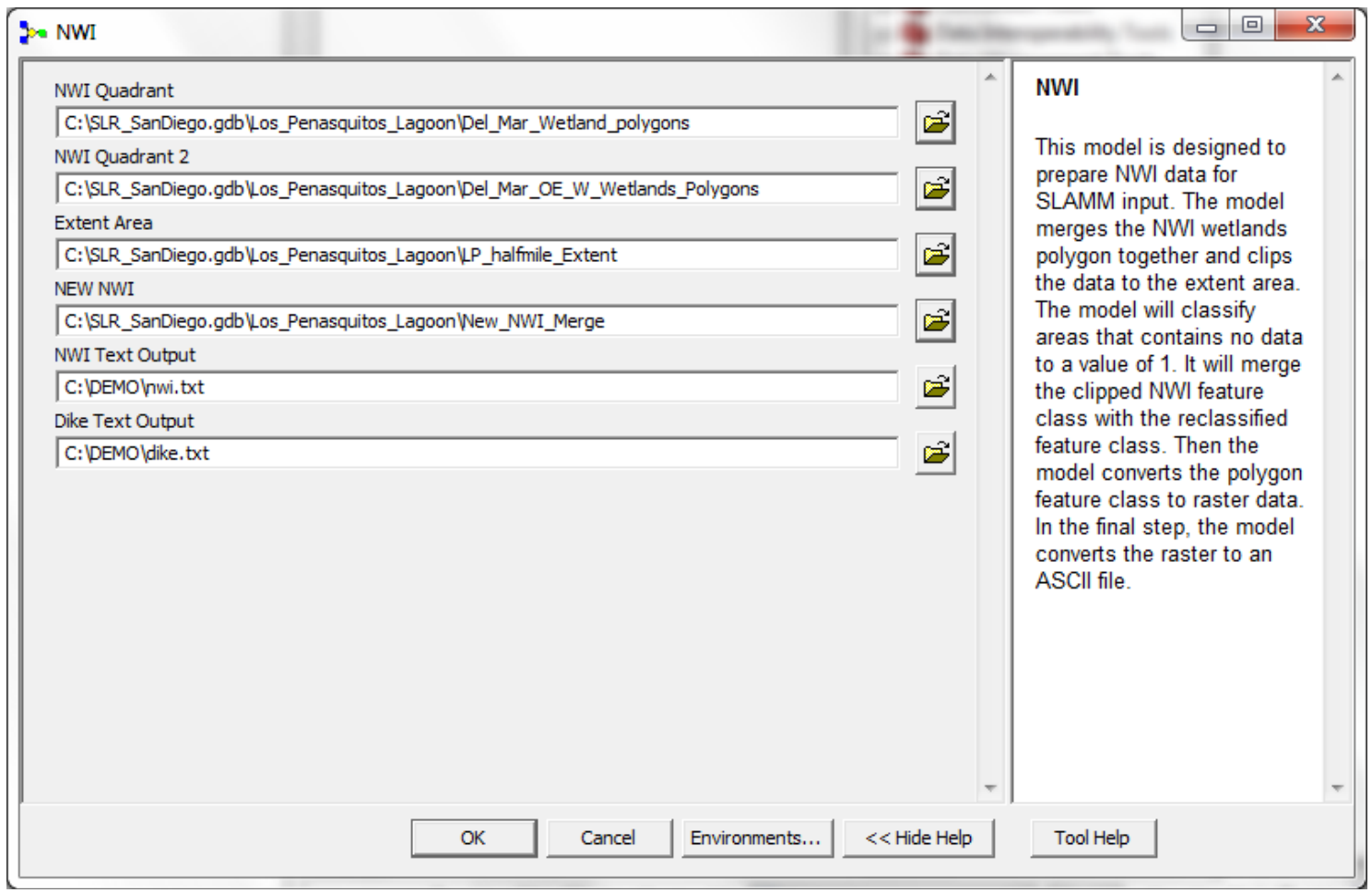

3. Click the Environments button on the bottom of the dialog box.

4. Select the General Settings option.

5. For Extent, click the browse button and select the Extent dataset from the geodatabase. For example, lp_dem_extent or te_dem_extent. This step is very critical to ensure the data created from this model will maintain the same extent area as the DEM and Slope datasets created in the DEM and Slope tool (shown below).

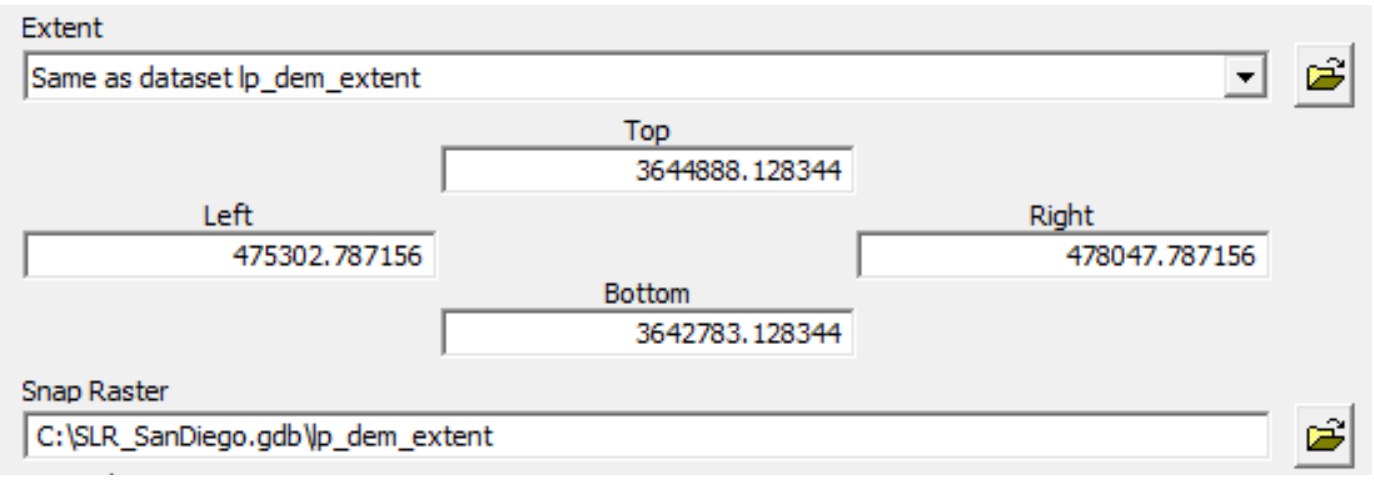




\section{Manual NWI Reclassification}

Use the New NWI feature dataset created from the NWI tool for this process. This method is critical to predicting accurate results.

1. Add the NWI feature dataset to an ArcMap document.

2. Add an aerial photo image (TIGER or other).

3. Open the attribute table. Select the SLAMMCODE field, right click, and sort ascending.

4. What to look for: SLAMMCODE 0 and 1 . Value 0 was assigned to any polygons that did not have a NWI attribute code that matched the NWI attribute code from the SLAMMCODE table during the spatial join. The model classified all areas within the extent but outside the NWI polygons with a value of 1 (Developed Dry Land).

5. Start an edit session in ArcMap using the Editor tool to reclassify the polygons by comparing the NWI polygons to the aerial photo to determine the proper classification of the areas assigned SLAMMCODE 0 and 1.

\section{SLAMM6 Application}

The DEM and Slope tool and the NWI tool produce the four ASCII files that are used as input data for the SLAMM application.

1. Open SLAMM6 application.

2. Click on New Simulation button.

3. Type in a name and description for area of interest.

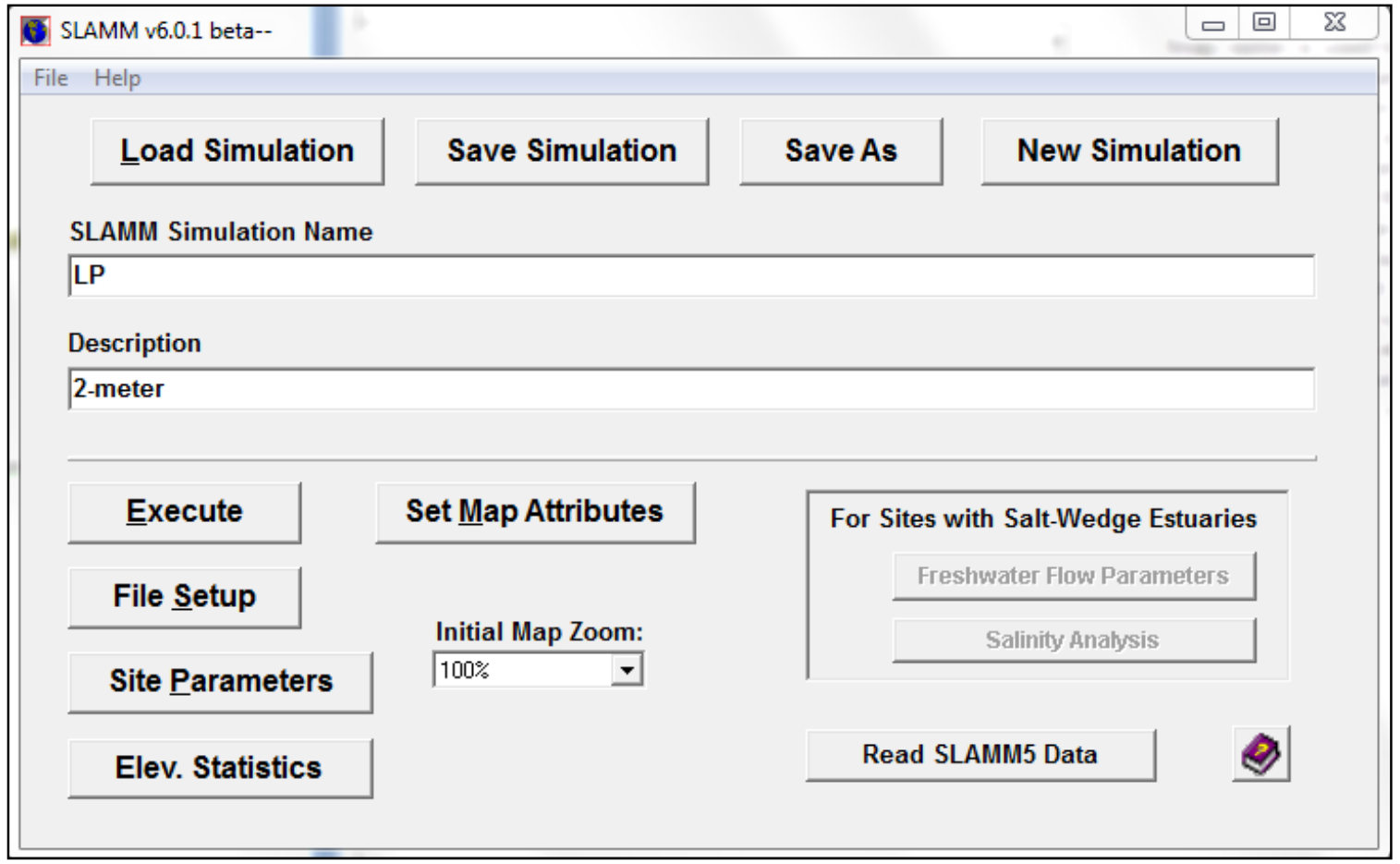

4. Click on the File Setup button. 
5. Select the required datasets created from the tools: dem.txt, nwi.txt, slope.txt, and dike.txt (Optional).

6. Select the Re-check Files' Validity button to make sure that all the datasets have the same number of columns and rows. If not, the SLAMM application will produce a "Range check error."

7. Browse for an output location and type in a base name under the Base Output File Name window. For example, for Los Peñasquitos Lagoon use LP

8. Select Track all cells and click on the Count Button to check the Memory Utilization in GB. Make sure the size does not exceed 2 GB.

9. Click OK to return to the Main Menu.

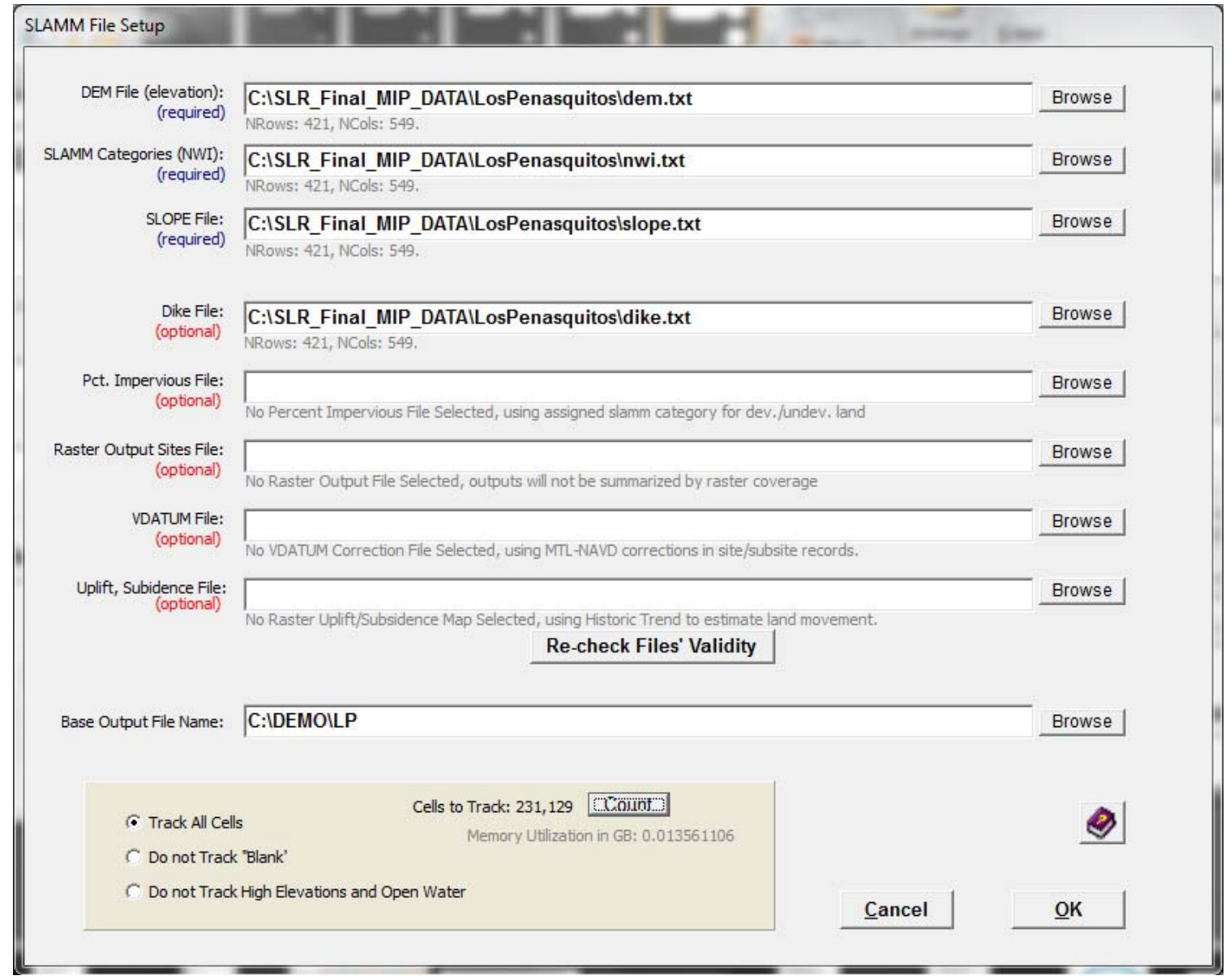

10. From the Main Menu, select the Site Parameters button.

11. Input the information for the study site(s):

- NWI Photo Date: 2009

- DEM Date: 2005

- Direction Offshore: West

- Historic Trend (millimeters/year): 1.778 (from IPCC report)

- Mean Tidal Level (MTL) - NAVD88 (m):

o Los Peñasquitos Lagoon 
$3.170 \mathrm{~m}-1.389 \mathrm{~m}=1.781 \mathrm{~m}$ (from NOAA Tidal and Currents Datum Report)

o Tijuana Estuary

$1.7 \mathrm{~m}-.93 \mathrm{~m}=0.77 \mathrm{~m}$ (from NOAA Tidal and Currents Datum Report)

- $\quad$ GT Great Diurnal Tide Range (m):

o Los Peñasquitos Lagoon

1.624 m (from NOAA Tidal and Currents Datum Report)

o Tijuana Estuary

1.637 m (from NOAA Tidal and Currents Datum Report)

Edit Sites and Subsites

\begin{tabular}{|l|l|}
\hline Parameter & Global \\
\hline Description & LP \\
\hline NWI Photo Date (YrY) & 2009 \\
\hline DEM Date (YrY) & 2005 \\
\hline Direction Offshore [n,s,e,w] & West \\
\hline Historic Trend (mm/yr) & 1.778 \\
\hline MTL-NAVD88 (m) & 1.781 \\
\hline GT Great Diurnal Tide Range (m) & 1.624 \\
\hline
\end{tabular}

12. Click OK to return to the Main Menu.

13. Click on the Execute button.

14. Select the sea level rise (SLR) scenarios to run. The Scenarios are based on the IPCC Special Reports on Emission Scenarios for year 2001. Multiple Scenarios can be selected at the same time with the estimated minimum, mean, and/or max predicted SLR for each scenario selected. Fixed SLR by 2100 could also be selected or specify a custom SLR amount by 2100.

15. Uncheck the Pause with Examination Tools option.

16. Select Include Dikes, Use Soil Saturation, and No-Data Elev Loaded as Blanks options.

17. Select Don’t Protect under Protection Scenarios to Run option.

18. Select Run Model for Specific Years and type in the year for the model to simulate.

19. Select the Save Output for GIS, click the GIS File Options button, select Only write GIS File in years shown below, type in the year for the model to produce GIS data for, and click OK. 


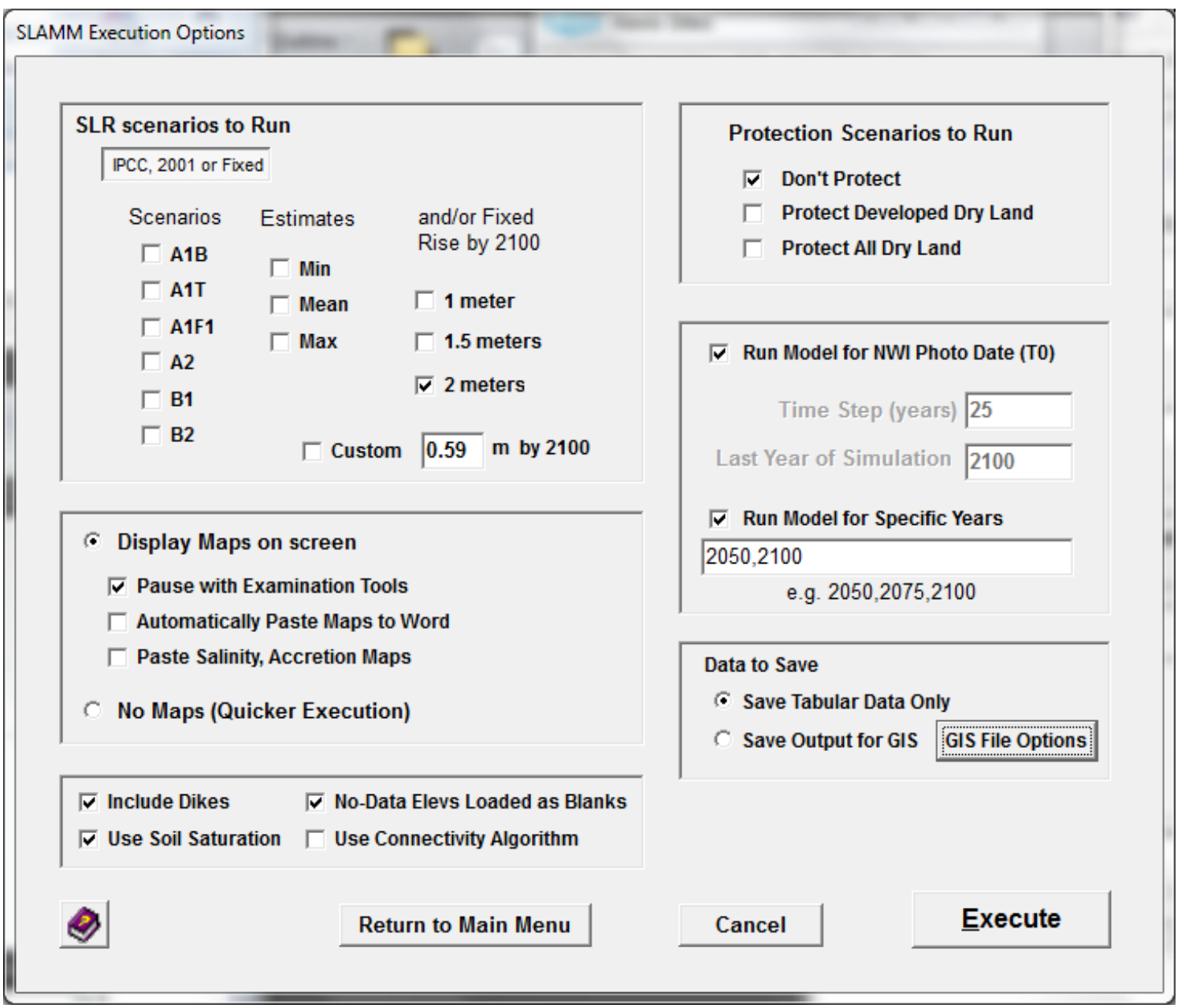

20. Select Execute to run SLAMM.

\section{SLAMM Exchange Format to Raster}

1. From the ArcMap document, open the SLR toolbox and open the SLAMM exchange Format to Raster tool.

2. Click on the Browse button under the Input SLAMM ASCII option and select the ASCII file created from the SLAMM simulations. To view the ASCII files, select File (*.ASC) from the Files of type menu.

3. Select the destination and type in the raster name for the SLAMM output raster dataset.

4. Click OK.

5. The raster dataset can be used for mapping and to assist the analysis when compared with the Comma Separated Value (.csv) output from SLAMM. 